US Army Corps

of Engineers ${ }_{\circledast}$

Engineer Research and

Development Center

Integrated Climate Assessment for Army Enterprise Planning

\title{
Analytical Model Software Integration Methods
}

Byron M. Garton

July 2019

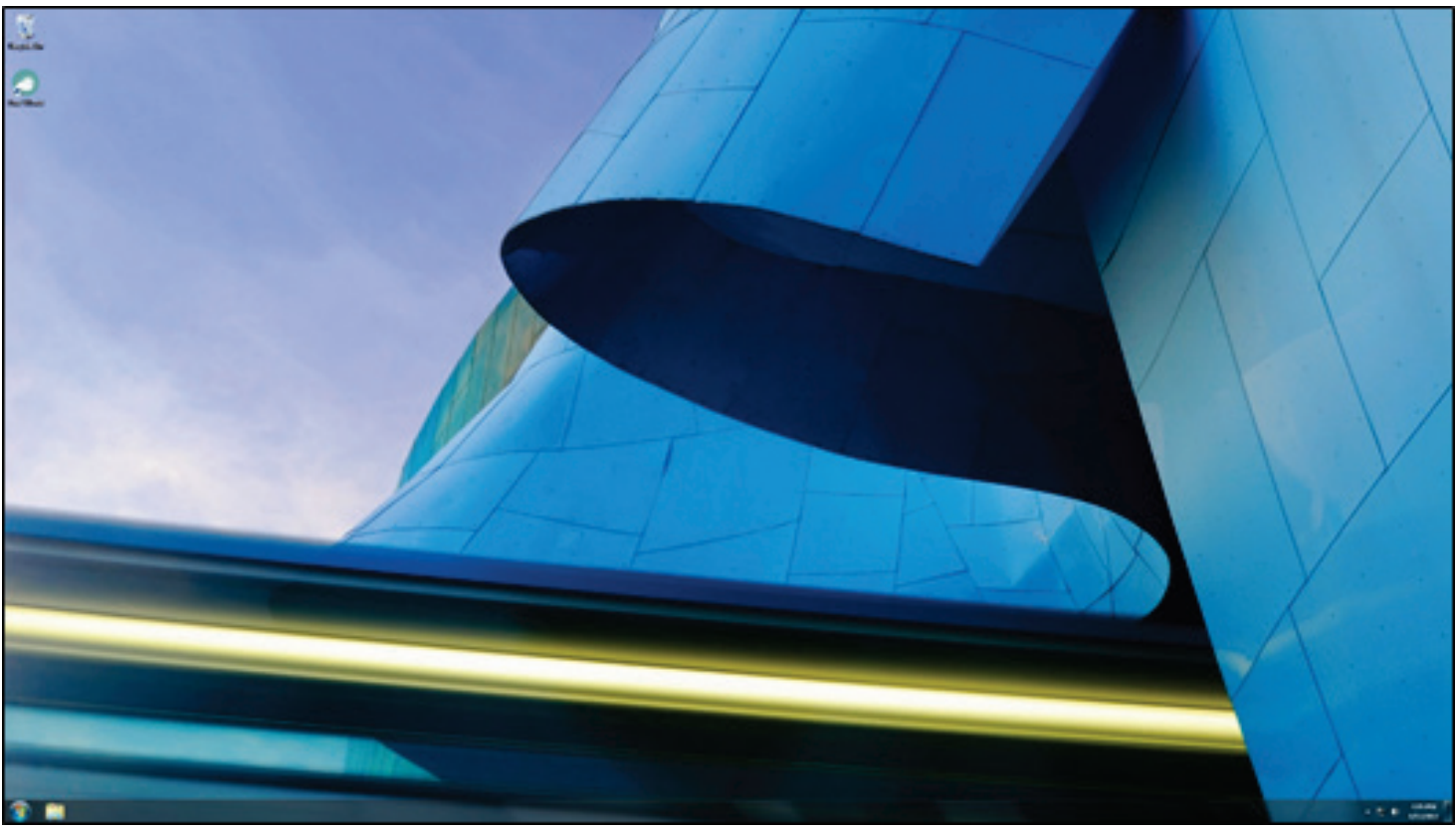


The U.S. Army Engineer Research and Development Center (ERDC) solves the nation's toughest engineering and environmental challenges. ERDC develops innovative solutions in civil and military engineering, geospatial sciences, water resources, and environmental sciences for the Army, the Department of Defense, civilian agencies, and our nation's public good. Find out more at www.erdc.usace.army.mil.

To search for other technical reports published by ERDC, visit the ERDC online library at http://acwc.sdp.sirsi.net/client/default. 


\title{
Analytical Model Software Integration Methods
}

\author{
Byron M. Garton \\ Information Technology Laboratory \\ U.S. Army Engineer Research and Development Center \\ 3909 Halls Ferry Road \\ Vicksburg, MS 39180-6199
}

Final Report

Approved for public release; distribution is unlimited.

$\begin{aligned} \text { Prepared for } & \text { U.S. Army Corps of Engineers } \\ & \text { Washington, DC 20314-1000 } \\ \text { Under } & \text { Project 402188, “Integrated Climate Assessment for Army Enterprise Planning” }\end{aligned}$ 


\section{Abstract}

This document explores and describes the methods and technologies developed and employed at the Engineer Research and Development Center-Information Technology Library (ERDC-ITL) to integrate various software models created by Principle Investigators (PIs) as part of the Integrated Climate Assessment for Army Enterprise Planning work package into a single software package. These software models identify and calculate various metrics related to the effects of climate change and its potential impact on force stationing, and are intended to be used in future analyses for the purpose of determining optimal force stationing. This software integration effort sought to understand these independently conceived and developed software models, capture and preserve them in their current state, and integrate them into a common computational environment while simultaneously documenting and optimizing their functionality. This work ensures that future analysis of climate change metrics will be easily accessible and executable by those seeking the data.

DISCLAIMER: The contents of this report are not to be used for advertising, publication, or promotional purposes. Citation of trade names does not constitute an official endorsement or approval of the use of such commercial products. All product names and trademarks cited are the property of their respective owners. The findings of this report are not to be construed as an official Department of the Army position unless so designated by other authorized documents. 


\section{Contents}

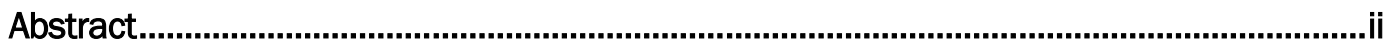

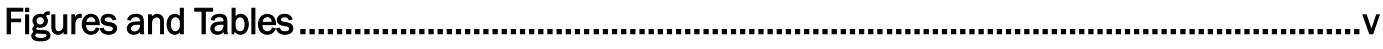

Preface

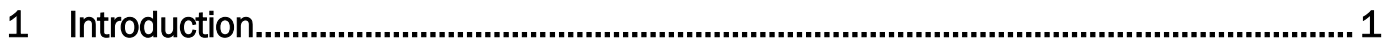

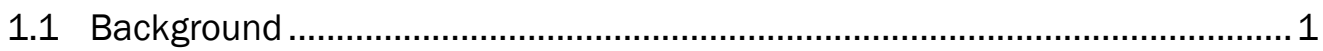

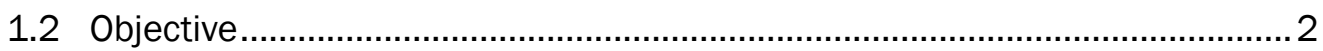

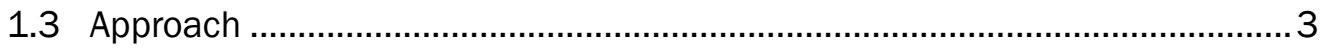

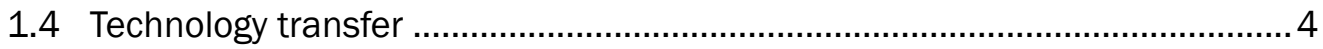

2 Common Computational Environment …………...................................................

3 Climate Change Assessment Wizard ...........................................................................8

4 Model Integration ..............................................................................................11

4.1 Temperature and precipitation projections model .......................................11

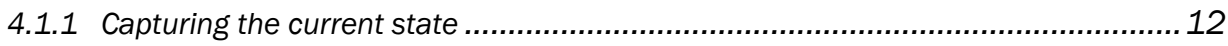

4.1 .2 Integrating into the Wizard .................................................................... 13

4.1.3 Known issues and limitations ......................................................................... 20

4.2 Heating and Cooling Degree Days Model..................................................21

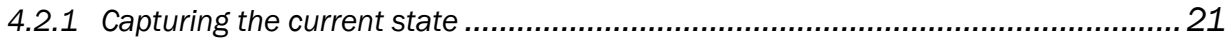

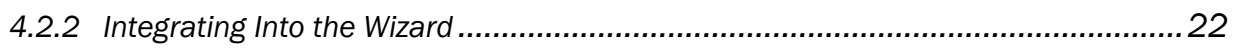

4.2.3 Known issues and limitations ........................................................................ 27

4.3 Threatened and Endangered Species Model............................................. 28

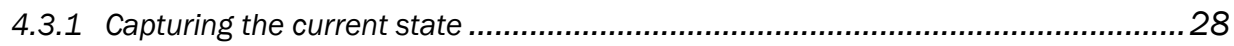

4.3.2 Integrating into the Wizard ................................................................................ 29

4.4 Frequency of Extreme Weather Events Model ........................................... 34

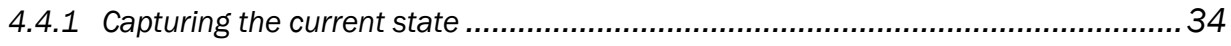

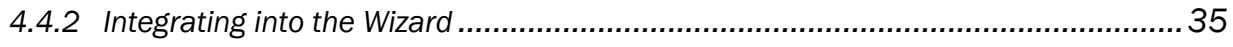

4.5 Range Encroachment Model.................................................................... 38

4.5.1 Capturing the current state ....................................................................... 38

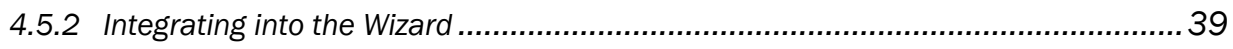

4.5.3 Known issues and limitations .................................................................... 47

4.6 Heat Risk on Ranges Model ............................................................... 48

4.6.1 Capturing the current state .................................................................... 48

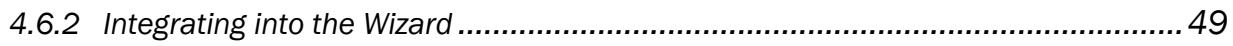

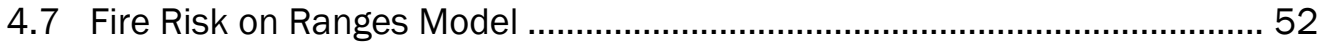

4.7.1 Capturing the current state .......................................................................... 53

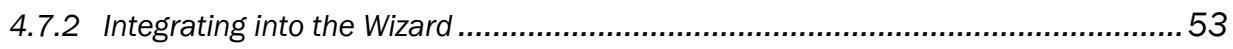

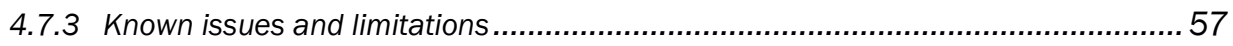

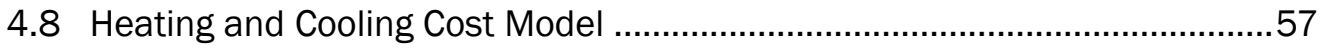

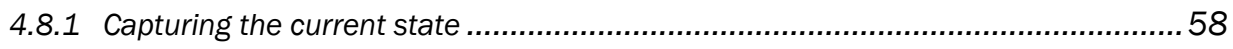




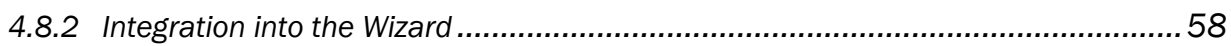

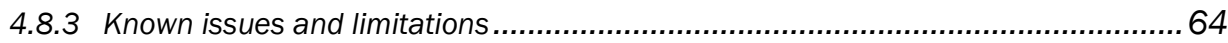

4.9 Regional Water Balance Model........................................................... 64

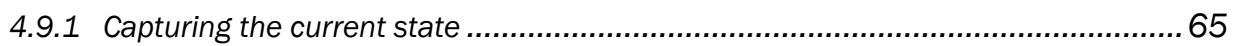

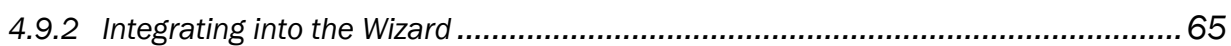

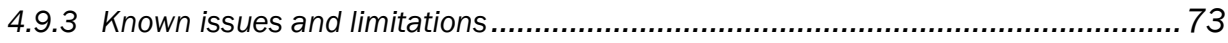

4.10 Building Maintenance Model ............................................................ 73

4.10.1 Capturing the current state .......................................................................... 73

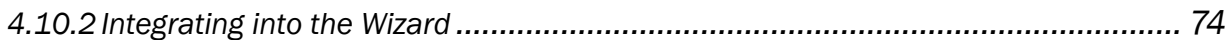

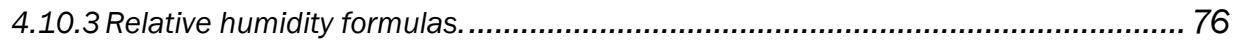

4.11 Growing Degree Days Model .......................................................... 80

4.11.1 Capture the current state ............................................................................. 80

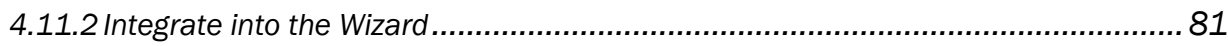

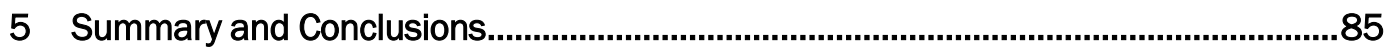

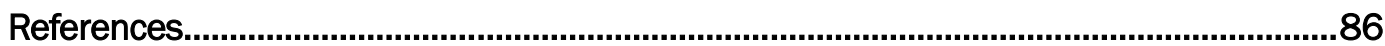

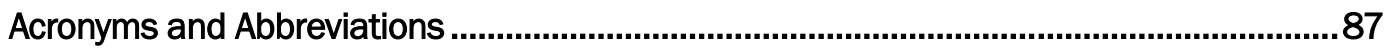

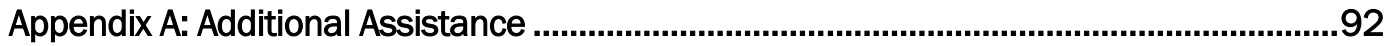

\section{Report Documentation Page}




\section{Figures and Tables}

\section{Figures}

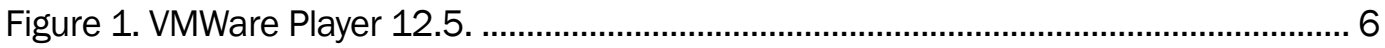

Figure 2. VMWare virtual environment desktop.............................................................. 6

Figure 3. Climate Change Assessment Wizard Application icon........................................... 8

Figure 4. Wizard desktop shortcut icon.............................................................................. 9

Figure 5. Wizard dashboard screen................................................................................ 10

Figure 6. Temperature and Precipitation Projections Model icon. ..................................... 14

Figure 7. Temperature and Precipitation Projections Model first screen............................ 14

Figure 8. Temperature and Precipitation Projections Model second screen. ..................... 15

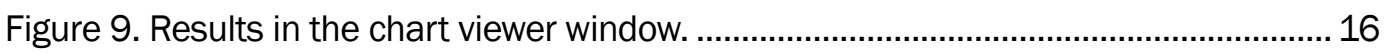

Figure 10. Chart comparison filter. ................................................................................ 16

Figure 11. Launch R Studio from the third model screen within the Wizard...................... 17

Figure 12. R Studio development environment. ............................................................. 18

Figure 13. Use the Code menu to run a script. ............................................................ 18

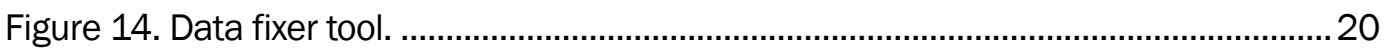

Figure 15. Heating and Cooling Degree Days Model icon...................................................2 22

Figure 16. Heating and Cooling Degree Days Model first screen.......................................23

Figure 17. Heating and Cooling Degree Days Model second screen................................... 24

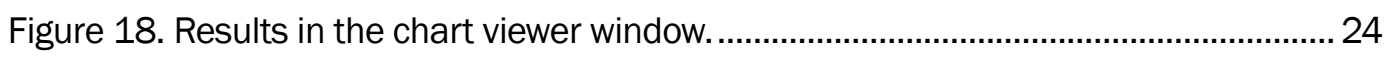

Figure 19. Launch Python IDLE from the third model screen within the Wizard. ............... 26

Figure 20. Python IDLE development environment. ............................................................ 26

Figure 21. Data Fixer tool.......................................................................................... 27

Figure 22. Threatened and Endangered Species Model icon. ...........................................29

Figure 23. Threatened and Endangered Species Model first screen. ................................ 30

Figure 24. Threatened and Endangered Species Model second screen.............................30

Figure 25. Results in the MS Excel ${ }^{\circledR}$ window................................................................. 31

Figure 26. Launch MS Excel ${ }^{\circledR}$ from the second Model screen within the Wizard............. 32

Figure 27. NatureServe Explorer web application. .............................................................33

Figure 28. Frequency of Extreme Events Model icon. ......................................................35

Figure 29. Frequency of Extreme Events Model first screen............................................36

Figure 30. Frequency of Extreme Events Model second screen. ......................................36

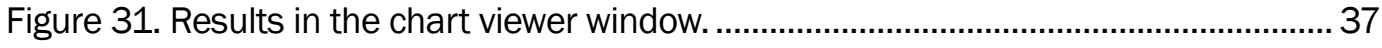

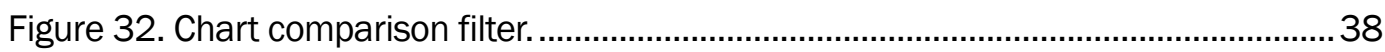

Figure 33. Range Encroachment Model icon. ...................................................................... 40

Figure 34. Range Encroachment Model first screen......................................................... 40

Figure 35. Range Encroachment Model second screen. .................................................... 41

Figure 36. Example of Model output file........................................................................ 41 
Figure 37. Launch buttons on the third model screen within the Wizard. ......................... 43

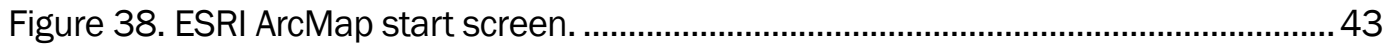

Figure 39. Run command prompt as administrator. ..................................................... 44

Figure 40. Command prompt window with Launch.bat command................................... 45

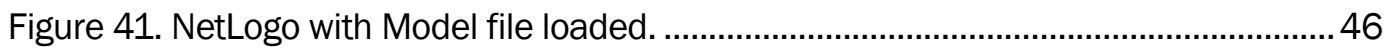

Figure 42. NetLogo with Model execution complete. ........................................................46

Figure 43. Range days lost to Heat Risk Model icon. ......................................................49

Figure 44. Range days lost to Heat Risk Model first screen..............................................50

Figure 45. Range days lost to Heat Risk Model second screen. ......................................50

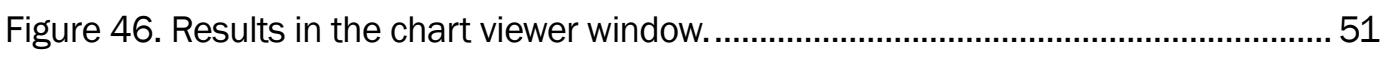

Figure 47. Range days lost to Fire Risk on Ranges Model icon. ........................................54

Figure 48. Range days lost to Fire Risk on Ranges Model first screen...............................54

Figure 49. Range days lost to Fire Risk on Ranges Model second screen..........................55

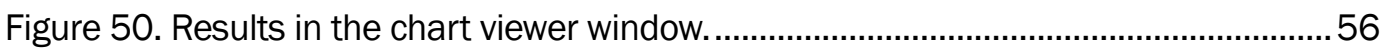

Figure 51. Heating and Cooling Cost Model icon...........................................................59

Figure 52. Heating and Cooling Cost Model first screen.................................................59

Figure 53. Heating and Cooling Cost Model second screen............................................60

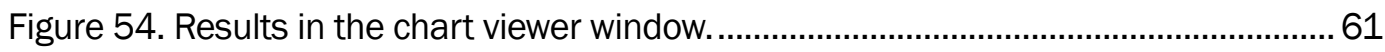

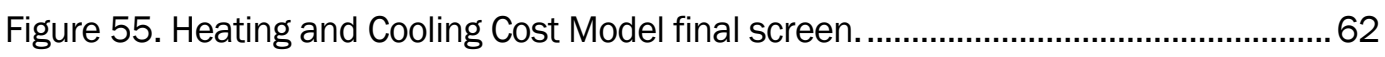

Figure 56. Data connections function in MS Excel ${ }^{\circledR}$......................................................... 64

Figure 57. Regional Water Balance Model final screen launch buttons............................66

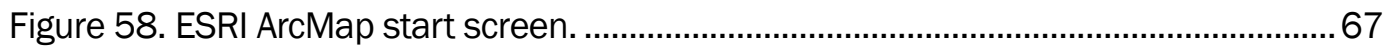

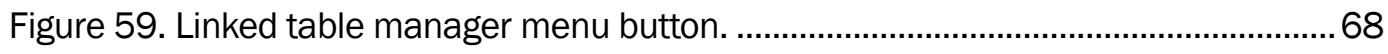

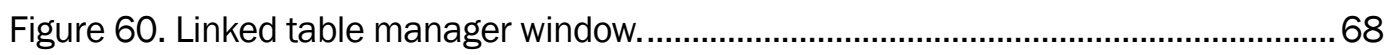

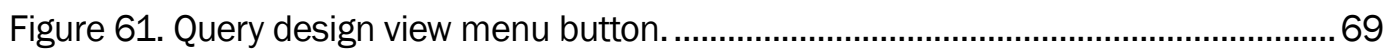

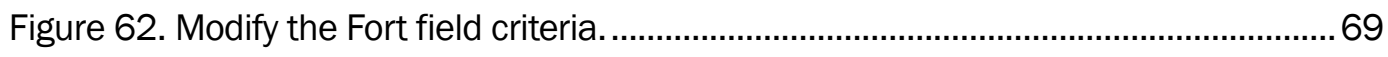

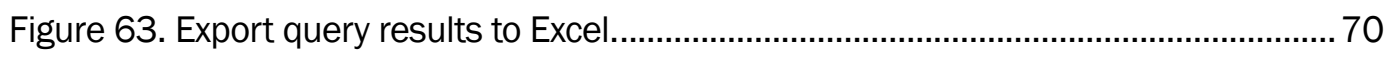

Figure 64. Stella manage persistent links menu item.................................................... 71

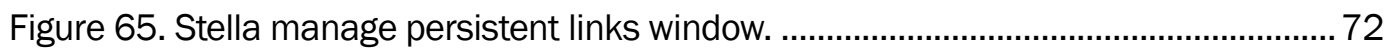

Figure 66. Building Maintenance icon on the home screen............................................. 75

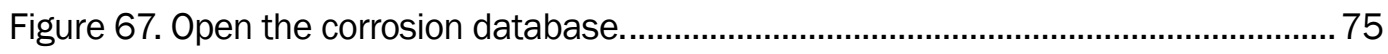

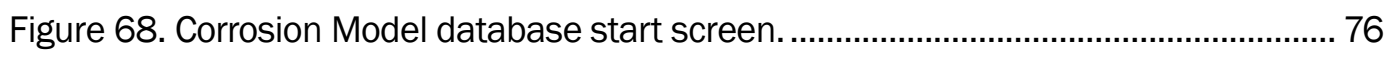

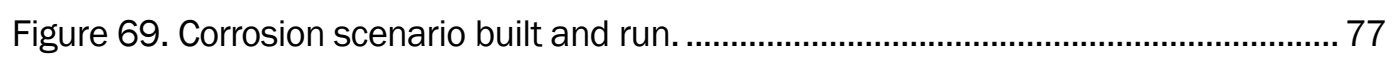

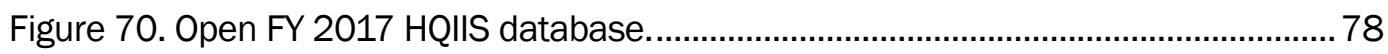

Figure 71 . Execute the query by double clicking it. ........................................................... 78

Figure 72. Use the filter to limit results to the site of current interest. .............................. 79

Figure 73. Export filtered table to Excel spreadsheet........................................................ 79

Figure 74. Growing Degree Days (GDD) Model icon......................................................... 81

Figure 75. GDD Model first screen................................................................................ 82

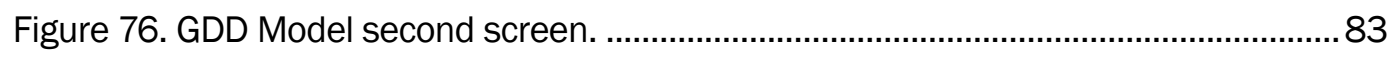

Figure 77. Results in the chart viewer window................................................................ 83 


\section{Tables}

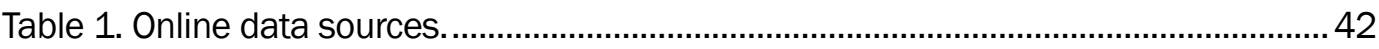

Table 2. Doctrinal heat risk categories and guidelines.....................................................52

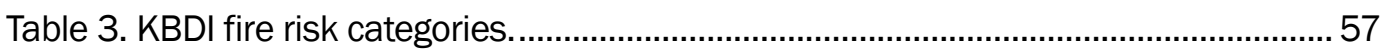




\section{Preface}

This research was conducted for the U.S. Engineer Research and Development Center-Construction Engineering Research Laboratory (ERDC-CERL) under Project 402188, Integrated Climate Assessment for Army Enterprise Planning. The Technical Monitor was Dr. James D. Westervelt of ERDC-CERL.

The work was performed by the Information Technology Laboratory (ITL), Scientific Software Branch (SSB), of the Computational Science and Engineering Division (CSED). At the time of publication, Mr. Timothy W. Dunaway was Chief of the SSB, Dr. Jerrell R. Ballard was Chief of the CSED, and Mr. Robert M. Wallace was the Technical Director. The Deputy Director of ERDC-ITL was Ms. Patti S. Duett, and the Director was Dr. David A. Horner.

COL Ivan P. Beckman was the Commander of ERDC, and Dr. David W. Pittman was the Director. 


\section{Introduction}

\subsection{Background}

The Integrated Climate Assessment for Army Enterprise Planning work package was initiated to develop new analytical methods for incorporating the direct and indirect impacts of climate change and related dynamic processes such as urban encroachment into Army enterprise long-term planning processes (e.g., Base Realignment and Closure [BRAC], stationing) conducted through the Military Value Analysis (MVA) process. The purpose was to assure that existing Army installation force stationing decision metrics are calculated in a way that reliably accounts for scientific understanding of climate change impacts. The existing installation decision metrics used in enterprise decision processes are measures for ranking an installation's value and contribution to the overall Army mission. They represent the ability to support current and future mission capabilities, availability and condition of lands and facilities, and cost of operations. Therefore, it is critical that these metrics respond to dynamic climate change impacts. The research improves enterprise decisions by providing analytical capabilities that account for the impacts of climate change scenarios. These capabilities provide the Army with a consistent and multi-tiered approach for assessing climate change impacts, from local to national scales.

Army strategic planning guidance (U.S. Army Regulation 5-10 [HQDA 2010]) provides long-range goals for 10-20 years into the future and affects all installations. Long lead times are required to modify military force structure, create the necessary facility support, program the funding, and develop political support for a change in the base structure. The effective use of planning is critical to balancing the operational, facility, and environmental requirements, with political sensitivities involved, in developing new stationing decisions. The payoff of this research is improved planning processes for national and regional stationing, realignment, and associated activities to systematically account for the possible future consequences of climate change and related dynamic trends.

This research began with algorithms and techniques developed in other projects associated with the work package. These computational models support the integration of climate change data into the forecasting of 
existing installation decision metric values that affect Army enterprise planning decisions. Each of these models were developed independently on the Principle Investigators (PIs) choice of computing platform, which resulted in a very fragmented process. The primary product resulting from the software integration research and development effort is a common computational environment that captures, organizes, documents, and provides easy access to a suite of analysis tools that provide climatesensitive metrics by using the underlying models developed by the other researchers within the work package.

\subsection{Objective}

The primary objective of the software integration research and development effort was to capture the suite of existing analysis models in a single common operating environment and develop an application to assist users in viewing existing output data as well as building new data for various installations and future climate scenarios. The existing models convert forecasted climate data for Army installations into estimates of how various metrics associated with the installations are likely to change over time. Analytical methods have been developed within the primary work package to provide metrics for the following installation areas of interest:

- Predicted temperature and precipitation values

- Encroachment on firing ranges by urban development

- Changes in maneuver area capacity

- Risk of fires on firing ranges

- Risk of heat related injury on training ranges

- Building maintenance costs

- Heating and cooling energy usage

- Frequency of extreme weather events

- Regional water balance

- Changes in heating and cooling degree days

- Changes in growing degree days

- Risk to threatened and endangered species.

Each analytical approach makes use of different data inputs, different computer operating systems, and different processing software. The task of integrating all the methodologies into a single solution included coordination of all work packages the PIs were involved with, developing each model, and capturing their current methodologies. A single operating environment must also implemented where all the approaches are 
centrally accessible, providing a simple to use and easily accessible location for quickly computing and obtaining results based on several climate scenario inputs. Outputs generated by the computational models are intended to be digested into other systems within Army planning communities to provide them with information to support the optimal stationing decision process.

\subsection{Approach}

As mentioned previously, each analytical method, or algorithm, for determining the impact of climate change on Army installation decision metrics was developed independently and executed on the PIs platform of choice. The approach to integrating each independently developed model consisted of three basic steps: (1) understand the processes and methodologies of each model, (2) capture the current state of each model, and (3) integrate each model into a single common computational environment.

Many interactions including face to face meetings, calls and emails, and various presentations were conducted and attended by those involved in the work package in an effort to understand the methodologies employed by each of the work package's PIs who conducted the initial research.

Understanding the methodologies included seeing the process executed from start to finish while focusing on the types of inputs, processing software requirements, computer languages used, and types and definition of the resulting output data. Reviewing technical reports that described the PI's research in great detail was also a vital part of the initial process of researching and understanding the analytical methods. All of these sources of information and data combined together to satisfy the first and most important step of gaining a basic understanding of the problem.

The next step in the integration effort was to capture the existing computational methods in their current state, regardless of their shortcomings or inefficiencies. Capturing a computational model includes gaining access to any software that may be used within the process, computer code or scripts that are run to accomplish a particular task, and any and all files that are used as inputs into the process or produced as output at the end of the process. Some models relied heavily on Government off the Shelf (GOTS) and Commercial off the Shelf (COTS) software applications such as data modeling environments and data preprocessing programs while others relied only on custom written code 
and scripts that perform a single computational task to produce output. Some were simply a MS Excel ${ }^{\circledR}$ spreadsheet with fast running scripts and macros inside while others were large data processing codes that run for extended periods of time. Regardless of the methods and intentions, these files, applications, and environments were captured to preserve the current working state of the models and identify areas of potential improvement.

Finally, after understanding and capturing the exiting analytical methods, the task of integrating them into a common computational environment was performed. A common computational environment was defined in the scope of this integration effort as: an operating environment where each of the models could reside and run, and all of the various requirements for each of them including software and code interpreters could be installed. Virtualization technology, which is a method of running an independent operating system within a computers main operating system, satisfied all the necessary requirements and was chosen as the best method for the preservation and integration of the various computational models. Along with the virtualized operating system, an application was developed to assist future users in accessing and running the integrated models. The user assistance application, which for this integration effort was named the Climate Change Assessment Wizard, serves as a central location for the code, application shortcuts, inputs, outputs, and documentation for all of the analytical models. It serves as a sort of one-stop-shop for anyone looking to view the output data or build new data as new climate scenarios are created.

This three-step approach of understanding the methodologies and processes associated with each model, capturing the current state of each model, and integrating each model into a single common computational environment by using operating system virtualization and a user assistance Wizard application served as the blueprint for the completion of the software integration effort.

\subsection{Technology transfer}

It is anticipated that the results of this work will provide enhancements to decision support capabilities in support of The Center of Army Analysis (CAA) Army stationing analyses (restructuring and realignment analysis). It is anticipated that the resulting software and datasets, when combined with CAA feedback, will support CAA subject matter experts with the Comprehensive Omnibus Budget Reconciliation Act (COBRA) and the Optimal Stationing of Army Forces (OSAF) models. 


\section{Common Computational Environment}

Implementing a common computational environment was essential to capturing and integrating the various computational models. Since the models were developed independently on the PI's choice of platform, a method to contain them in a single centralized location that allowed each to continue to operate within their chosen platforms and technologies needed to be either chosen from existing off the shelf solutions or custom developed. After researching available COTS and GOTS solutions, the decision was made to use an existing commercial virtualization application to support the integration effort.

VMWare is a commercial application that the government previously has purchased through enterprise level agreements and has provided to internal programs free of additional charges. The software allows an operating system (e.g., MS Windows $7^{\circledR}$ ), to be installed within an existing operating system for the purpose of preserving the state of the virtual system in a series of files that can be saved and copied to other locations and launched within any current common operating system. Launching the virtual system requires the host operating system to install a free application from VMWare called VMWare Workstation Player (Figure 1). The software can be downloaded from the following URL:

http://www.vmware.com/products/player/playerpro-evaluation.html.

VMware virtual operating system environments are simply a directory that contains various files associated with what is typically referred to as a virtual machine (VM). The VM files consist of configuration settings and virtual hard disks. After installing the free player application, the virtual environment can be launched by opening the VMX file that was delivered at the completion of the effort, CC Windows 7 x64.vmx.

To load the VM, select it from the list on the left hand side of the screen then click the green play button in the top menu bar. Once the VM completes loading in VMWare Player, a familiar MS Windows $7{ }^{\circledR}$ desktop screen appears (Figure 2). 
Figure 1. VMWare Player 12.5.

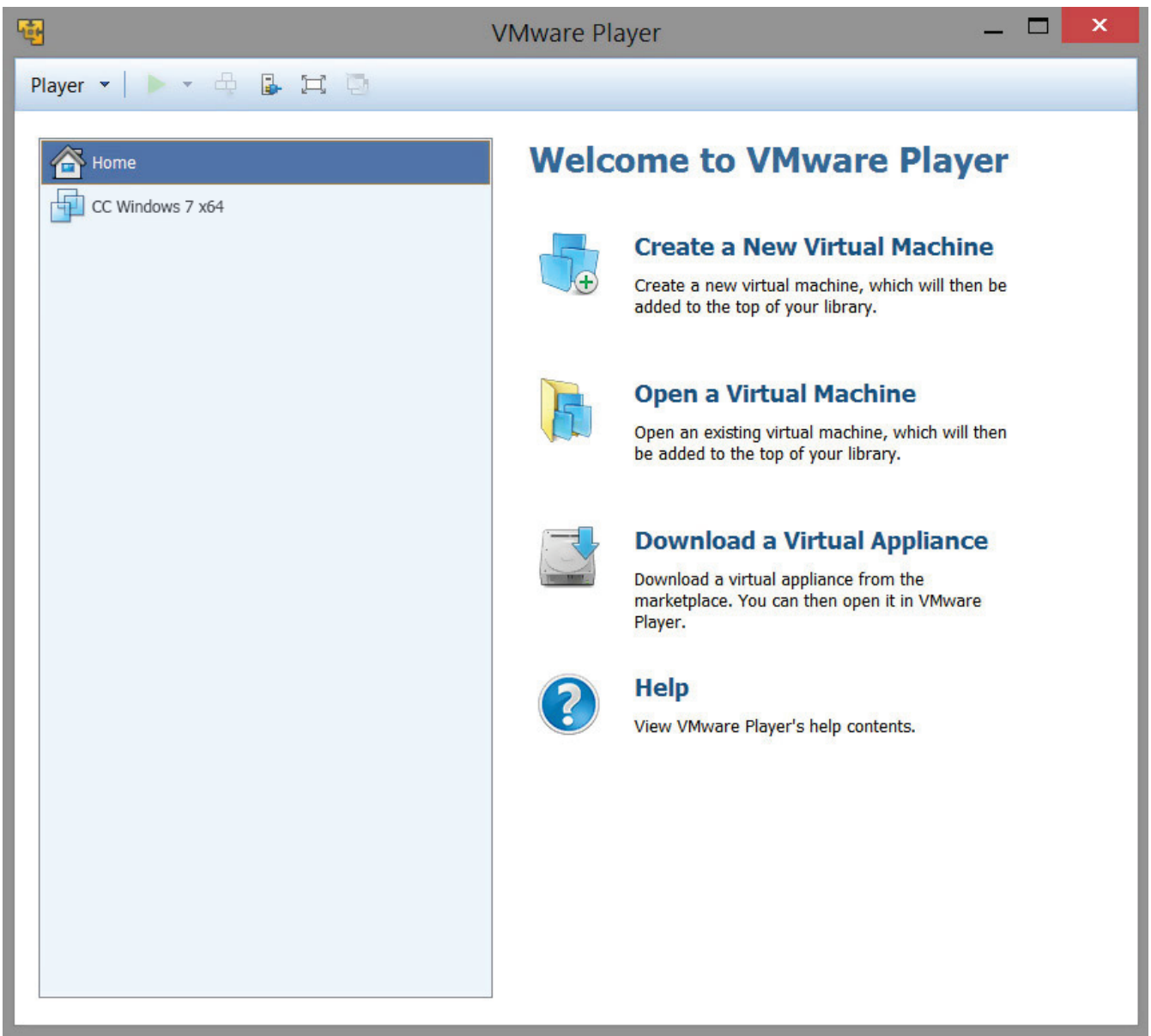

Figure 2. VMWare virtual environment desktop.

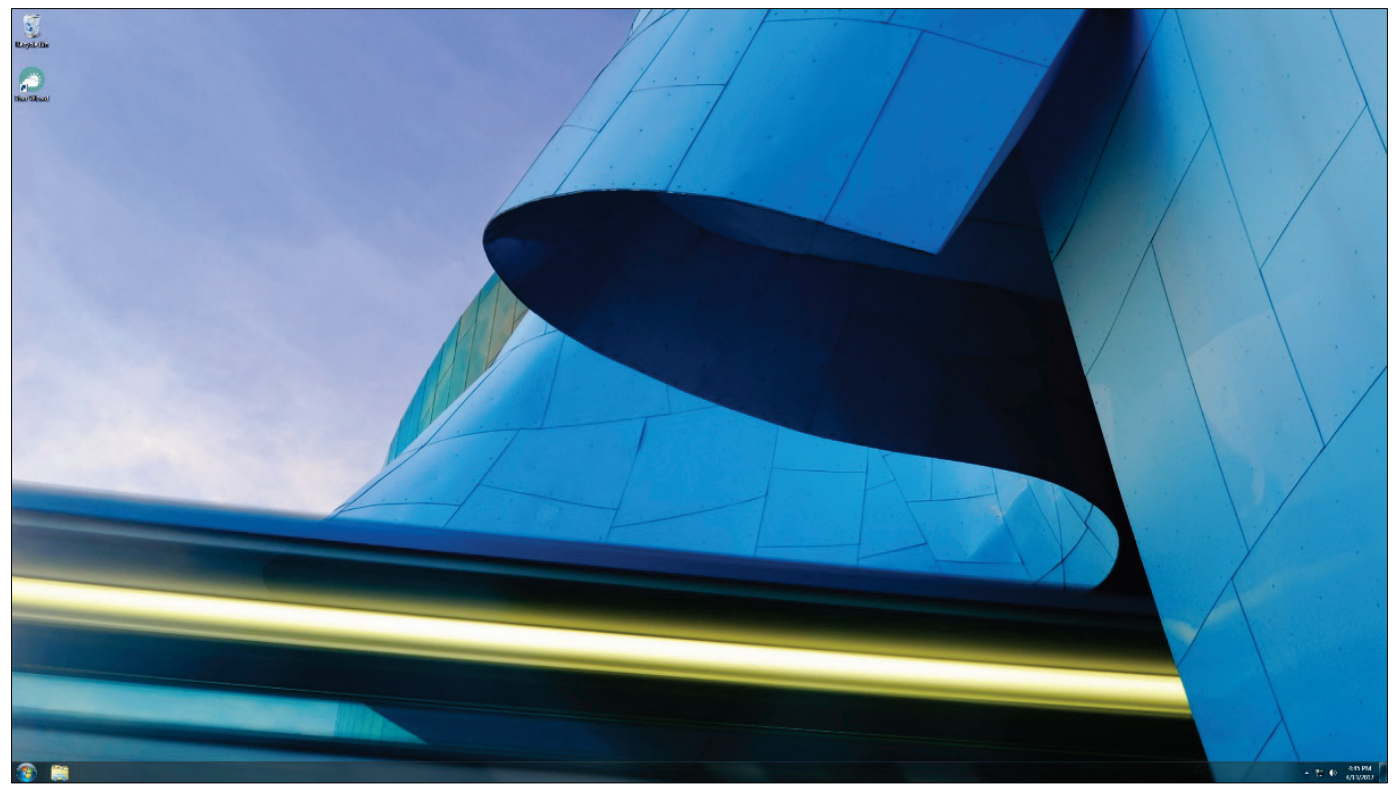


The VM shares the physical resources of its host environment including system memory, processors, hard disks, and other peripheral devices such as printers and network connections. The default resource settings for the virtual operating system are set low on purpose so that less powerful host computers will be able to at least launch the file. Default settings are 16 gigabytes (GB) of system memory, eight central processing cores (CPUs), and $500 \mathrm{~GB}$ of hard disk space. Much greater resource settings are required to execute the Temperature and Precipitation Projection Model and the Range Encroachment Model, and those requirements are listed in their respective chapters. The settings can be increased to meet those requirements if the host computer has enough resources available.

Also, since the virtual environment is hosted within another operating system, applicable security requirements are inherited from the host system. Security requirements vary widely between organizations, therefore, no security features (e.g., antivirus, firewall) are implemented in the VM, although host security features and requirements remain in effect. 


\section{Climate Change Assessment Wizard}

An integral part of the software integration effort was to create a user assistance application designed to aid in the viewing of individual model output data and the execution of the various model data processing capabilities. The VM described in Chapter 2 includes the user assistance application, or Wizard, which provides a central access point to the various models and houses the complete documentation for each model.

A very important part of the software integration effort was to streamline and enhance the operation of the models as they were created by the various PIs. After understanding and capturing each model, efforts were taken to identify potential improvement areas within the methodologies or computer codes to enhance the models features and operation. The Wizard application plays a pivotal role in this enhancement effort by providing a code base for migration from slower or less feature filled technologies to more modern technologies and techniques for various computational tasks.

Display and presentation of output data was also inconsistent across the models and the Wizard is also able to provide improvements in that area. By writing a custom charting application within the Wizard, many types of datasets were able to be displayed in a consistent and appealing manner. Bar charts and line graphs are simple but powerful tools in presenting climate change data to users in a way that helps them understand the impact that climate has on a number of Army installation metrics.

The Wizard application icon appears on the VM desktop as a shortcut to the application. To launch the Wizard, double click the shortcut icon (Figures 3 and 4).

Figure 3. Climate Change Assessment Wizard Application icon.

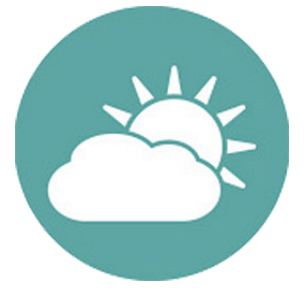


Figure 4. Wizard desktop shortcut icon.

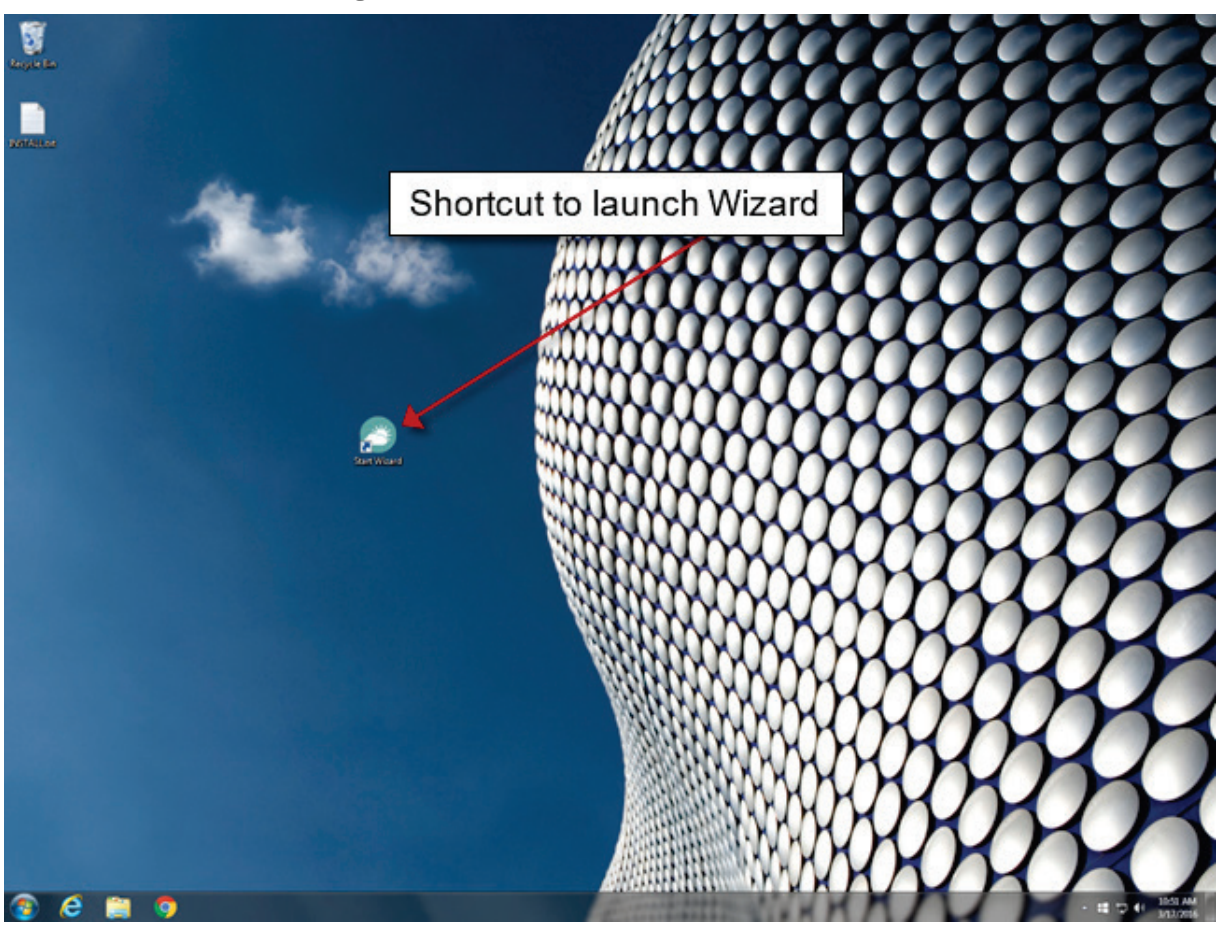

When the application is launched, a dashboard screen is shown with an icon representing each analytical model (Figure 5). From the dashboard, the user can click on an icon to launch that particular model. Each model is different, the processes involved in each are documented in their respective user guide. Those guides are available inside the model processes, usually on the final screen, or within the VM at C: \Models $\backslash$ Help-Documents.

Clicking on an icon from the dashboard screen will launch the sub-process for that particular model. Each model Wizard sub-process contains a series of screens where the user can view output data in various formats and presentation modes and in some cases, process new data from within the Wizard. Complete documentation for each model is available within the sub-process for that model along with a Wizard User Guide document (available by clicking the top left icon on the dashboard screen). Once a model process is complete, the user returns to the dashboard screen to continue to the next model or close the Wizard application. 
Figure 5. Wizard dashboard screen.

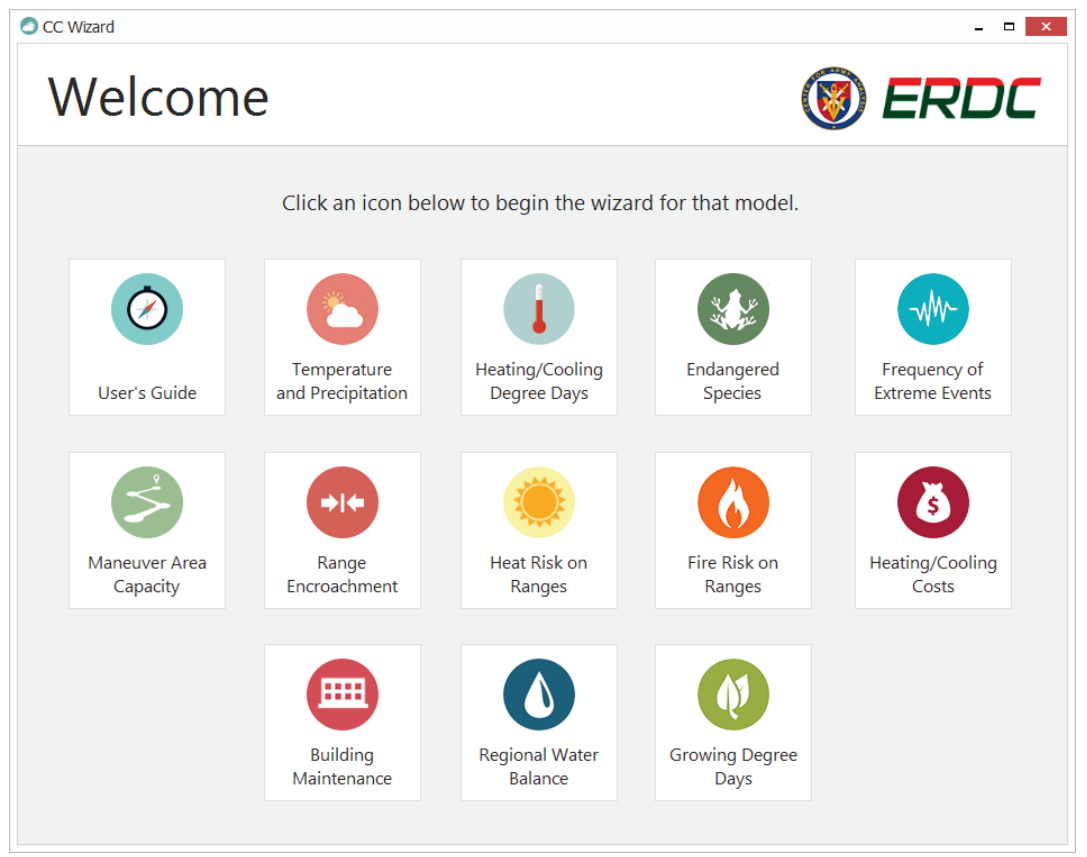




\section{Model Integration}

\subsection{Temperature and precipitation projections model}

The potential effects of climate change on temperature and precipitation at Department of Defense (DoD) installations are far ranging, and understanding their impacts is essential to maintaining optimal force stationing and readiness. The Temperature and Precipitation Projections Model attempts to predict changes in daily and monthly average temperature and precipitation for several scenarios from future climate projections for various DoD installations.

Many different methods for modeling climate change have been created and tested over the years as part of an effort to understand climate change at a more precise level. Under the World Climate Research Programme (WCRP) the Working Group on Coupled Modelling (WGCM) established the Coupled Model Intercomparison Project (CMIP) as a standard experimental protocol for studying the output of coupled atmosphereocean general circulation models (AOGCM). The CMIP facilitates assessment of the strengths and weaknesses of climate models that can enhance and focus the development of future models. $\mathrm{CMIP}_{5}$ (formally: Coupled Model Intercomparison Project Phase 5) is the most current and extensive of the CMIPs. The objectives of CMIP 5 were to:

- Evaluate how realistic the models are in simulating the recent past

- Provide projections of future climate change on two time scales, near term (out to about 2035) and long term (out to 2100)

- Understand some of the factors responsible for differences in model projections, including quantifying some key feedbacks such as those involving clouds and the carbon cycle.

The Temperature and Precipitation Projections Model is written in the $\mathrm{R}$ programming language and parses $\mathrm{CMIP}_{5}$ data that is stored in Network Common Data Format (NetCDF) files. NetCDF is a machine-independent data format that is often used for the sharing of array-oriented scientific data such as that produced during the $\mathrm{CMIP}_{5}$ study. Temperature and precipitation data is extracted by the model for a series of DoD installations and output into the standard Comma Separated Values (CSV) format. The exported values represent daily and monthly temperature and precipitation projections into the future broken into 10-year increments 
starting at the year 2020 and proceeding up to the year 2100. Monthly data is further processed into average values for each month within a 10year epoch and also averages for the entire epoch. The climate data output from this model serves as the basis for importing projected temperature and precipitation into other models.

\subsubsection{Capturing the current state}

The Temperature and Precipitation Projections Model was received as a script written in the R programming language and a complete set of CMIP5 climate change prediction data in NetCDF file format. The predicted climate dataset contained a large set of GCM (General Circulation Models) with various Representative Concentration Pathways (RCP) within each GCM.

The GCM is a numerical prediction model that attempts to describe physical processes in the atmosphere, ocean, cryosphere, and land surface for the purpose of predicting global climate change into the future. Although there are numerous computational scenarios available within the CMIP5 study, nine were chosen for the purpose of this work package.

- Canadian Centre for Climate Modelling and Analysis (CCCma)

- Community Climate System Model, University Corporation for Atmospheric Research (CCSM)

- Centre National de Recherches Meteorologiques, Meteo France, France (CNRM)

- Commonwealth Scientific and Industrial Research Organisation (CSIRO)

- Geophysical Fluid Dynamics Laboratory, National Oceanic and Atmospheric Administration (NOAA) (GFDL)

- Institut Pierre Simon Laplace (IPSL), France

- Atmosphere and Ocean Research Institute, the University of Tokyo (MICROC5)

- Max Planck Institute for Meteorology, Germany (MPI-ESM-LR)

- The Norwegian Earth System Model (NorESM).

The RCP is a greenhouse gas concentration trajectory that is used as an input into the computation of GCMs. The RCP does not represent greenhouse gas emissions, only concentrations in the atmosphere. There are several RCPs included in the $\mathrm{CMIP}_{5}$ study, but three were chosen for the purpose of this work package to represent an upper bound (worst case scenario), middle, and lower bound (best case scenario): 
- $\quad$ RCP 8.5 (worst case)

- $\mathrm{RCP} 4.5$

- RCP 2.6 (best case).

These chosen GCM and RCP inputs are parsed from within the larger CMIP5 dataset by the R script ClimateData_Processing_V3c.R and stored locally within the VM in CSV files. Within the CMIP5 study data, daily and monthly temperature and precipitation values are available to researchers at the following file transfer protocol (FTP) site: $\mathrm{ftp}$ ://gdodcp.ucllnl.org/pub/dcp/archive/cmip5/. Daily values are stored in the folder Bias Corrected Constructed Analogs (BCCA), and monthly values are stored in folder Bias Corrected Spatially Downscaled (BCSD). These two folders must be downloaded from the FTP site and stored locally prior to executing the R script. Each step for viewing and building data sets is thoroughly documented in Section 4.1.2 to limit user confusion and ensure accurate results.

Software requirements for the Temperature and Precipitation Projections Model include the R Studio development environment, a basic text editor such as MS Notepad ${ }^{\circledR}$, and MS Excel ${ }^{\circledR}$ version 2013 or higher.

A working knowledge of Microsoft Office products is recommended as well as a basic understanding of editing file paths in a text file and executing $R$ code within the R Studio environment.

Hardware requirements for this model are quite substantial. A minimum of nine processor cores (eight required for script) are required to execute the code. Memory minimum requirements are 64 GB of random access memory (RAM) and 5 terabytes (TB) of hard disk storage space (local or network).

\subsubsection{Integrating into the Wizard}

There are two parts to the Temperature and Precipitation Projections Model: viewing the output data and building new output data. Pre-built datasets for this model that were processed using current CMIP 5 climate scenarios are stored within the VM. The ability to view this output data is built in to the Wizard application.

After launching the Wizard from the VM desktop, the Temperature and Precipitation Projections Model is launched by clicking the icon from the Wizard dashboard screen (Figures 6 and 7). 
Figure 6. Temperature and Precipitation Projections Model icon.

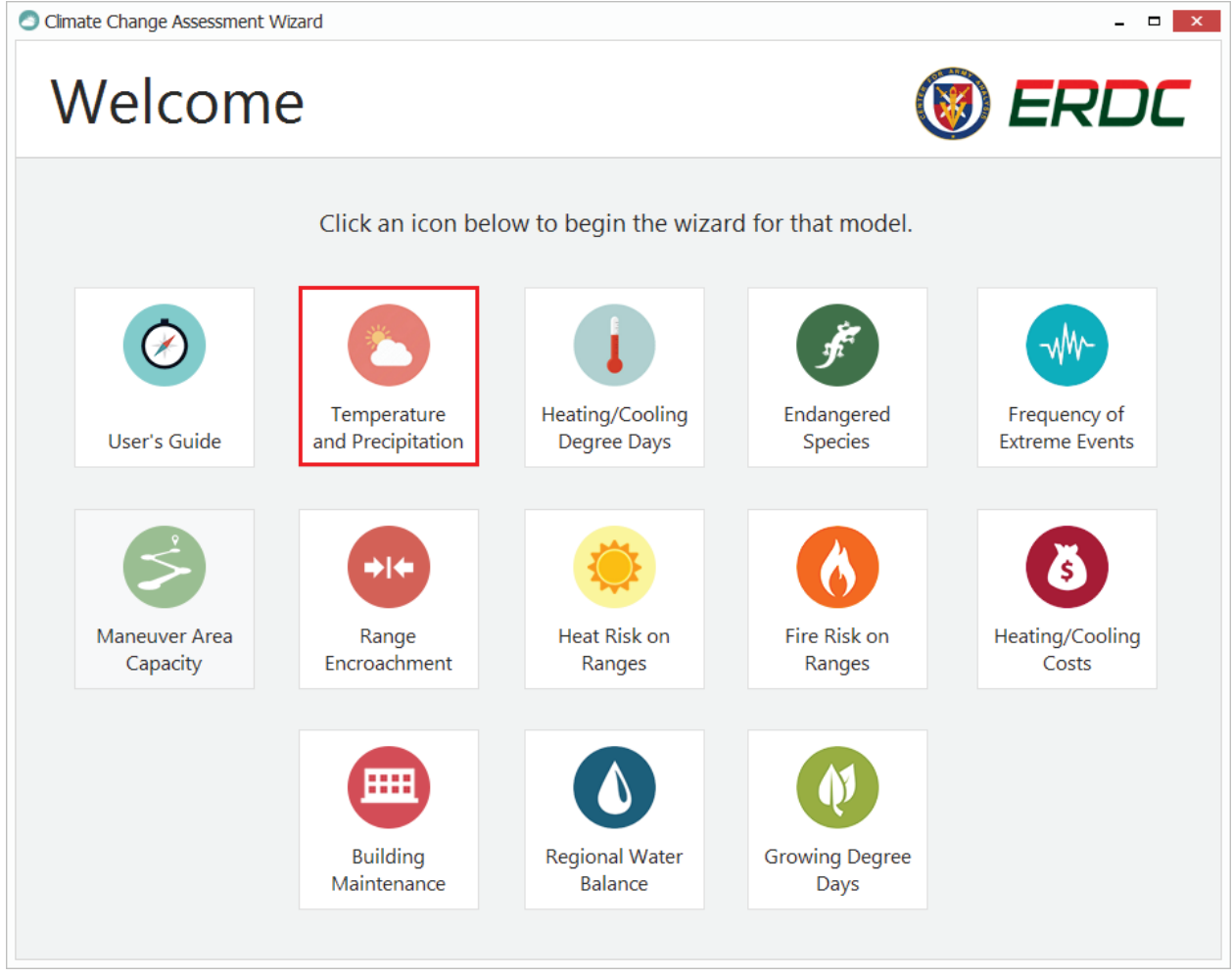

Figure 7. Temperature and Precipitation Projections Model first screen.

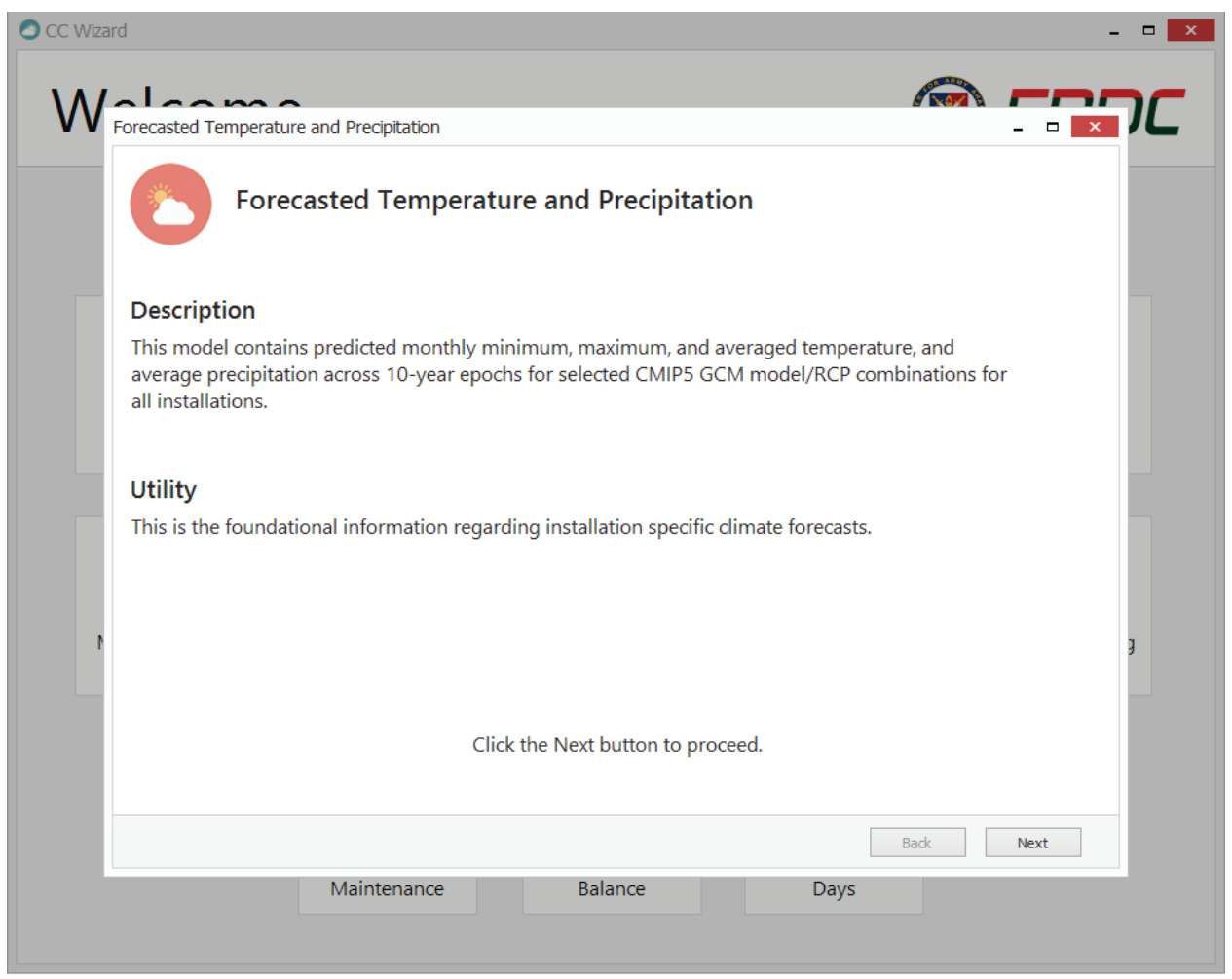


The second screen within the model allows the end user to view the datasets in graphical or tabular mode (Figure 8). Choose the desired view type from the View drop down combo box. Options within this box are Graphs and Tabular. Graphs displays the data as standard line graphs while Tabular displays the data in a table layout within a MS Excel ${ }^{\circledR}$ spreadsheet.

Figure 8. Temperature and Precipitation Projections Model second screen.

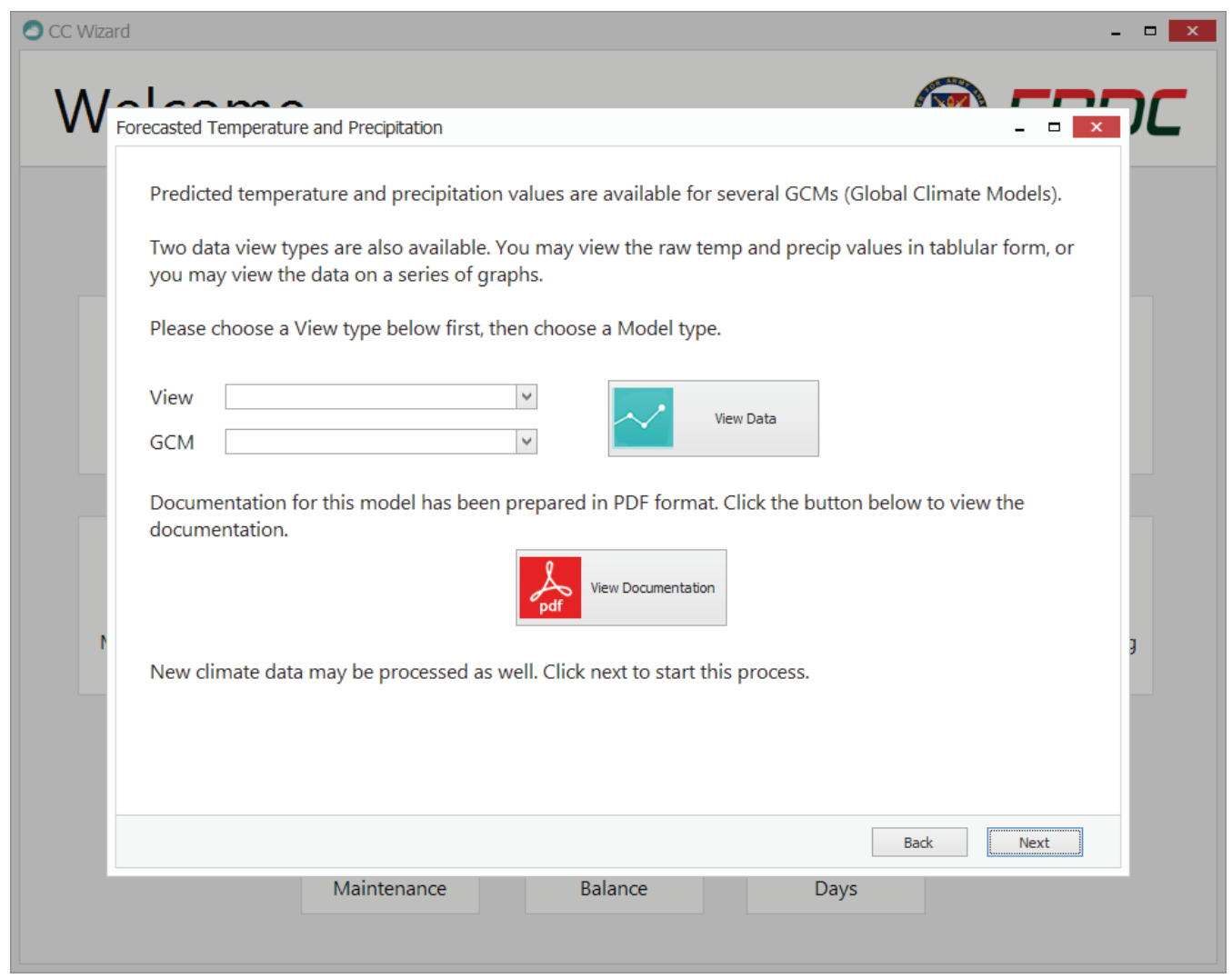

Next, choose a GCM and RCP type from the drop down combo box to filter only data related to that GCM/RCP. Each GCM contains the three standard RCPs, with the exception of the CNRM and GFDL models.

Once both of the choices are made, click the View Data button to launch the chart viewer window (Figure 9). 
Figure 9. Results in the chart viewer window.

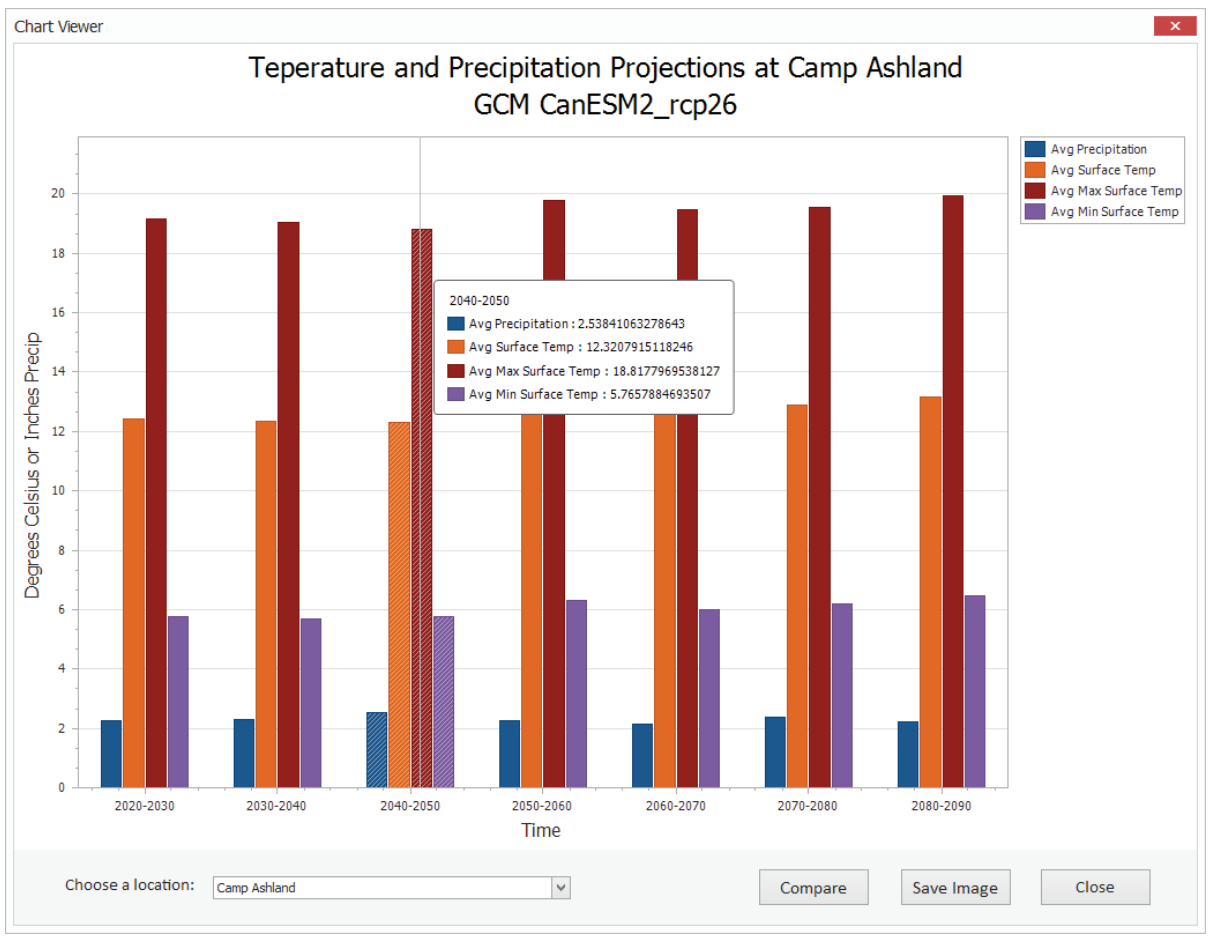

Average Precipitation, Surface Temp, Max Surface Temp, and Min Surface temp values are charted on the $\mathrm{Y}$-axis, and 10-year epochs are charted on the $\mathrm{X}$-axis. The user can change the charted values by choosing a different geographical location from the drop down combo box near the bottom left of the window. Upon selecting a location, the data will automatically filter to include only those values found within the chosen area.

Users may also limit the variables that are charted. Clicking the Compare button near the bottom right of the window brings up a dialog where variables may be shown or hidden from the chart (Figure 10).

Figure 10. Chart comparison filter.

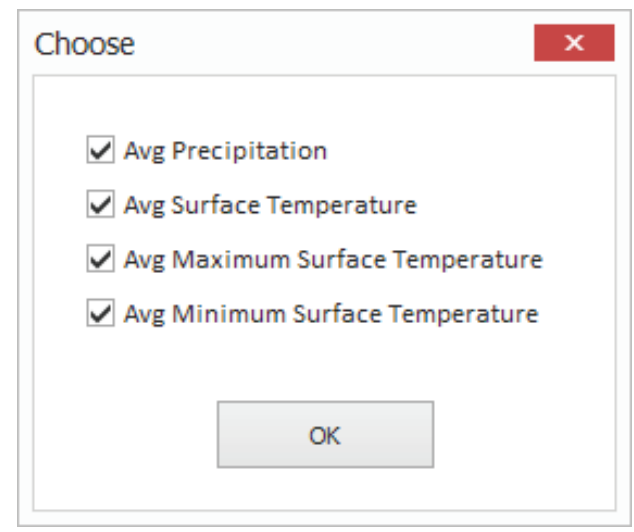


Charts may be saved to the users' computer by clicking the Save Image button near the bottom right of the window. The resulting file is saved to a location of the users choosing in the universal Joint Photographic Experts Group (JPEG) image file format.

Future climate studies may result in updates to existing GCMs or even the addition of new ones. When these climate inputs become available, it will be necessary to execute the second part of the model, building new data. Building new data is accomplished within the VM by running an R Script from the R Studio development environment. The following instructions should be followed carefully to produce new data from this model.

The R Studio development environment is pre-installed inside the VM and may be launched automatically from the Wizard application or accessed from the Windows Start menu Figures 11 and 12).

To run a script in R Studio, use the Code menu at the top. Choose Run Region-> Run All (Figure 13).

Figure 11. Launch R Studio from the third model screen within the Wizard.

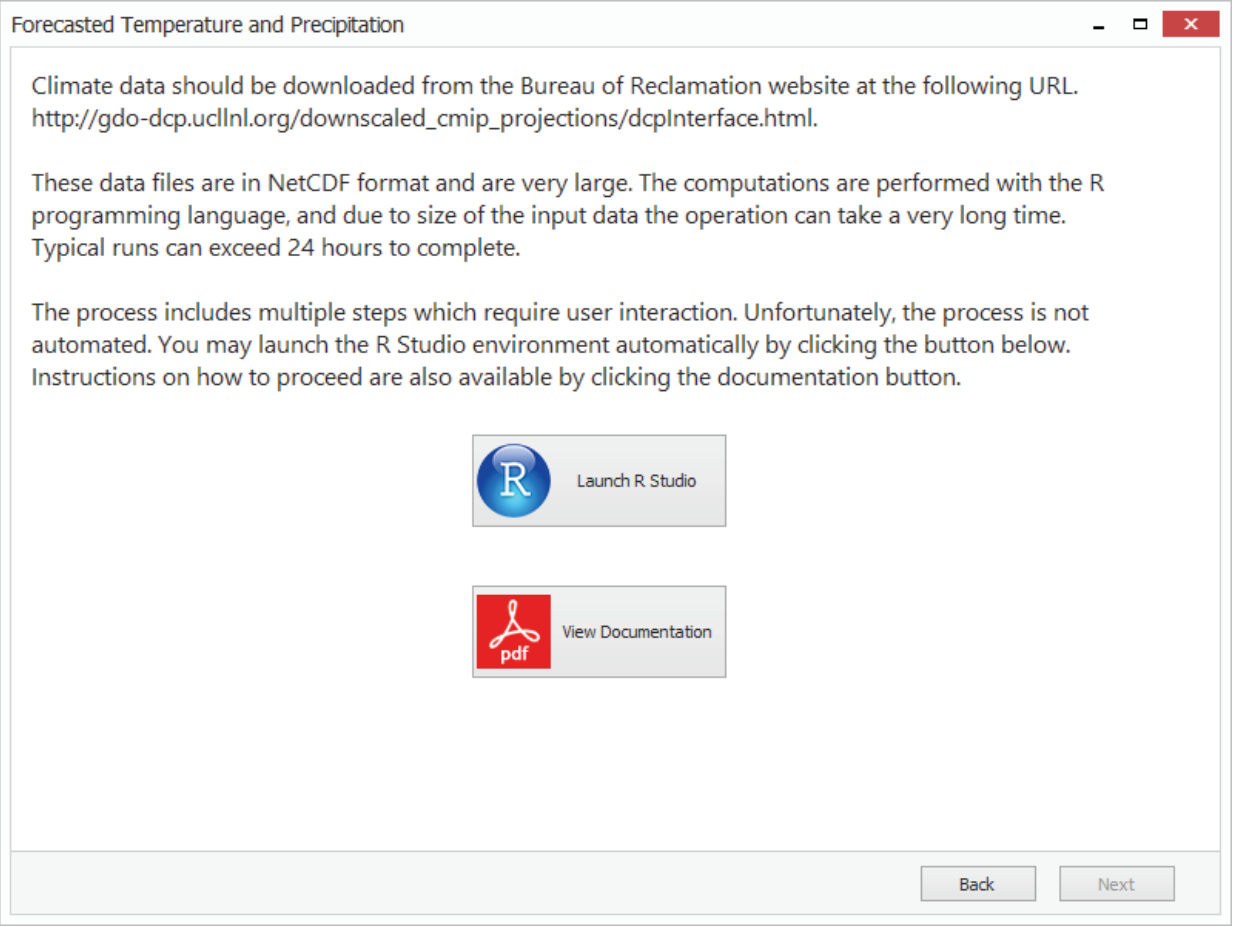


Figure 12. R Studio development environment.

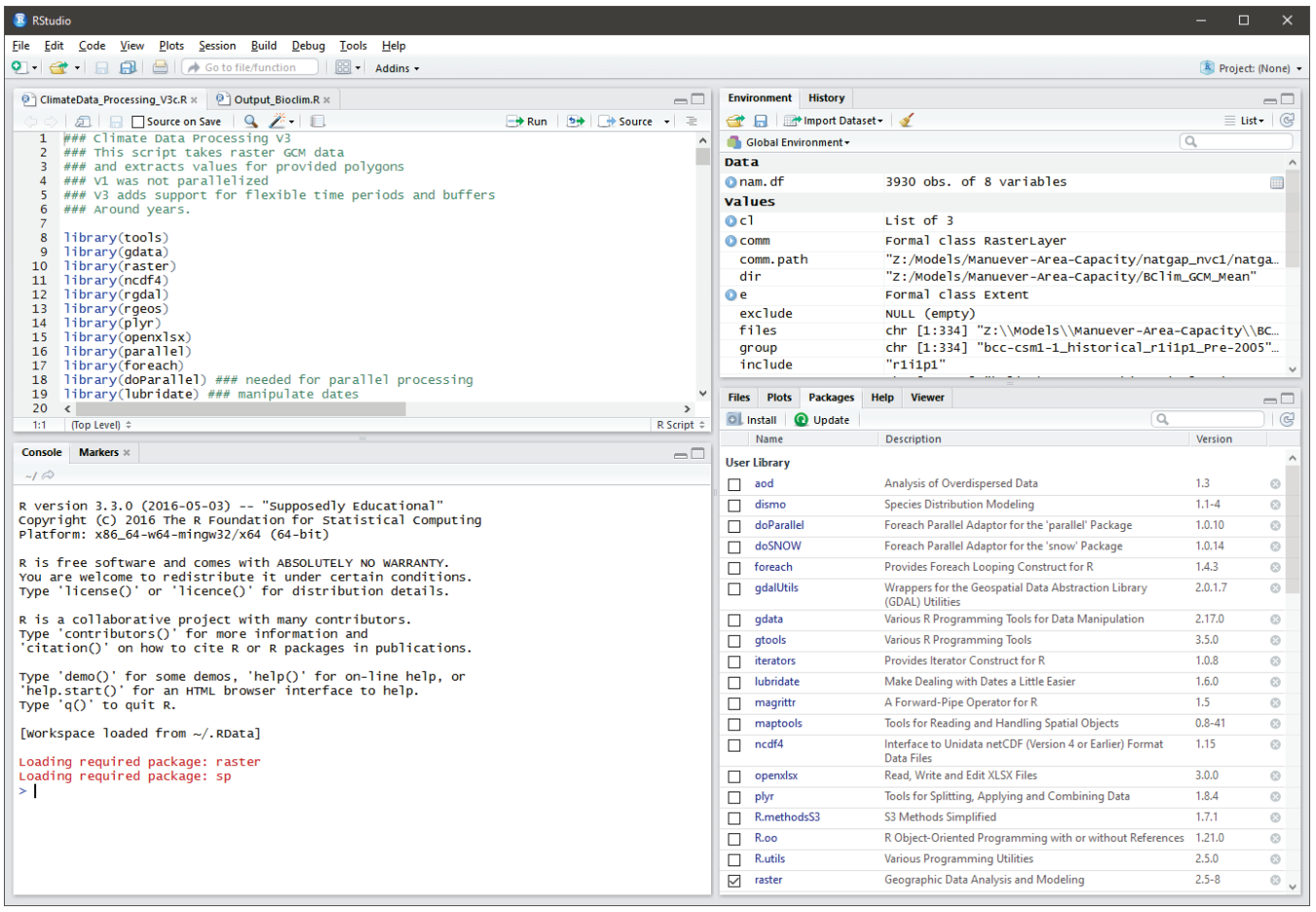

Figure 13. Use the Code menu to run a script.

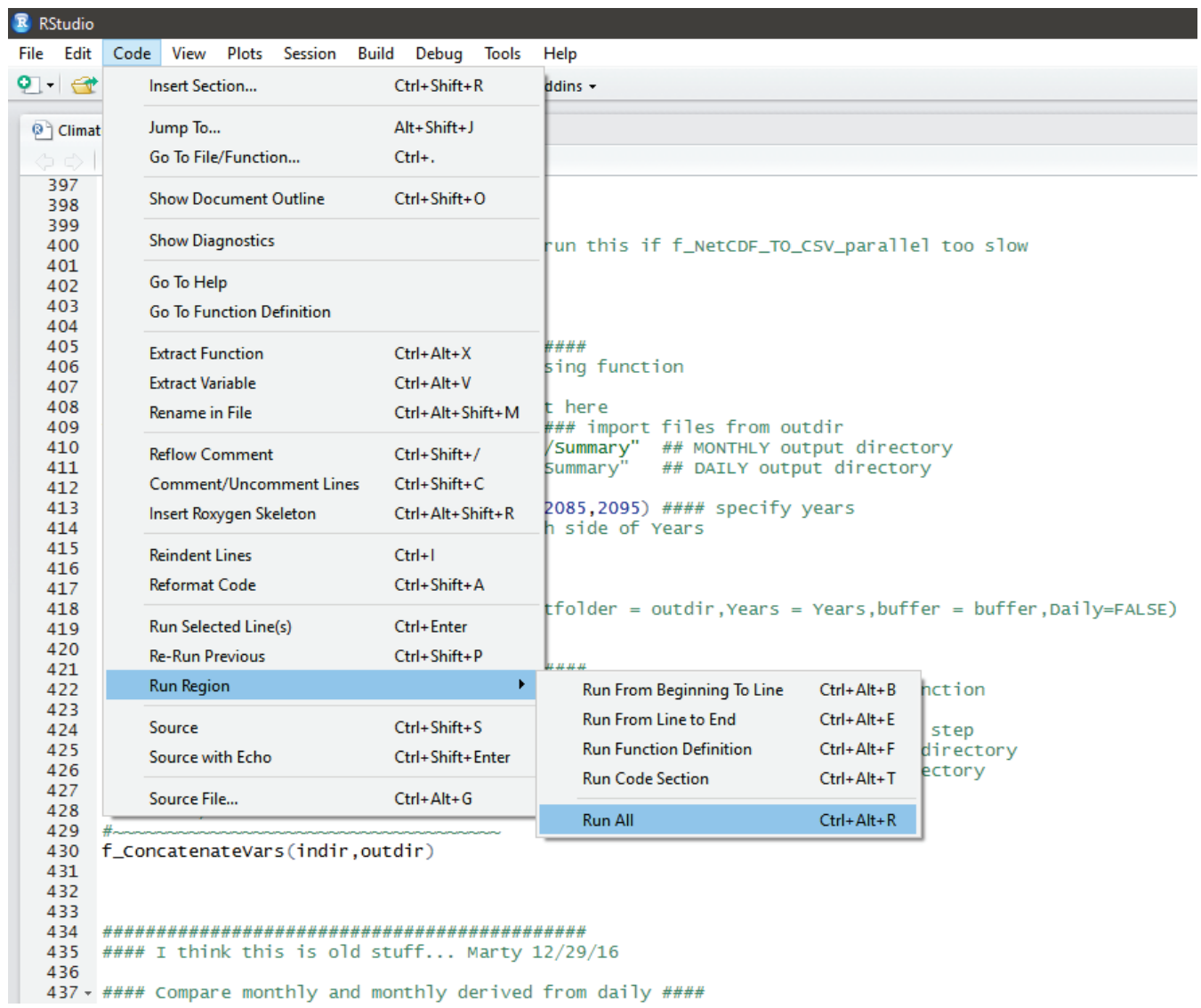


After opening R Studio, the appropriate R script should be loaded automatically. If it is not, open the R script by selecting File->Open File and browse to the file $\mathrm{C}: \backslash$ Models $\backslash$ Temp-PrecipProjections $\backslash$ Model $\backslash$ ClimateData_Processing_V3.R. Once the file is loaded, review the following lines to ensure the script performs the proper actions:

- Lines 379-381. These lines define the input directories for the monthly and daily NetCDF files. BCSD indicates monthly data, and BCCA indicates daily data. Uncomment the appropriate line depending on the action required by removing the \# symbol and placing it in front of the previous action.

- Line 383. Three RCPs were chosen to represent the upper, middle, and lower bounds. If additional RCPs are required, add them to the list.

- Lines 387-388. These lines define the output directories for the monthly and daily calculated results. Comment out the appropriate line using the same \# symbol method mentioned previously.

- Lines 396-400. These lines execute the functions that format the outputs in CSV format. Although all three can run at the same time, it is safer to run one at a time. That way, errors can be caught without having to wait until all functions complete. Uncomment one line at a time by removing the \# symbol, execute the script, then replace the \# symbol and repeat for the other lines. Line 400 is a variant of function on line 399 and should not be used unless the function on line 399 fails.

- Lines 410-411. These lines define the output directory for the summarization function that formats the CSV output. Comment/uncomment them if processing daily or monthly values as described in previous steps, then uncomment line 418 and run the $R$ script. Make sure to comment previous function calls on lines 396-400 to prevent running them again.

- Lines 425-426. These lines define the output directory for the concatenation function that further formats the CSV output. Comment/uncomment them if processing daily or monthly values as described in previous steps, then uncomment line 430 and run the $\mathrm{R}$ script. Make sure to comment previous function calls on lines 396-400 and line 418 to prevent running them again.

Output from this model is in the form of CSV files, one for each GCM/RCP combination. Please note that this process can be rather lengthy, 
depending on the number of GCMs that are being processed. It is not unusual for the script to run for several hours.

The data that results from running the $\mathrm{R}$ script is still in a state that is not easily usable. A separate data formatting application was developed as part of the software integration effort to format the output properly. Locate the EXE file in the model folder within VM. (C: $\backslash$ Models $\backslash$ Temp-PrecipProjections $\backslash$ Model $\backslash$ DataFixer.exe). Set the input and output paths by clicking the Change buttons. Ensure that the output folder that is entered exists before starting the process. Finally, click Fix It to process the data (Figure 14).

Figure 14. Data fixer tool.

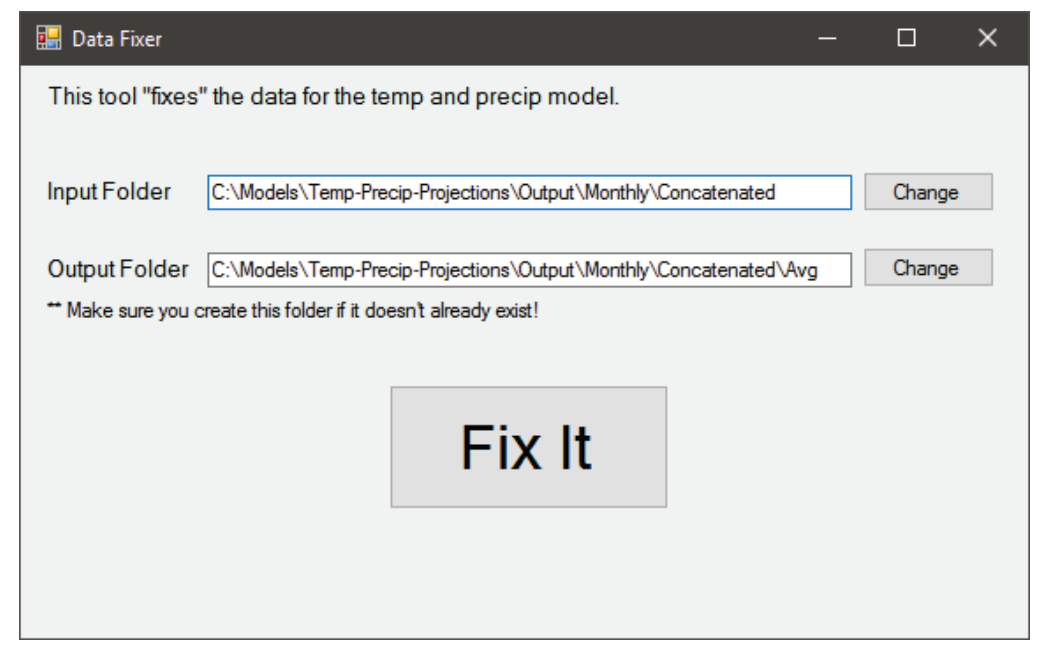

Post-processing the data is fairly quick. It should not take more than a couple of minutes to complete. After this step, the data is ready to be viewed within the Wizard application. The post-processing app source code is located at $\mathrm{C}: \backslash$ Model $\backslash \mathrm{S} \backslash \mathrm{VS}$ Projects $\backslash$ DataFixerTempPrecip.

\subsubsection{Known issues and limitations}

Building new data with this model can be a very length process. Depending on the number of GCMs being processed, it is not unusual for the R script to take several hours complete, even on very powerful, modern computers.

As mentioned previously, significant hardware specifications are required to run this model. Typical desktop computers will not meet these requirements. A minimum of nine processor cores (eight required for 
script) are required to execute the code. Memory minimum requirements are $64 \mathrm{~GB}$ of RAM and $5 \mathrm{~TB}$ of hard disk storage space (local or network).

\subsection{Heating and Cooling Degree Days Model}

It is important to Army stationing planners to determine the potential impact of climate change on the number of days that heating or cooling of occupied structures is required. Heating and cooling requirements have a direct impact on the cost of operating an installation, and the increase or decrease in energy requirements an installation may experience if climate change has enough of an impact to affect the number of heating and cooling degree days an installation experiences during a given period of time.

Heating degree days (HDD) is defined as the number of days where the average daily temperature is below $65{ }^{\circ} \mathrm{F}$, the temperature below which buildings need to be heated. Cooling degree days (CDD) is defined as the number of days where the average daily temperature is above $65^{\circ} \mathrm{F}$, and people start to use air conditioning to cool their buildings.

This model attempts to predict the number of days that interior temperature control systems will be required to either heat or cool an occupied structure. The predicted effect of climate change on heating and cooling degree days is intended to be used in other force stationing analysis applications as a MVA attribute.

\subsubsection{Capturing the current state}

The Heating and Cooling Degree Days Model was received as a script written in the Python programming language. The script accepts daily temperature and precipitation values that are the output of the Temperature and Precipitation Projections Model that was discussed in Section 4.1. Those outputs are required to be present in the VM for this model to execute. Outputs from this model represent the number of days within a selected 10-year epoch that are predicted to occur in the heating and cooling degree day categories.

Executing the model is a two-step process that requires using Python IDLE development environment, MS Excel ${ }^{\circledR}$, and a basic text editor such as MS Notepad ${ }^{\circledR}$. Each step for viewing and building data sets is thoroughly documented in the following sections to limit user confusion and ensure accurate results. 
Software requirements for the Heating and Cooling Degree Days Model include the Python IDLE development environment, a basic text editor such as MS Notepad ${ }^{\circledR}$, and MS Excel ${ }^{\circledR}$ version 2013 or higher.

A working knowledge of Microsoft Office products is recommended as well as a basic understanding of editing file paths in a text file and executing Python code within the IDLE environment.

\subsubsection{Integrating Into the Wizard}

There are two parts to the Heating and Cooling Degree Days Model: viewing the output data and building new output data. Pre-built datasets for this model were processed using daily values from the Temperature and Precipitation Projections Model and are stored within the VM. The ability to view this output data is built in to the Wizard application.

After launching the Wizard from the VM desktop, the Heating and Cooling Degree Days Model is launched by clicking the icon from the Wizard dashboard screen (Figures 15 and 16).

Figure 15. Heating and Cooling Degree Days Model icon.

\section{Welcome}

(2) ERDC
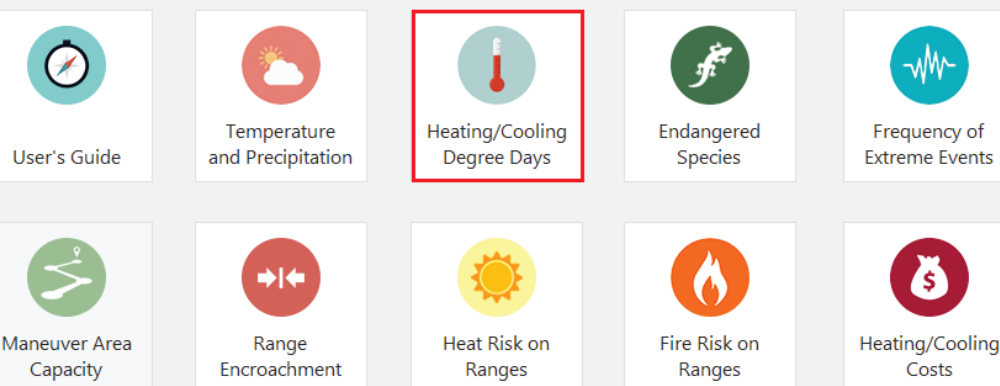

Fire Risk on
Ranges
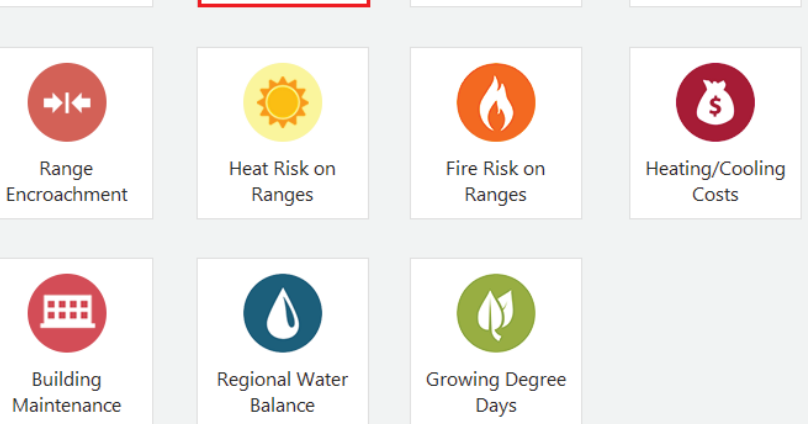
Figure 16. Heating and Cooling Degree Days Model first screen.

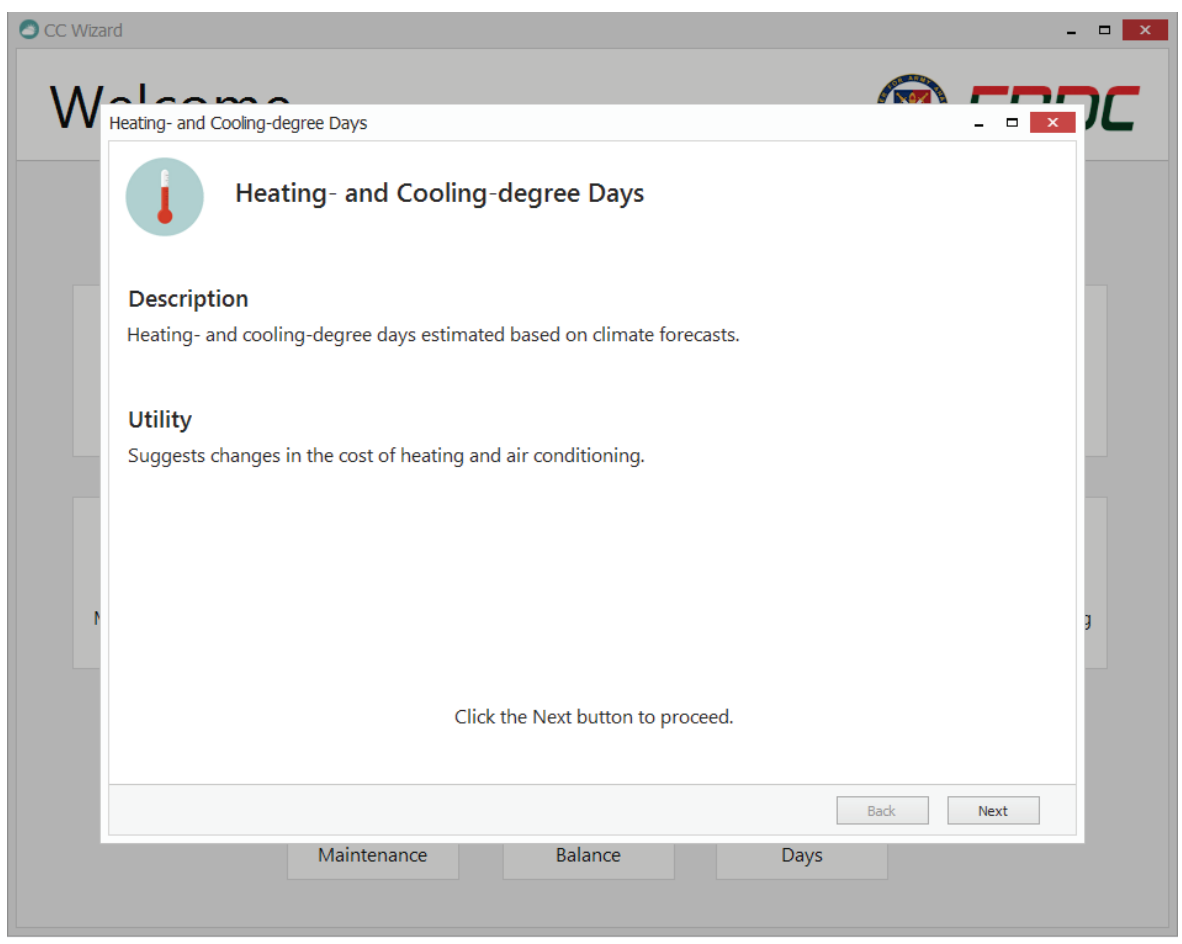

The second screen within the model allows the end user to view the datasets in graphical or tabular mode. Choose the desired view type from the View drop down combo box. Options within this box are Graphs and Tabular. Graphs displays the data as standard line graphs while Tabular displays the data in a table layout within a MS Excel ${ }^{\circledR}$ spreadsheet (Figure 17).

Next, choose a GCM and RCP type from the drop down combo box to filter only data related to that GCM/RCP. At the time of this publication, there are $10 \mathrm{GCMs}$ within the dataset for this model. RCP 2.6, 4.5, and 8.5 were chosen to represent lower bound, middle, and upper bounds for each GCM. Each GCM contains these RCPs, with the exception of CNRM and GFDL.

Once both of the choices are made, click the View Data button to launch the chart viewer window (Figure 18). 
Figure 17. Heating and Cooling Degree Days Model second screen.

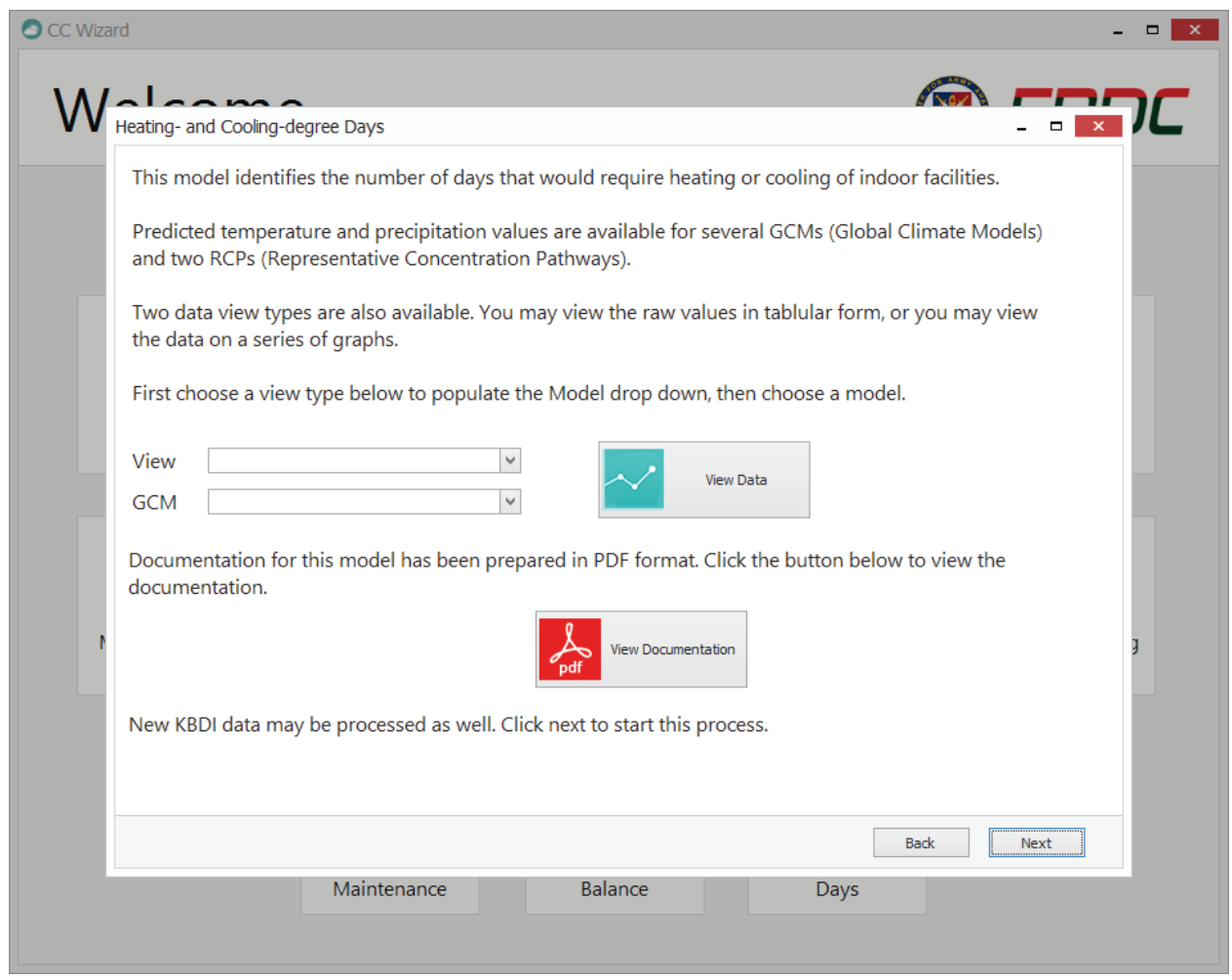

Figure 18. Results in the chart viewer window.

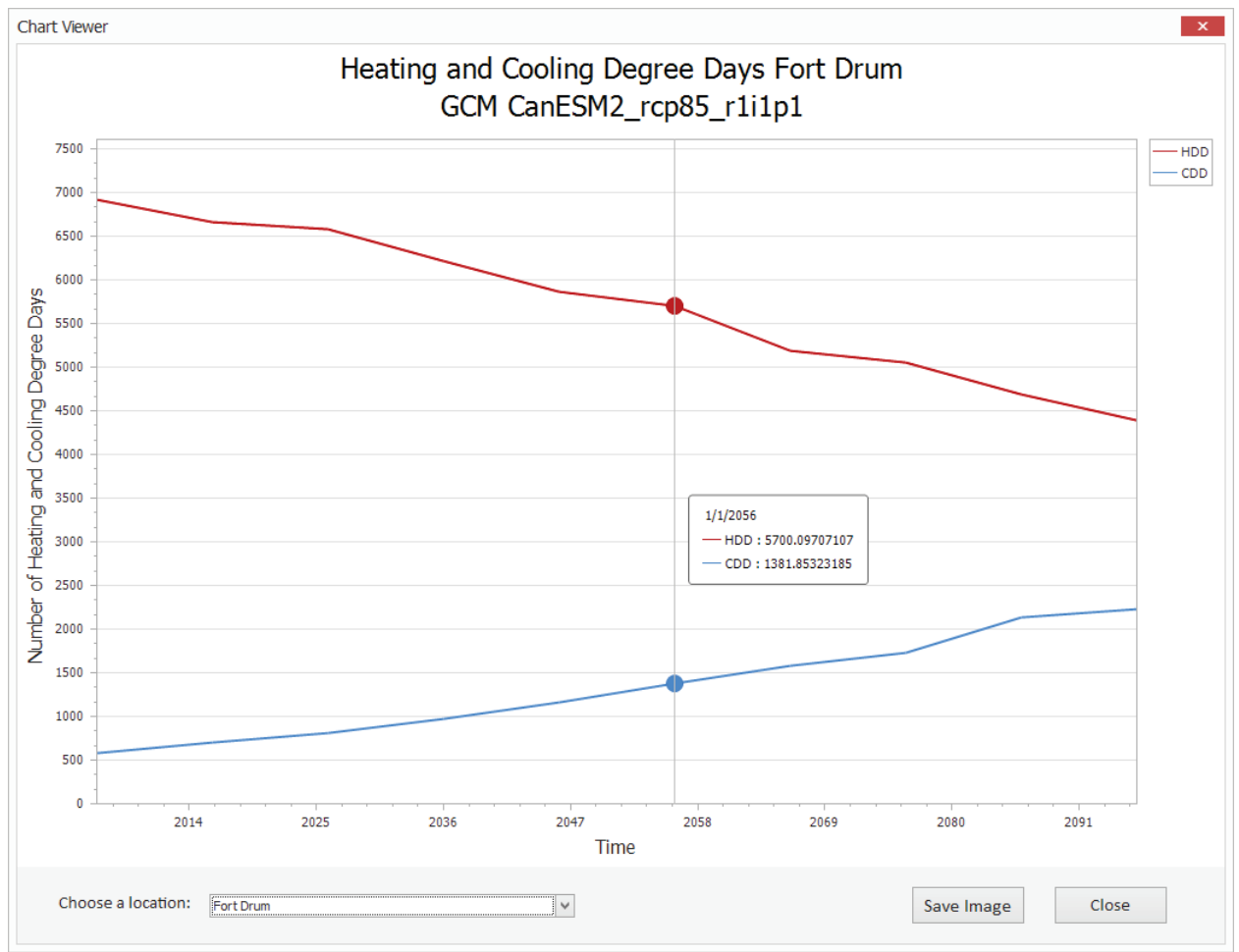


The average number of heating and cooling degree days for epochs ending in 2100 are plotted as line graphs with the number of days charted on the $\mathrm{Y}$-axis, and 10-year epochs are charted on the $\mathrm{X}$-axis. The user can change the charted values by choosing a different geographical location from the drop down combo box near the bottom left of the window. Upon selecting a location, the data will automatically filter to include only those values found within the chosen area.

Charts can be saved to the user's computer by clicking the Save Image button near the bottom right of the window. The resulting file is saved to a location of the users choosing in the universal JPEG image file format.

If in the future new climate data is processed through the Temperature and Precipitation Projections Model, new data can be generated from the Heating and Cooling Degree Days Model as well. Building new datasets is not possible within the Wizard interface, but can be accomplished within the VM by running a Python Script from the Python IDLE development environment. The following instructions should be followed carefully to produce new data from this model.

The Python IDLE development environment is pre-installed inside the VM and may be launched automatically from the Wizard application or accessed from the Windows Start menu (Figures 19 and 20).

After opening IDLE, open the Python script by selecting File->Open and browse to the file $\mathrm{C}: \backslash$ Model $\backslash$ Shared-Data $\backslash$ Model $\backslash$ heat-fire risk days climate projections.py. Once the file is loaded, ensure line 19 points to a text file that contains a list of GCMs to process. This file has been pre-made, so no adjustments to it should be necessary, unless new GCMs are to be processed. The file location is $\mathrm{C}: \backslash$ Models $\backslash$ Data$2 \backslash G C M$ Model Runs. txt. Use a text editor such as MS Notepad ${ }^{\circledR}$ to make modifications to this file. Also note that daily climate data from the Temperature and Precipitation Model must be processed prior to running this Heating and Cooling Degree Days Model. Refer to lines 16-18 for the file paths. If new climate data is to be processed, the files that are output from the Temperature and Precipitation Model must be located in the same prior directory, or lines 16-18 must be modified to match the location of the output files. Refer to the user guide for that model for more information about its output files. 
Figure 19. Launch Python IDLE from the third model screen within the Wizard.

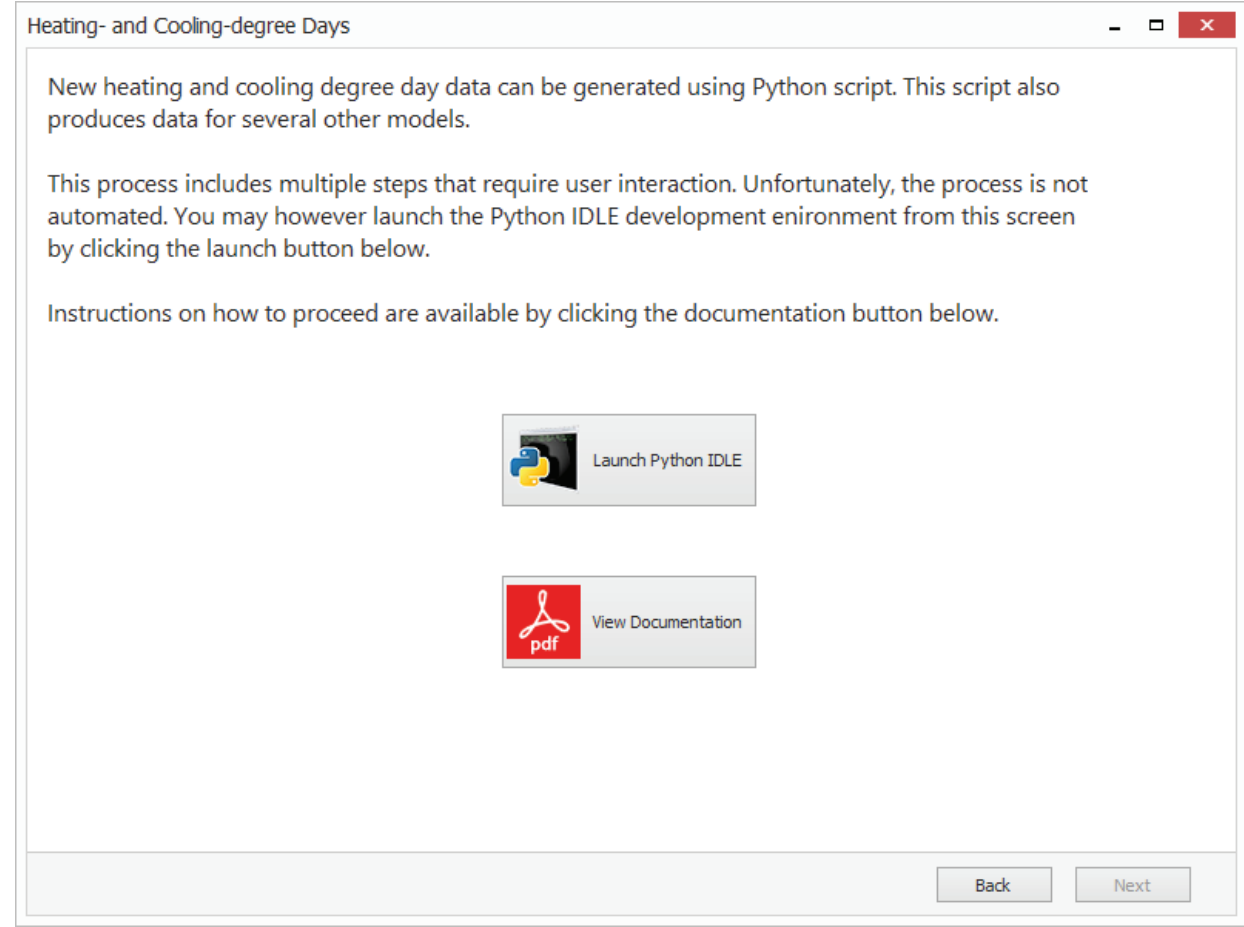

Figure 20. Python IDLE development environment.

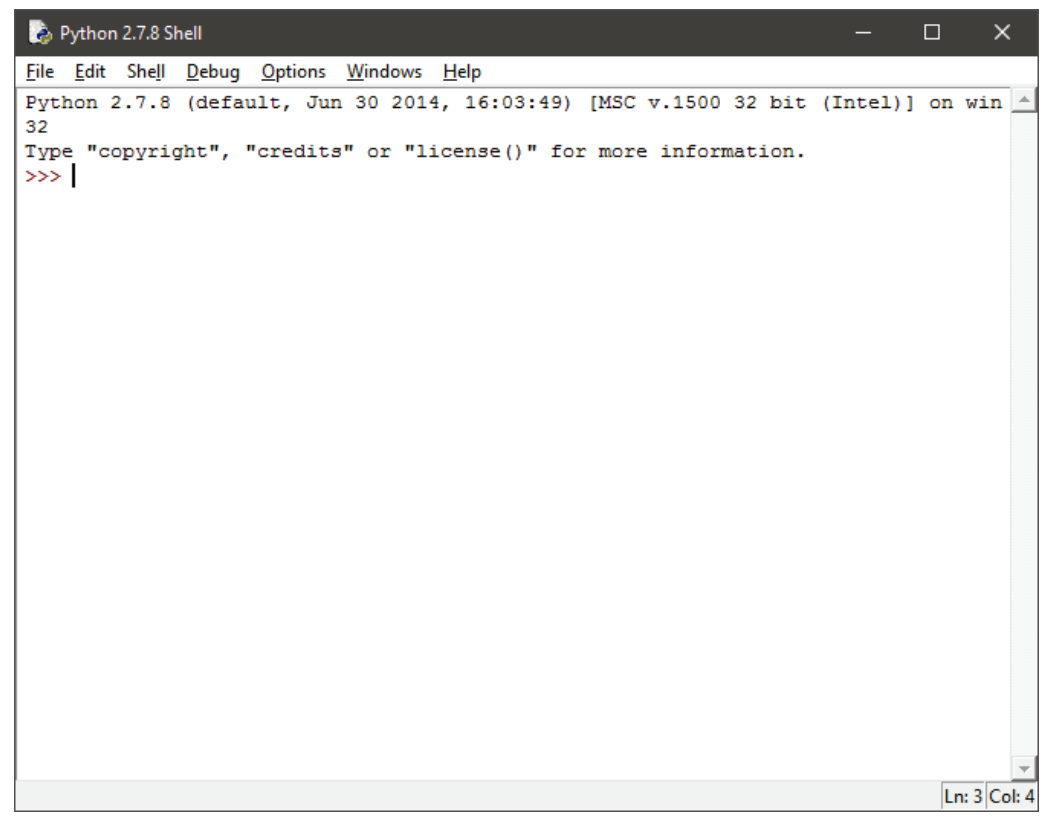

Output from this model is in the form of CSV files, one for each GCM/RCP combination. Please note that this process can be rather lengthy, depending on the number of GCMs that are being processed. It is not unusual for the script to run for several hours. 
The output generated by the Python script is still in a state that is not readily usable, so an additional tool to further process the data into a proper format we developed. This post processing application is located in the model folder within VM. (C: \Models \SharedData \DataFixer.exe). Double click the file to launch the tool. Set the input and output paths by clicking the Change buttons. Ensure that the output folder that is entered exists before starting the process. Finally, click Fix It to process the data (Figure 21).

Figure 21. Data Fixer tool.

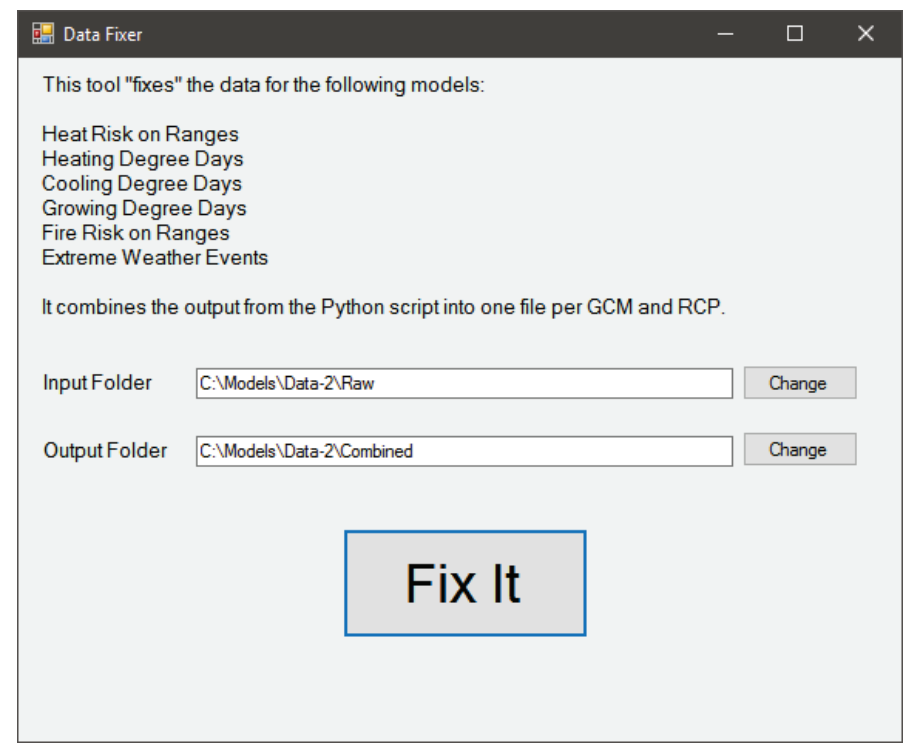

Post processing the data is fairly quick. It should not take more than a couple of minutes to complete. After this step, the data is ready to be viewed within the Wizard application. The post processing app source code is located at $\mathrm{C}: \backslash$ Model $\backslash \mathrm{S} \backslash \mathrm{VS}$ Projects $\backslash$ DataFixerHeatFire.

\subsubsection{Known issues and limitations}

Building new data with this model can be a very length process. Depending on the number of GCMs being processed, it is not unusual for the Python script to take several hours complete, even on very powerful, modern computers.

Also to reiterate, the input data for this model is the output data from the Temperature and Precipitation Projections Model. That model must be run to build the input data for this model prior to attempting to build new heating and cooling degree days data. 


\subsection{Threatened and Endangered Species Model}

A key concern of force stationing analysts is the potential for climate change driven increases in the number of species listed under the U.S. Endangered Species Act (ESA) and stress to federally listed species, because both pose additional management requirements and challenges, as well as potential restrictions on training land use.

This work developed an approach for characterizing this component of installation climate change vulnerability that integrates multiple factors related to exposure, sensitivity, adaptive capacity, and number of listed and at-risk species. The approach was applied to Continental U.S. (CONUS) Army installations having Integrated Training Area Management (ITAM) programs. Additionally, the vulnerability assessment was used to rank installations across Army based on the aggregate vulnerabilities of species.

The approach to the vulnerability assessment demonstrated by the model is suitable for evaluating whether climate change driven impacts to listed and at-risk species is likely to affect installation resilience. The predicted effect of climate change on the vulnerability of threatened and endangered species is intended to be used in other force stationing analysis applications as an MVA attribute.

\subsubsection{Capturing the current state}

The Threatened and Endangered Species Model was received as a set of step-by-step instructions without any other type of implementation. The process of capturing the model consisted of analyzing those steps one-byone, then replicating them in a MS Excel ${ }^{\circledR}$ spreadsheet. The model makes use of the MS Excel ${ }^{\circledR}$ built in scripting capabilities know as Visual Basic for Applications (VBA).

Software requirements for this model include MS Excel ${ }^{\circledR}$ version 2013 or higher. Data collection prior to model execution requires an internet connection and internet browser. A working knowledge of Microsoft Office products is recommended as well as a basic understanding of accessing websites and downloading files from the internet. 


\subsubsection{Integrating into the Wizard}

There are two parts to the Threatened and Endangered Species Model: viewing the output data and building new output data. Pre-built output data for this model was processed using the newly developed model spreadsheet and the required input data that was collected from the internet. The output data is stored in the model spreadsheet that is stored within the VM. The ability to view this output data is built in to the Wizard application.

After launching the Wizard from the VM desktop, the Threatened and Endangered Species Model is launched by clicking the icon from the Wizard dashboard screen (Figures 22 and 23).

The second screen within the model allows the end user to view the datasets in tabular mode. Use the Launch Model button on the second screen to view the data in a table layout within a MS Excel ${ }^{\circledR}$ spreadsheet (Figures 24 and 25). This MS Excel ${ }^{\circledR}$ file is located within the VM at $\mathrm{C}: \backslash$ Models $\backslash \mathrm{TES} \backslash$ Model $\backslash \mathrm{TES}-$ Model .xlsm.

Figure 22. Threatened and Endangered Species Model icon.

Climate Change Assessment Wizard

\section{Welcome}

(2) ERDC

Click an icon below to begin the wizard for that model.

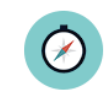

User's Guide

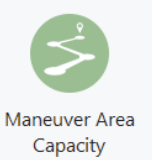

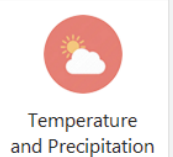
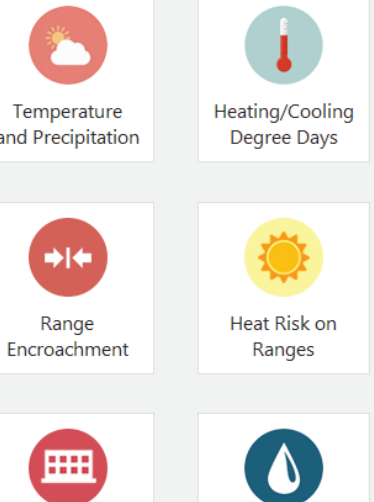

Building Building
Maintenance
Degree Days
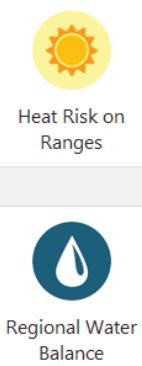
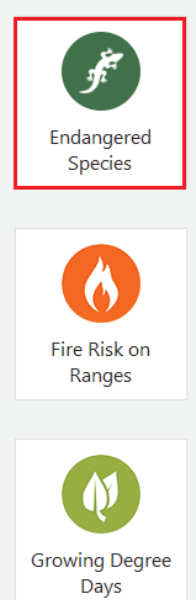

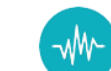

Frequency of

Extreme Events

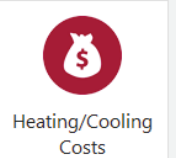


Figure 23. Threatened and Endangered Species Model first screen.

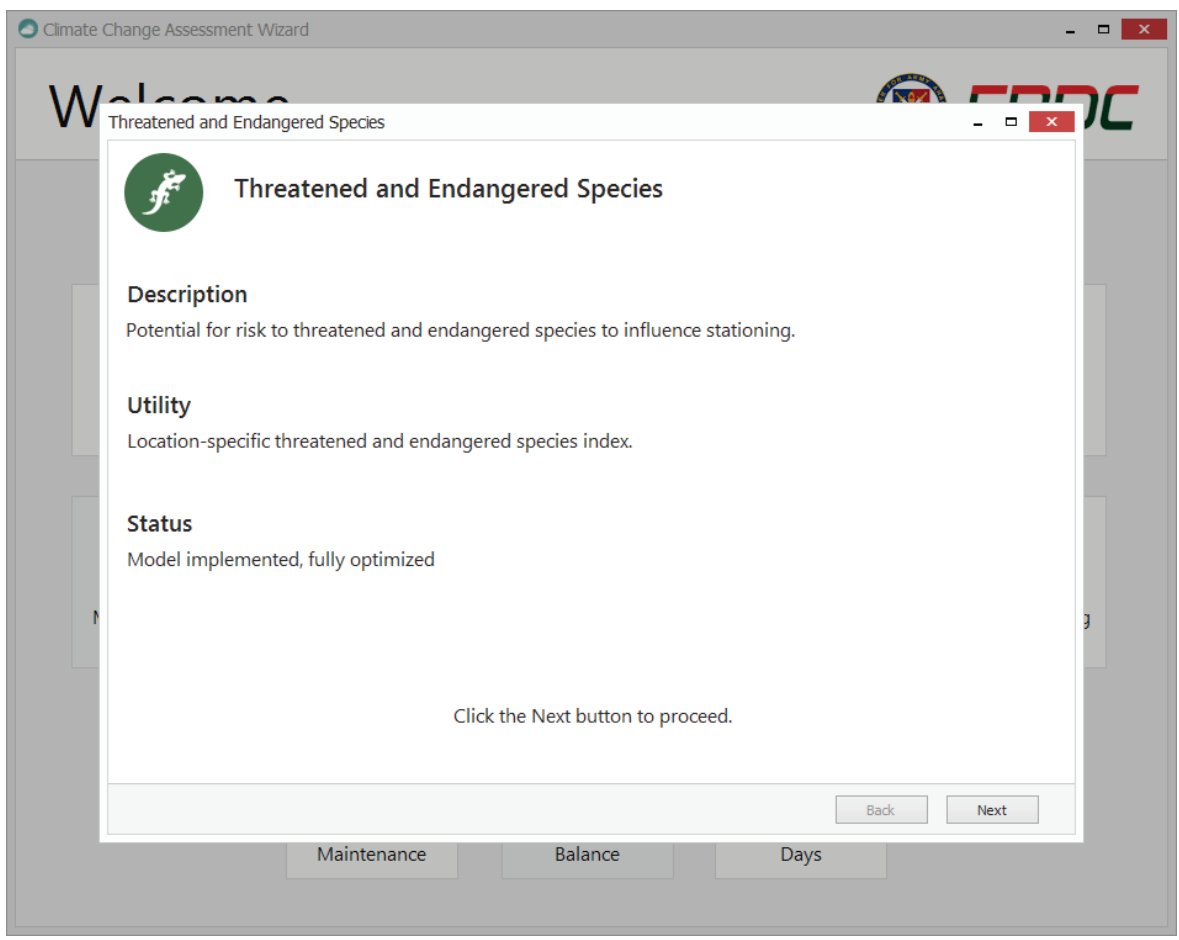

Figure 24. Threatened and Endangered Species Model second screen.

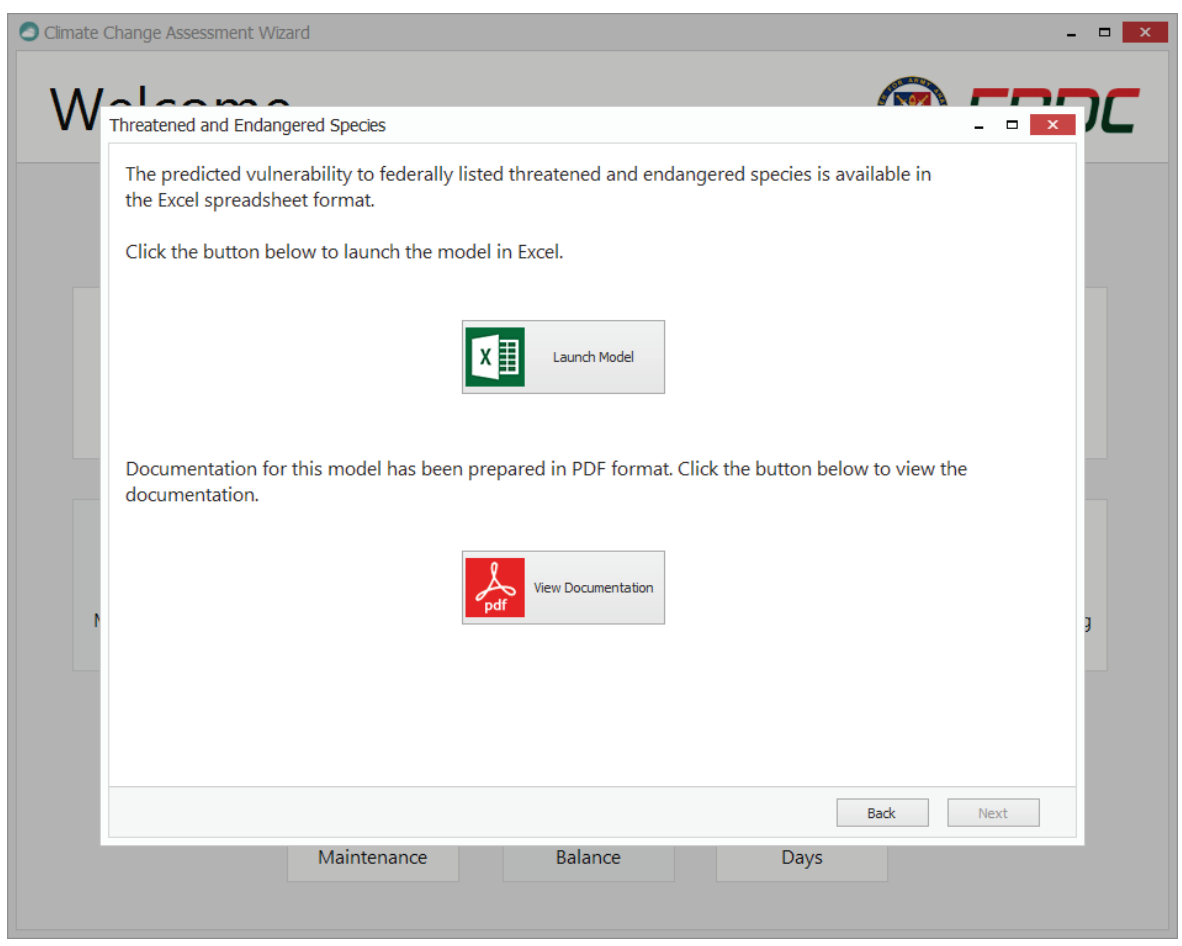


Figure 25. Results in the MS Excel ${ }^{\circledR}$ window.

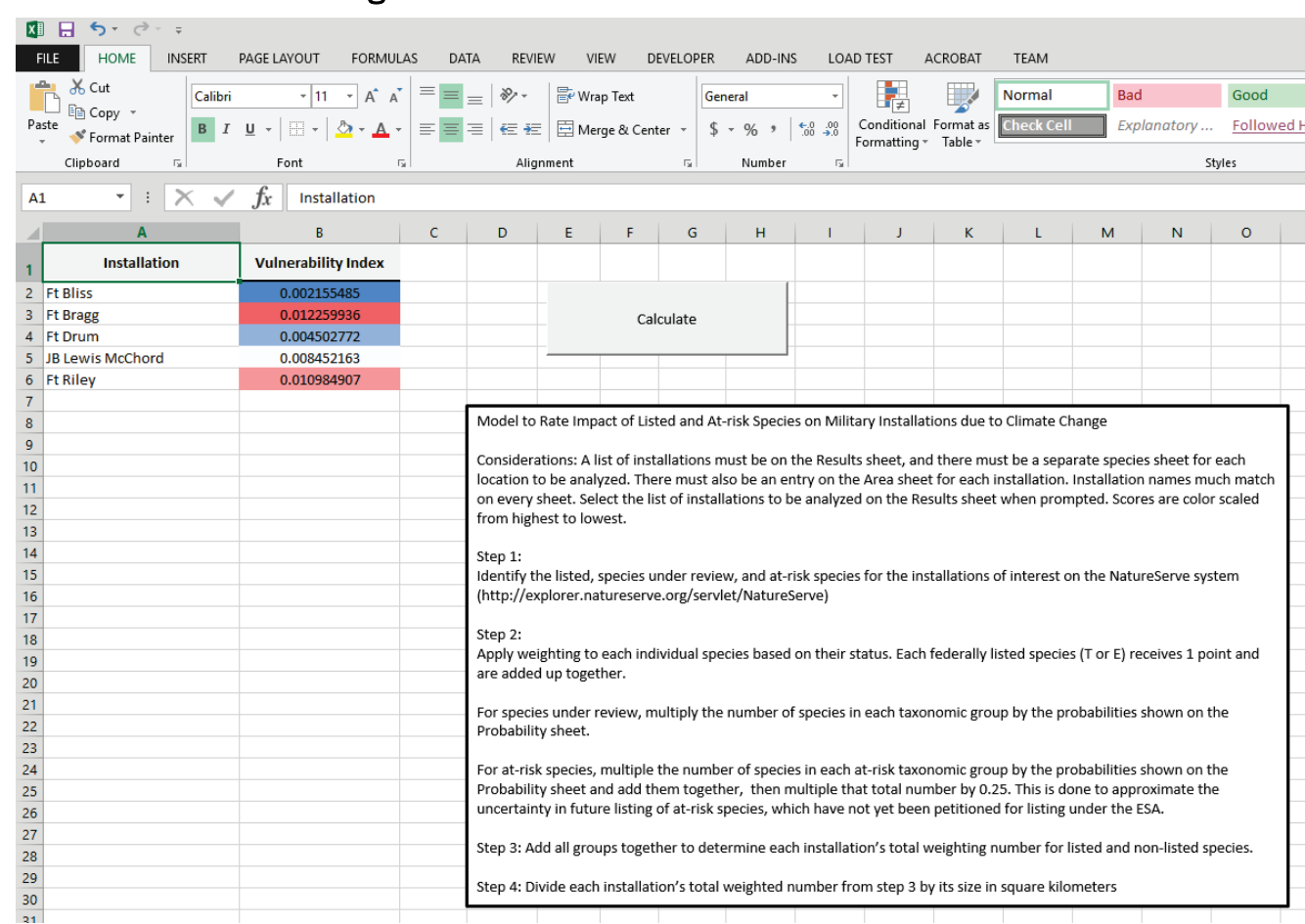

Each installation that was analyzed is assigned a Vulnerability Index score that may be used as an MVA attribute in other force stationing analysis applications. A color scale was added to the values to help distinguish the upper and lower bands. These colors do not correspond with any doctrinal thresholds and are simply for aesthetics.

Building new datasets can be accomplished within the MS Excel ${ }^{\circledR}$ spreadsheet that contains the Vulnerability Index scores. The following instructions should be followed carefully to produce new data from this model.

The MS Excel ${ }^{\circledR}$ spreadsheet may be launched automatically from the Wizard application or accessed manually by opening $\mathrm{C}: \backslash$ Models $\backslash \mathrm{TES} \backslash$ Model $\backslash \mathrm{TES}-$ Model . xlsm from within MS Excel ${ }^{\circledR}$ (Figure 26). 
Figure 26. Launch MS Excel ${ }^{\circledR}$ from the second Model screen within the Wizard.

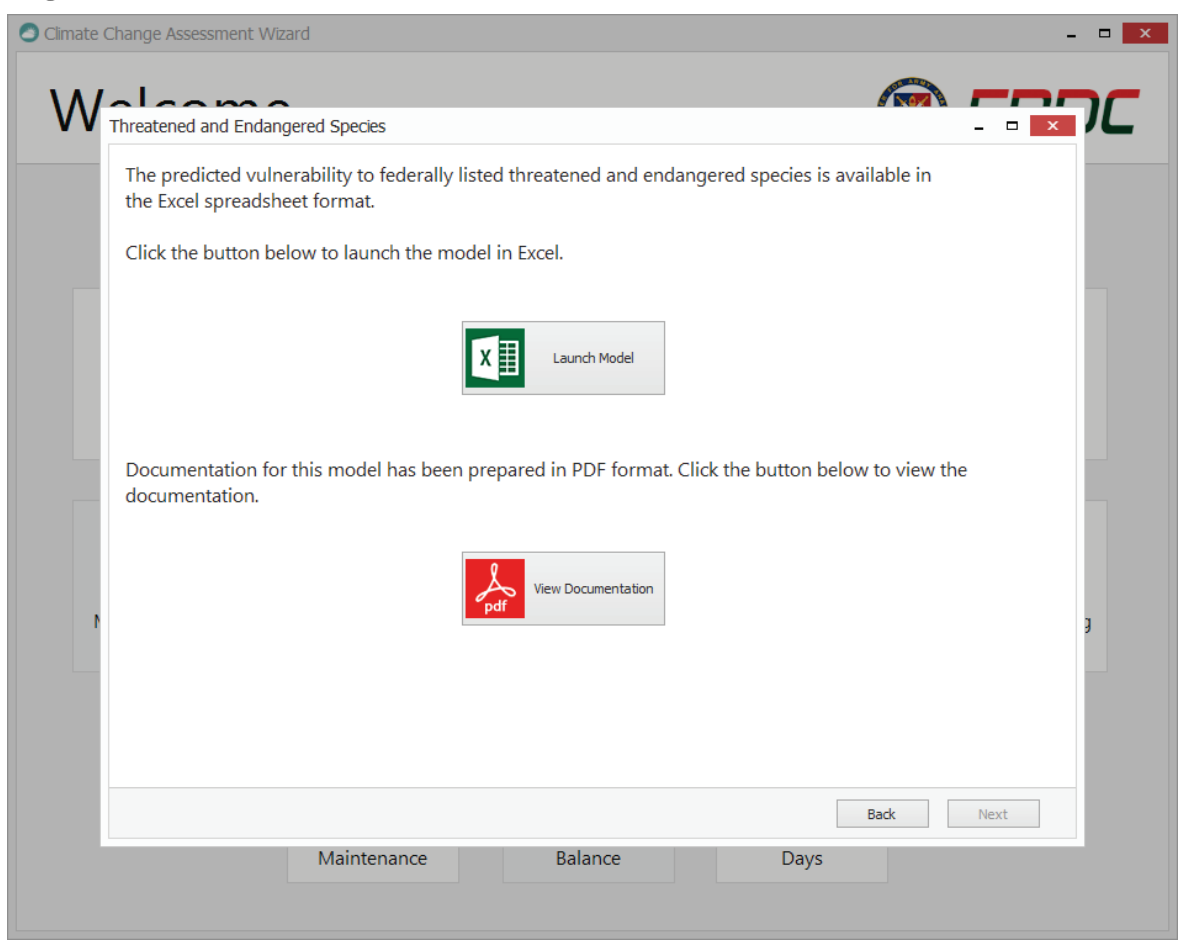

After opening the MS Excel ${ }^{\circledR}$ spreadsheet, enable macros if requested in the banner below the ribbon menu. Follow these steps carefully to calculate new vulnerability scores.

1. List the installations to be analyzed in column A on the Results worksheet. Note that these installation names must match throughout the process.

Identify the listed, species under review, and at-risk species for the installations of interest. This is accomplished by accessing the federally listed species database by accessing the NatureServe Explorer website at http://explorer.natureserve.org/servlet/NatureServe. Use the Location search feature as shown in (Figure 27).

A tabular list of all listed species for each DoD installation of interest must be retrieved from the NatureServe Explorer system. The system allows users to search for results by state or by county and download them in MS Excel ${ }^{\circledR}$ format. Place the exported data into the model MS Excel ${ }^{\circledR}$ workbook by adding a new sheet and naming it according to the previously defined list of installations. Make sure the name matches the original list on the Results worksheet exactly. Repeat this process for all listed installations. 
Figure 27. NatureServe Explorer web application.

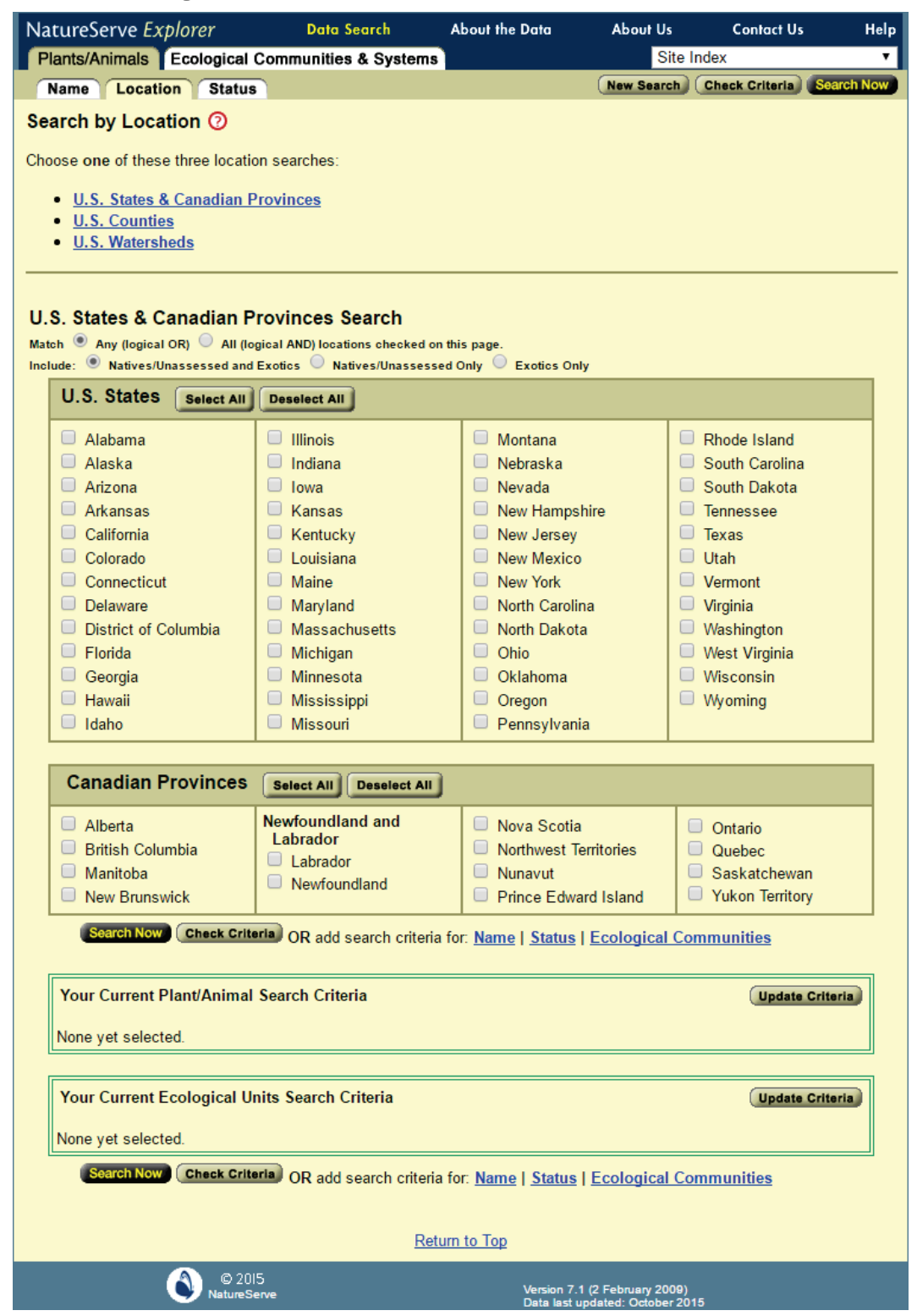

2. Locate the area for each of the installations to be analyzed and enter it into columns A and B on the Area worksheet. Area is defined as the square kilometers of land that an installation occupies. Google searching seems to be the best method of obtaining this data. Make sure to enter the Installation name exactly as it appears on the Results worksheet.

Return to the Results worksheet and click the Calculate button to start the VBA calculation process. This process runs very quickly and populates the Vulnerability Index values in column B. Save the results by using the save function in MS Excel ${ }^{\circledR}$. 


\subsection{Frequency of Extreme Weather Events Model}

Extreme weather events such as droughts, excessive rain events, and extended periods of high temperatures can have a negative impact on future force readiness and effectiveness. The frequency of extreme weather events algorithm attempts to predict the likelihood of extreme weather events by calculating probabilities for several scenarios from future climate projections for various DoD installations.

The extreme events prediction algorithm takes installation location and daily local min, max, and mean temperature and daily precipitation values as inputs and produces output values that represent the number of days within a variety of weather related categories.

- Number of days with a temperature greater than $95^{\circ} \mathrm{F}$

- Number of days with a temperature greater than $100^{\circ} \mathrm{F}$

- Number of instances with a temperature greater than $100^{\circ} \mathrm{F}$ for three consecutive days

- Number of days with a temperature less than $10^{\circ} \mathrm{F}$

- Number of days with measured precipitation greater than 2 in.

- Number of days with measured precipitation less than 0.01 in.

The predicted event frequencies are intended to be used in other force stationing analysis applications as an MVA attribute.

\subsubsection{Capturing the current state}

The Frequency of Extreme Weather Events Model was received as a script written in the Python programming language. In fact, it uses the Python script previously described in Section 4.2. Each step for viewing the computed data is thoroughly documented in the following sections to limit user confusion and ensure accurate results.

Software requirements for the Frequency of Extreme Weather Events Model include the Python IDLE development environment, a basic text editor such as MS Notepad ${ }^{\circledR}$, and MS Excel ${ }^{\circledR}$ version 2013 or higher.

A working knowledge of Microsoft Office products is recommended as well as a basic understanding of editing file paths in a text file and executing Python code within the IDLE environment. 


\subsubsection{Integrating into the Wizard}

There are two-parts to the Frequency of Extreme Weather Events Model: viewing the output data and building new output data. Pre-built datasets for this model were processed using daily values from the Temperature and Precipitation Projections Model and are stored within the VM. The ability to view this output data is built in to the Wizard application.

After launching the Wizard from the VM desktop, the Frequency of Extreme Weather Events Model is launched by clicking the icon from the Wizard dashboard screen (Figures 28 and 29).

The second screen within the model allows the end user to view the datasets in graphical or tabular mode (Figure 30). Choose the desired view type from the View drop down combo box. Options within this box are Graphs and Tabular. Graphs displays the data as standard line graphs while Tabular displays the data in a table layout within a MS Excel ${ }^{\circledR}$ spreadsheet.

Figure 28. Frequency of Extreme Events Model icon.

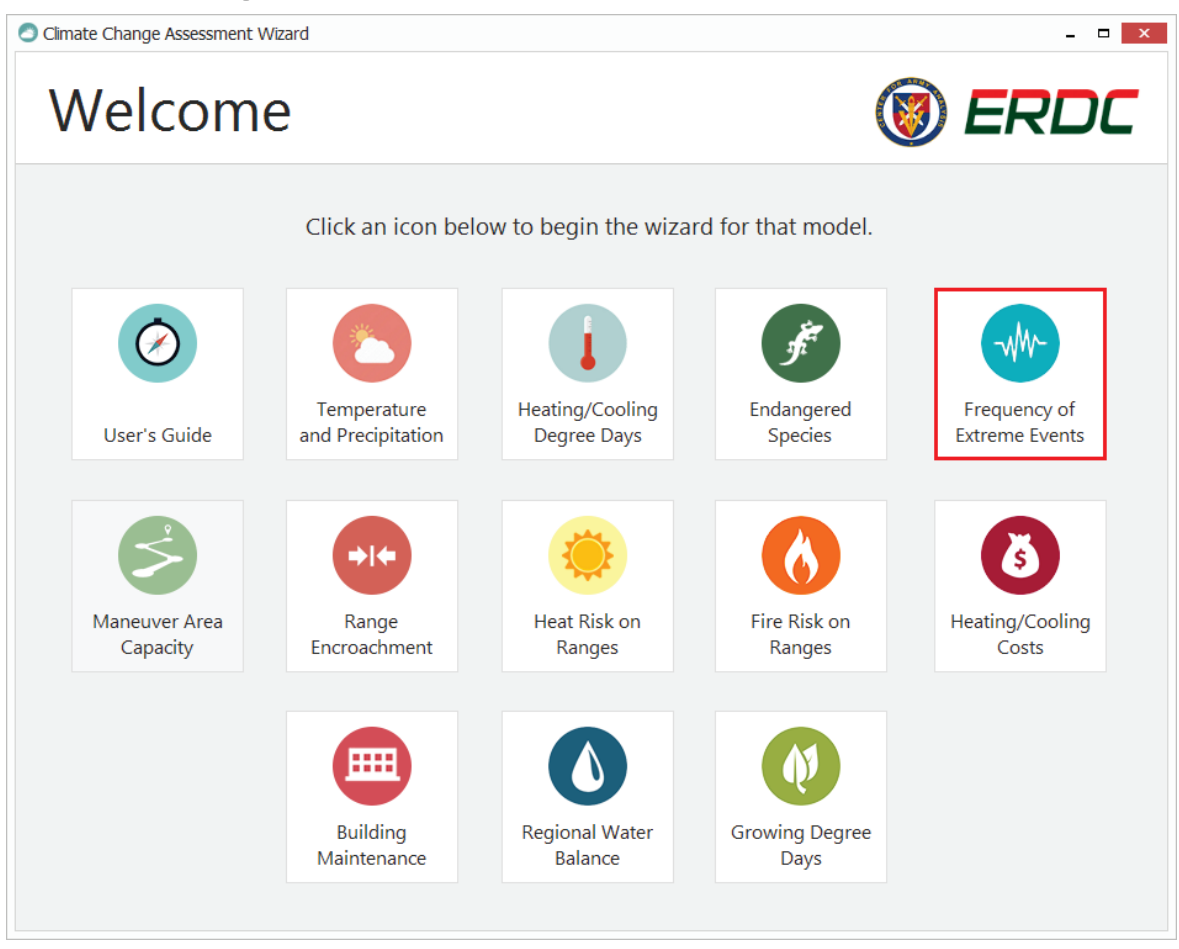


Figure 29. Frequency of Extreme Events Model first screen.

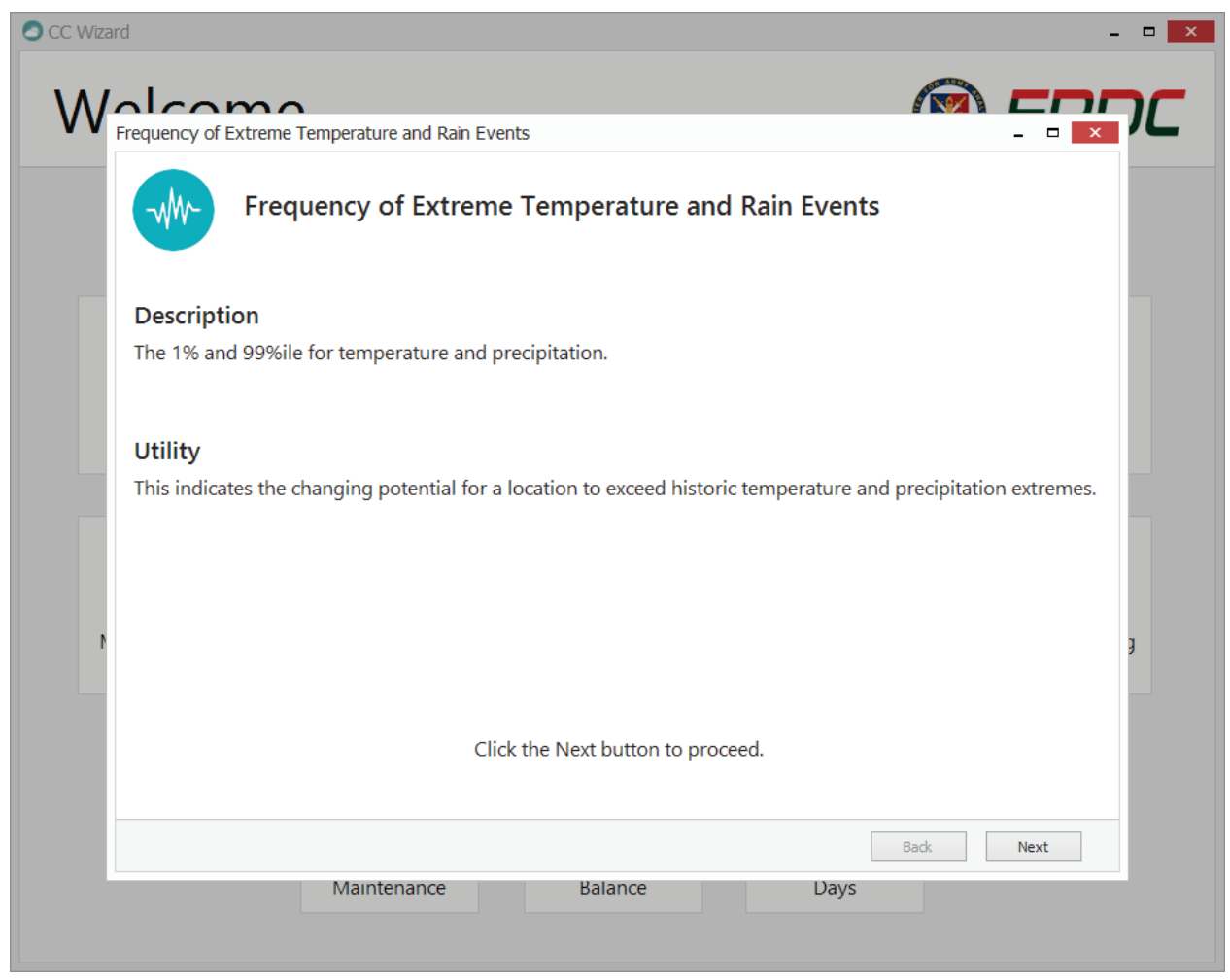

Figure 30. Frequency of Extreme Events Model second screen.

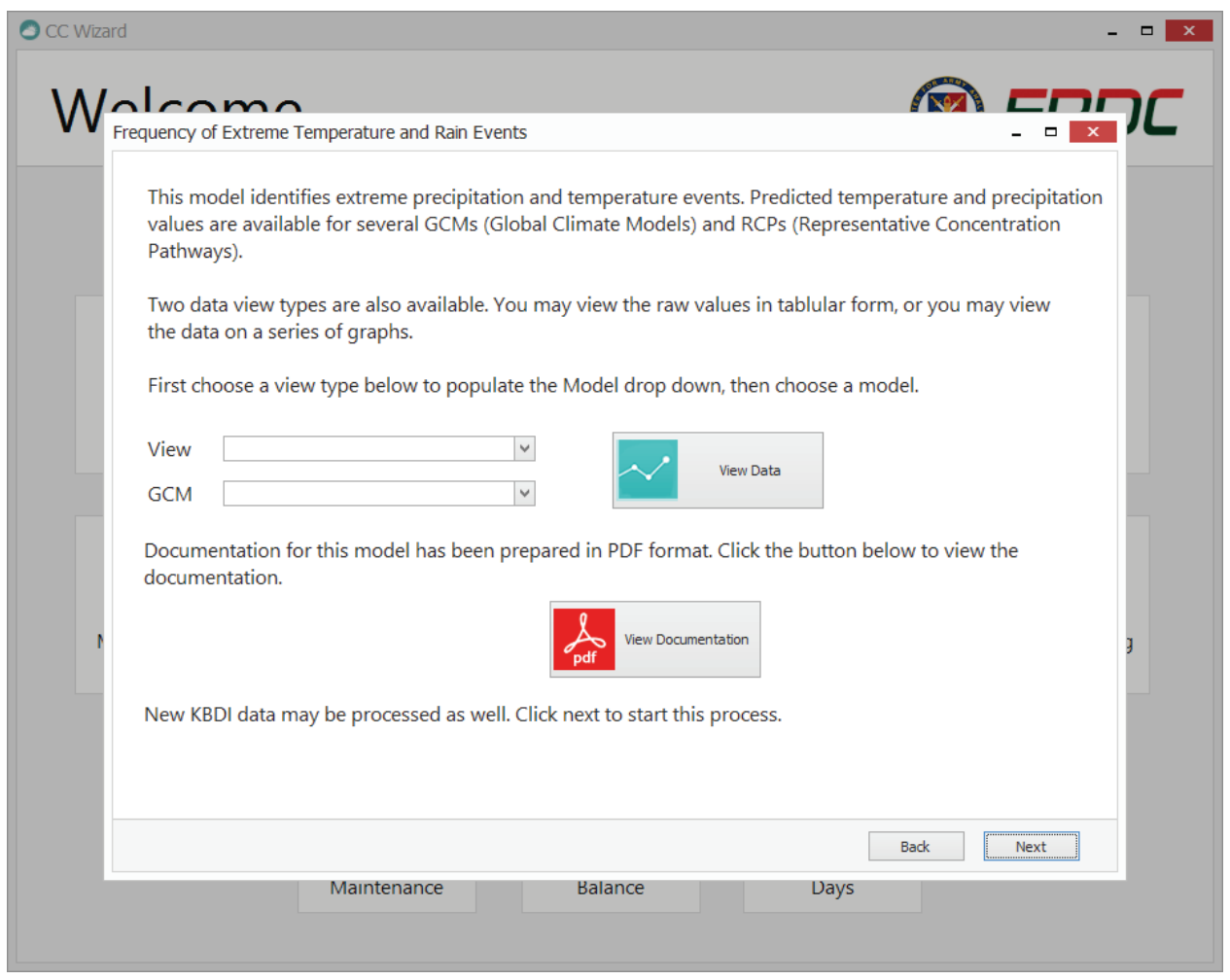


Next, choose a GCM and RCP type from the drop down combo box to filter only data related to that GCM/RCP. At the time of this publication, there are 10 GCMs within the dataset for this model. RCP 2.6, 4.5, and 8.5 were chosen to represent lower bound, middle, and upper bounds for each GCM. Each GCM contains these RCPs, with the exception of CNRM-CM-5 and GFDL-CM3.

Once both of the choices are made, click the View Data button to launch the chart viewer window (Figures 30 and 31).

Figure 31. Results in the chart viewer window.

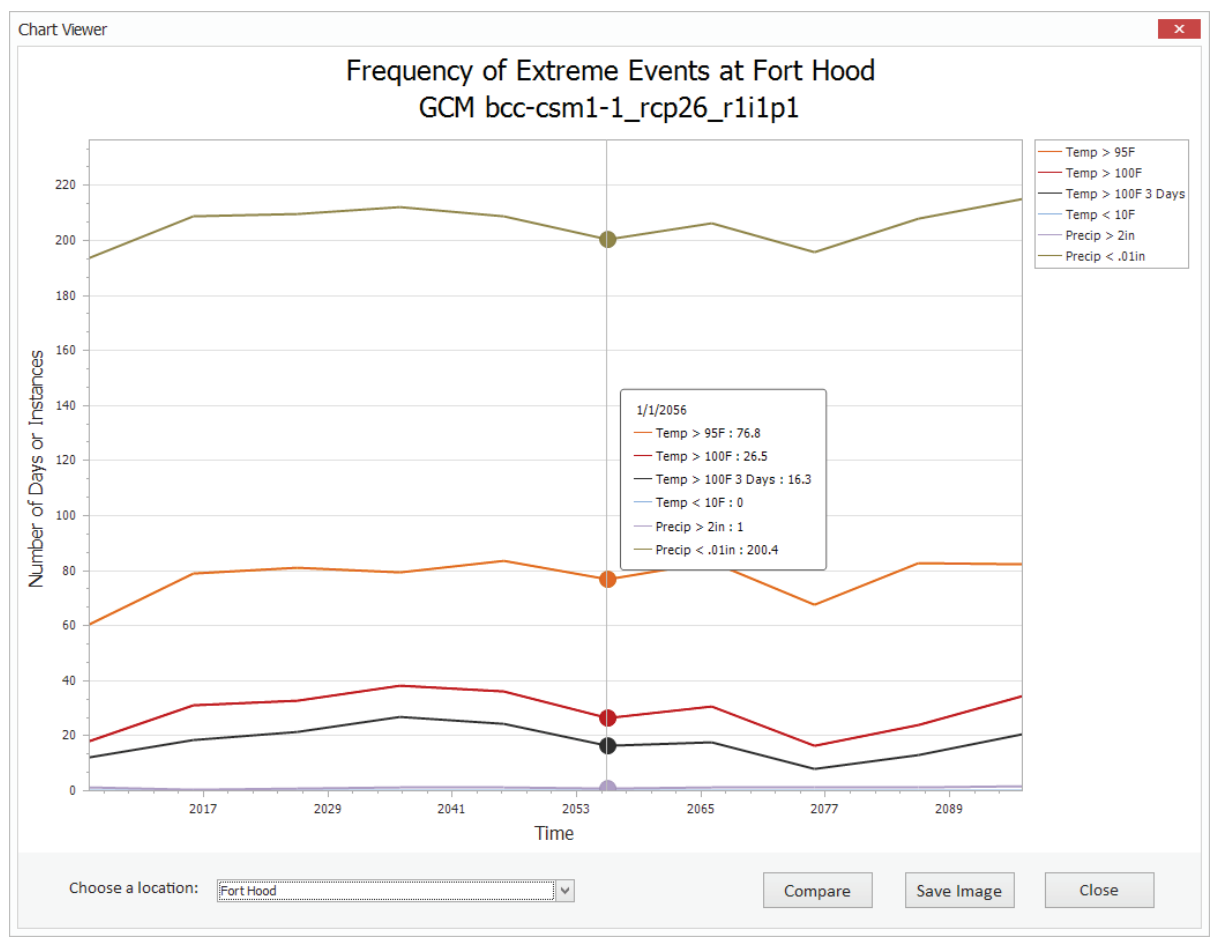

The average number of days or instances in six different event categories are plotted as line graphs with the number of days or instances charted on the $\mathrm{Y}$-axis, and 10-year epochs charted on the $\mathrm{X}$-axis. The user can change the charted values by choosing a different geographical location from the drop down combo box near the bottom left of the window. Upon selecting a location, the data will automatically filter to include only those values found within the chosen area.

Users may also limit the variables that are charted. Clicking the Compare button near the bottom right of the window brings up a dialog where variables may be shown or hidden from the chart (Figure 32). 
Figure 32. Chart comparison filter.

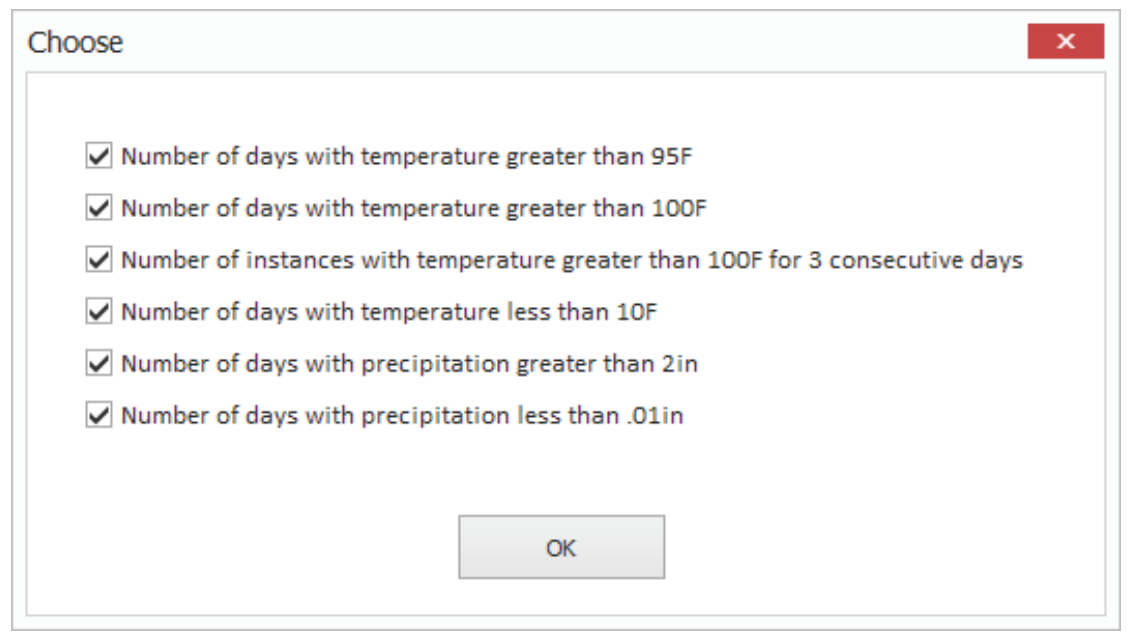

Charts may be saved to the user computer by clicking the Save Image button near the bottom right of the window. The resulting file is saved to a location of the user choosing in the universal JPEG image file format.

As mentioned previously, this model uses the Python script described in the Heating and Cooling Degree Days Model. In an effort to reduce redundancy, please refer to the process for building data using the Python IDLE environment described in Section 4.2.

\subsection{Range Encroachment Model}

Encroachment of urban development upon military installations can be expected to have an impact on the Army's costs and ability to fulfill its missions due to issues relating to noise complaints, reduction of natural buffer land surrounding installation boundaries, light pollution effects on nighttime training operations, and other potential impacts to operations on installations.

This model attempts to predict the risk of urban growth and development around military installations with active training and firing ranges. The predicted encroachment values are intended to be used in other force stationing analysis applications as an MVA attribute.

\subsubsection{Capturing the current state}

The Range Encroachment Model was received as a pair of Environmental Systems Research Institute (ESRI) ArcMap project files and a NetLogo project file. Software requirements for the Range Encroachment Model 
include ESRI ArcMap 10.3.1, NetLogo 5.3, a basic text editor such as MS Notepad ${ }^{\circledR}$, MS Excel ${ }^{\circledR}$ version 2013 or higher, and an internet connection and internet browser. A working knowledge of ArcMap, NetLogo, and Microsoft Office products is recommended as well as a basic understanding of accessing websites and downloading files from the internet.

Executing the model is a multi-step process that requires using ESRI ArcMap, NetLogo, and MS Excel ${ }^{\circledR}$ applications. Each step for viewing and building data sets is thoroughly documented in the following sections to limit user confusion and ensure accurate results.

Hardware requirements for this model are quite substantial. A minimum of nine processor cores (eight required for script) are required to execute the code. Memory minimum requirements are $100 \mathrm{~GB}$ of RAM and 1TB of hard disk storage space (local or network).

\subsubsection{Integrating into the Wizard}

There are two-parts to the Range Encroachment Model: viewing the output data and building new output data. Pre-built datasets for this model were processed and are stored within the VM. The ability to view this output data is built in to the Wizard application.

After launching the Wizard from the VM desktop, the Range Encroachment Model is launched by clicking the icon from the Wizard dashboard screen (Figures 33 and 34).

The second screen within the model allows the end user to view the datasets in tabular mode. Use the View Results button on the second model screen to view the data in a table layout within an MS Excel ${ }^{\circledR}$ spreadsheet (Figure 35). This MS Excel ${ }^{\circledR}$ file is located within the VM at $\mathrm{C}: \backslash$ Models $\backslash$ Range-

Encroachment $\backslash$ Output $\backslash$ Postprocessing_Output_ArcGIS $\backslash r e s u l$ ts-RUG \Rug-Output_Clean.xls. 
Figure 33. Range Encroachment Model icon.

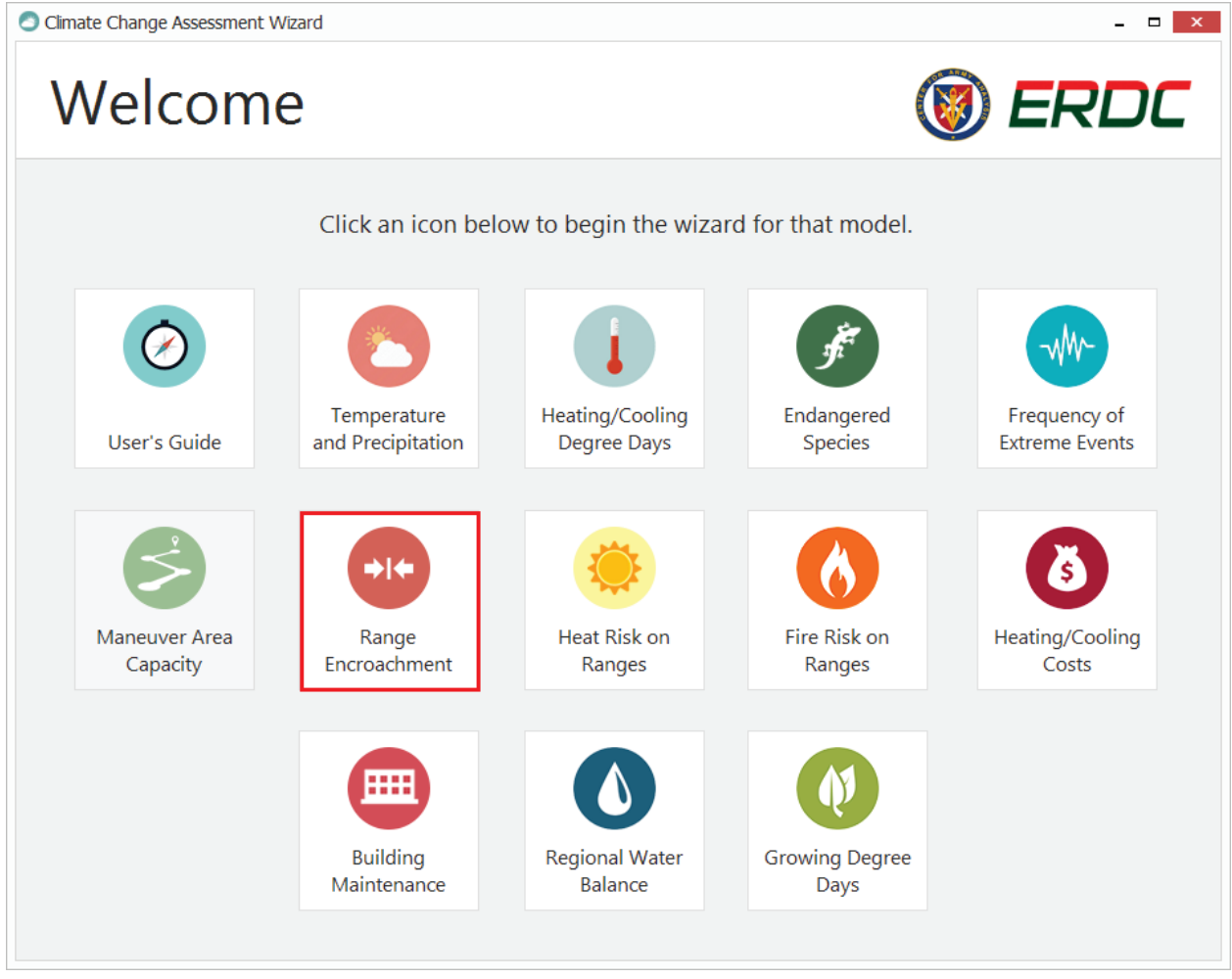

Figure 34. Range Encroachment Model first screen.

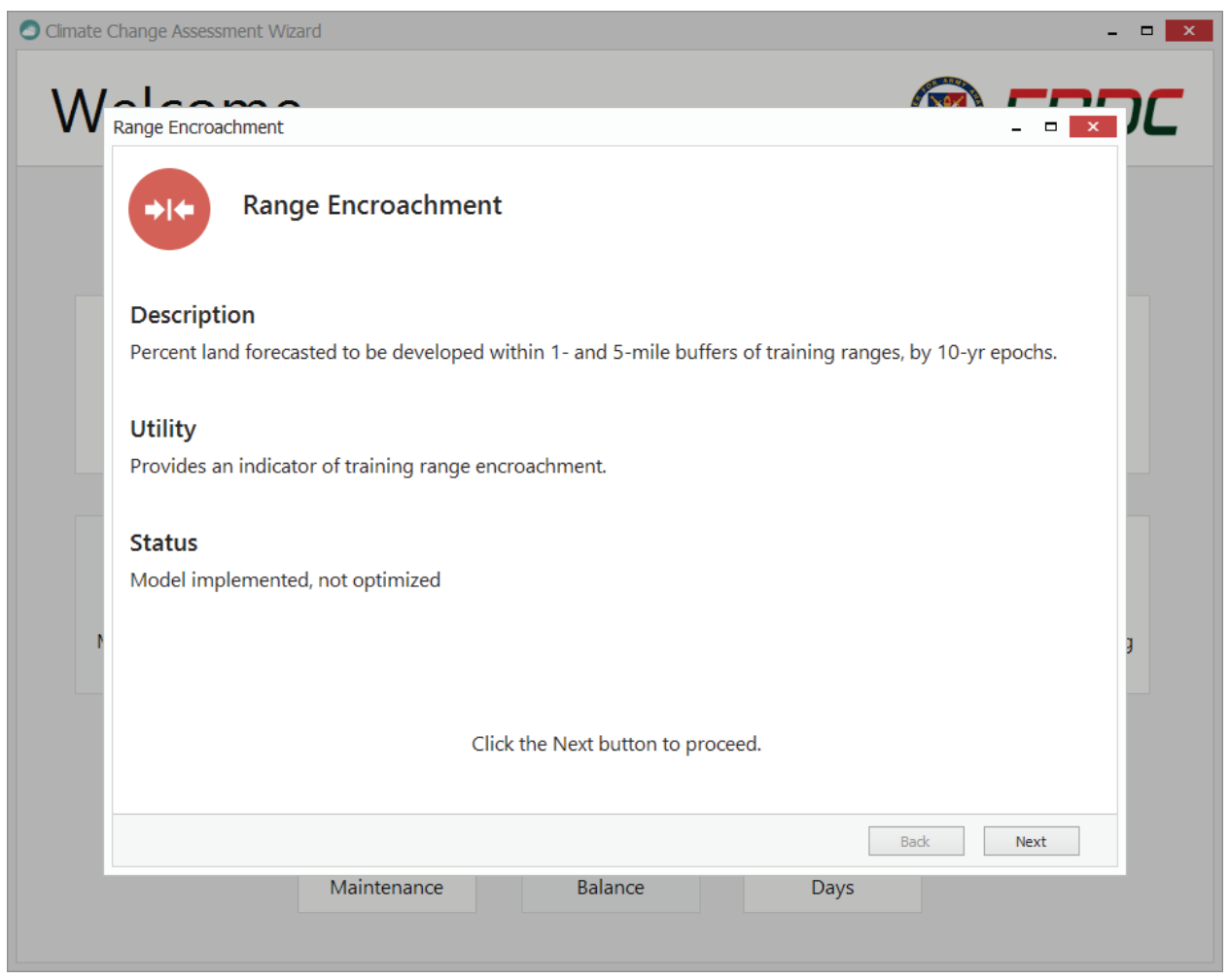


Figure 35. Range Encroachment Model second screen.

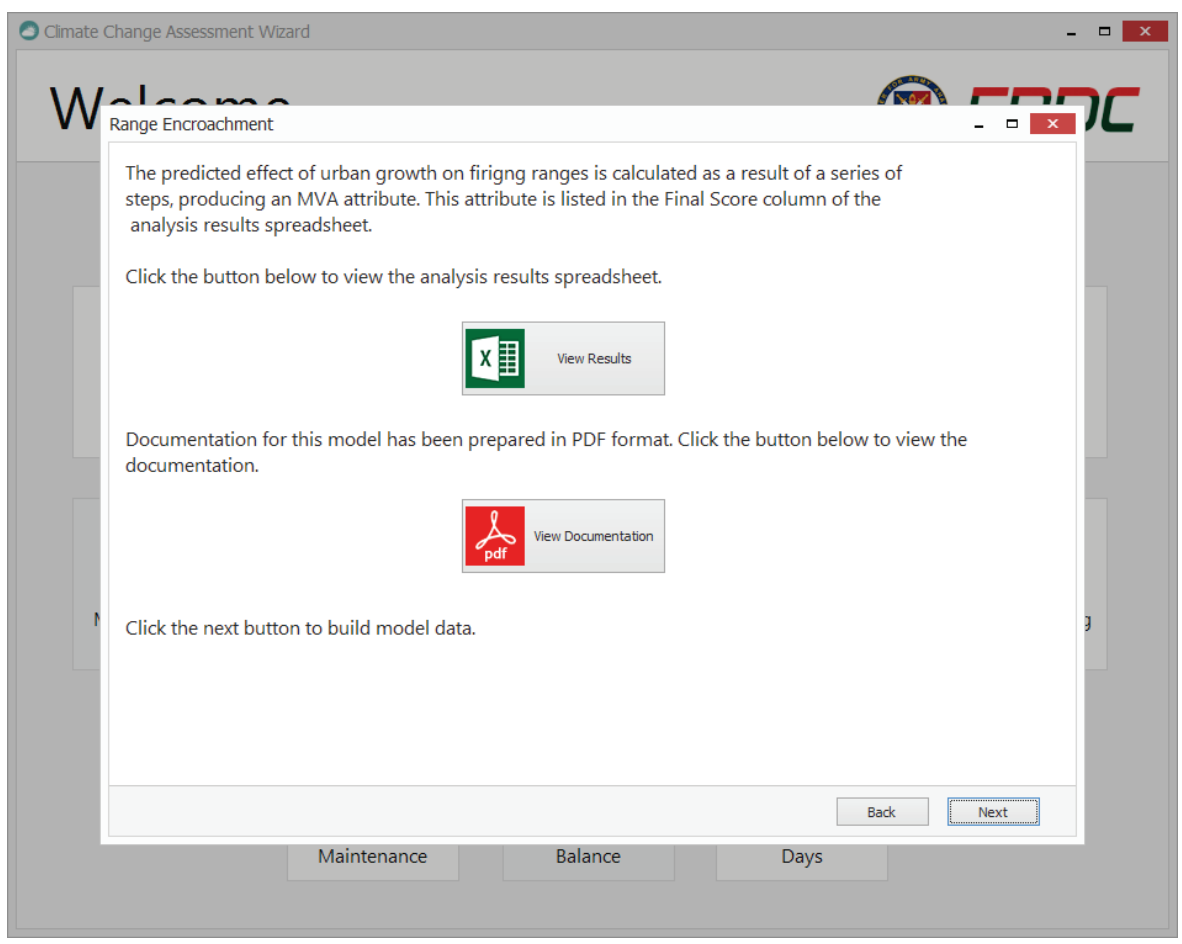

Each installation that was analyzed is assigned a final score that ranks it against the other installations that were analyzed (Figure 36). Installations with lower scores are less likely to experience range encroachment as a result of urban development. The final score value may be used as an MVA attribute in other force stationing analysis applications.

Figure 36. Example of Model output file.

\begin{tabular}{|c|c|c|c|c|c|c|c|c|c|c|c|}
\hline & & & & & & & & & & & \\
\hline $\begin{array}{l}\text { A } \\
\text { IJECT INSTALL }\end{array}$ & $\begin{array}{l}\mathrm{C} \\
\text { Growth 1mile }\end{array}$ & $\begin{array}{l}\text { D } \\
\text { Growth } 5 \text { mile }\end{array}$ & $\begin{array}{l}\mathrm{E} \\
\text { Growth } 10 \text { mile }\end{array}$ & $\begin{array}{l}F \\
\text { Pop Den5 }\end{array}$ & $\begin{array}{l}G \\
\text { Pop Den1 }\end{array}$ & $\begin{array}{c}\mathrm{H} \\
\text { Pop Den10 }\end{array}$ & & 100EP & $\begin{array}{l}K \\
\text { ev } 100 F P \text { Year? }\end{array}$ & ev $500 F P$ YearDe & \\
\hline 1Aphill & $\begin{array}{l}\text { Growth_Imile } \\
0.09\end{array}$ & $\begin{array}{l}\text { Growth_Smile } \\
0.09\end{array}$ & $\begin{array}{l}\text { Growth_10mile } \\
0.59\end{array}$ & Pop__en3 0.07 & Pop__ent 12 & Pop__ento 0.35 & & 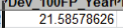 & 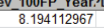 & 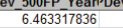 & 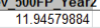 \\
\hline 2 Benning & 1.73 & 0.51 & 0.98 & 0.26 & 0.38 & 0.61 & 4.46 & 16.74608023 & 5.567094278 & 7.58422365 & 16.93937353 \\
\hline 3 Bliss & 0.72 & 0.42 & 1.56 & 0.27 & 0.42 & 0.74 & 4.13 & 0 & & 39.65568418 & 47.46215494 \\
\hline 4 Bragg & 0.40 & 0.29 & 0.73 & 0.31 & 0.41 & 0.77 & 2.92 & 6.990478486 & 4.821019646 & 4.343000141 & 6.948396601 \\
\hline 5 Campbell & 0.16 & 0.19 & 0.58 & 0.14 & 0.08 & 0.39 & 1.54 & 4.798906836 & 0.760727688 & 1.906439989 & 6.820959728 \\
\hline 6 Carson & 0.57 & 0.34 & 0.64 & 0.17 & 0.11 & 0.59 & 2.42 & 30.34013605 & 15.10204082 & 24.34291329 & 37.87767133 \\
\hline 7 Dix & 0.59 & 0.44 & 1.70 & 0.23 & 0.48 & 0.82 & 4.26 & 21.27487625 & 16.50671785 & 23.0246966 & 26.07570228 \\
\hline 8 Drum & 0.19 & 0.10 & 0.33 & 0.05 & 0.07 & 0.16 & 0.91 & 8.47107438 & 2.685950413 & 2.808988764 & 7.784911717 \\
\hline 9 Hood & 1.93 & 1.00 & 2.00 & 0.33 & 0.44 & 0.75 & 6.46 & 9.5253347 & 1.287553648 & 1.592251311 & 10.95825855 \\
\hline 10 Huachuca & 0.32 & 0.14 & 0.65 & 0.17 & 0.67 & 0.28 & 2.23 & 24.55977757 & 21.68674699 & 12.25895317 & 21.78276269 \\
\hline 11 Irwin & 0.09 & 0.05 & 0.14 & 0.00 & 0.00 & 0.00 & 0.27 & 6.694356218 & 0.537503054 & 16.49565904 & 19.16929755 \\
\hline 12 Jackson & 2.00 & 0.53 & 1.19 & 0.86 & 1.86 & 1.70 & 8.13 & 12.28481479 & 3.565766852 & 6.219701573 & 13.91803389 \\
\hline $13 \mathrm{Knox}$ & 0.32 & 0.25 & 0.48 & 0.21 & 0.44 & 0.58 & 2.29 & 15.49588223 & 6.000513263 & 19.4779233 & 26.89829951 \\
\hline 14 Leonardwood & 0.29 & 0.19 & 0.22 & 0.06 & 0.11 & 0.12 & 0.99 & 4.266055046 & 1.077981651 & 1.814807177 & 5.526912766 \\
\hline 15 Lewis & 1.00 & 0.49 & 1.00 & 0.64 & 0.97 & 1.76 & 5.87 & 8.557951482 & 1.752021563 & 3.979143798 & 8.850164654 \\
\hline 16 Polk & 0.08 & 0.04 & 0.12 & 0.03 & 0.03 & 0.09 & 0.39 & 2.757212152 & 2.757212152 & 2.553044678 & 2.553044678 \\
\hline 17 Richardson & 1.28 & 0.62 & 1.20 & 1.00 & 2.00 & 2.00 & 8.10 & 17.38030714 & 2.547425474 & 3.636963696 & 19.22112211 \\
\hline 18 Riley & 1.14 & 0.37 & 0.49 & 0.13 & 0.23 & 0.27 & 2.63 & 3.757058891 & 2.054281434 & 5.091032264 & 8.175120671 \\
\hline 19 Rucker & 0.31 & 0.13 & 0.22 & 0.14 & 0.24 & 0.29 & 1.32 & 4.893841289 & 1.039000151 & 4.609869111 & 7.427199242 \\
\hline 20 Sill & 1.05 & 0.40 & 0.52 & 0.20 & 0.49 & 0.36 & 3.02 & 14.21147763 & 4.665612291 & 6.926367935 & 16.02792164 \\
\hline 21 Stewart & 0.95 & 0.67 & 1.63 & 0.14 & 0.07 & 0.40 & 3.86 & 18.82456916 & 8.197083517 & 6.123198384 & 11.55274029 \\
\hline 22 Wainright & 0.00 & & 0.00 & & & 0.14 & 0.28 & 0.59473549 & 0.587393076 & 13.63964519 & 14.47895601 \\
\hline
\end{tabular}

New datasets are built within the VM by executing a series of steps that require using two different data processing applications. The following instructions should be followed carefully to produce new data from this model. 
The first step in building new data is to collect the necessary source data from sources online. Table 1 lists the sources for the required data.

Table 1. Online data sources.

\begin{tabular}{|l|l|}
\hline \multicolumn{1}{|c|}{ Data } & \multicolumn{1}{c|}{ Source } \\
\hline Army Installations & Army Mapper Program (http://mapper.army.mil/). \\
\hline Training Areas & Sustainable Range Program can be found at: https://srp.army.mil/) \\
\hline Digital Elevation Model & (http://viewer.nationalmap.gov) \\
\hline Landcover map & (http://www.mrlc.gov/). \\
\hline Roads & (http://viewer.nationalmap.gov/). \\
\hline Flood Hazard & HIFLD@hq.dhs.gov or by calling (202) 282-9541 \\
\hline Protected Areas & http://gapanalysis.usgs.gov/padus/data/download/ \\
\hline ACUB & http://www.aec.army.mil/Services/Conserve/ArmvCompatibleUseBufferProgram.aspx. \\
\hline LandScan Data & HIFLD@hq.dhs.gov or by calling (202) 282-9541 \\
\hline
\end{tabular}

After the data has been collected, the data must be formatted in a particular fashion. This formatting is accomplished by using the ESRI ArcMap application. ArcMap can be launched automatically from within the Wizard application on the third model screen or from the Windows start menu (Figures 37 and 38).

After opening ArcMap, open the range encroachment data preprocessing project by selecting File->open and browse to the file $\mathrm{C}: \backslash$ Models $\backslash$ RangeEncroachment \Model_Files \Step1_RUG_preprocessing_ARCGI $S \backslash$ PreProcessing_CONUS.mxd (or PreProcessing_ALASKA.mxd if analysis of Alaska is desired). This file may also be in the Recent list as seen in Figure 38.

Once the project is loaded, open the toolbox viewer by clicking the Toolbox menu bar icon . Add the RUG_preprocessing_10.2 toolbox by right clicking ArcToolbox at the top of the viewer then clicking Add Toolbox. The toolbox file is located at $C: \backslash$ Models $\backslash$ Range-

Encroachment $\backslash$ ModelFiles $\backslash$ Step1_RUG_preprocessing_ARCGIS $\backslash$ RUG_PreProcessing -10.2. tbx. Expand the newly added toolbox by clicking the plus sign to the left to show the models inside. 
Figure 37. Launch buttons on the third model screen within the Wizard.

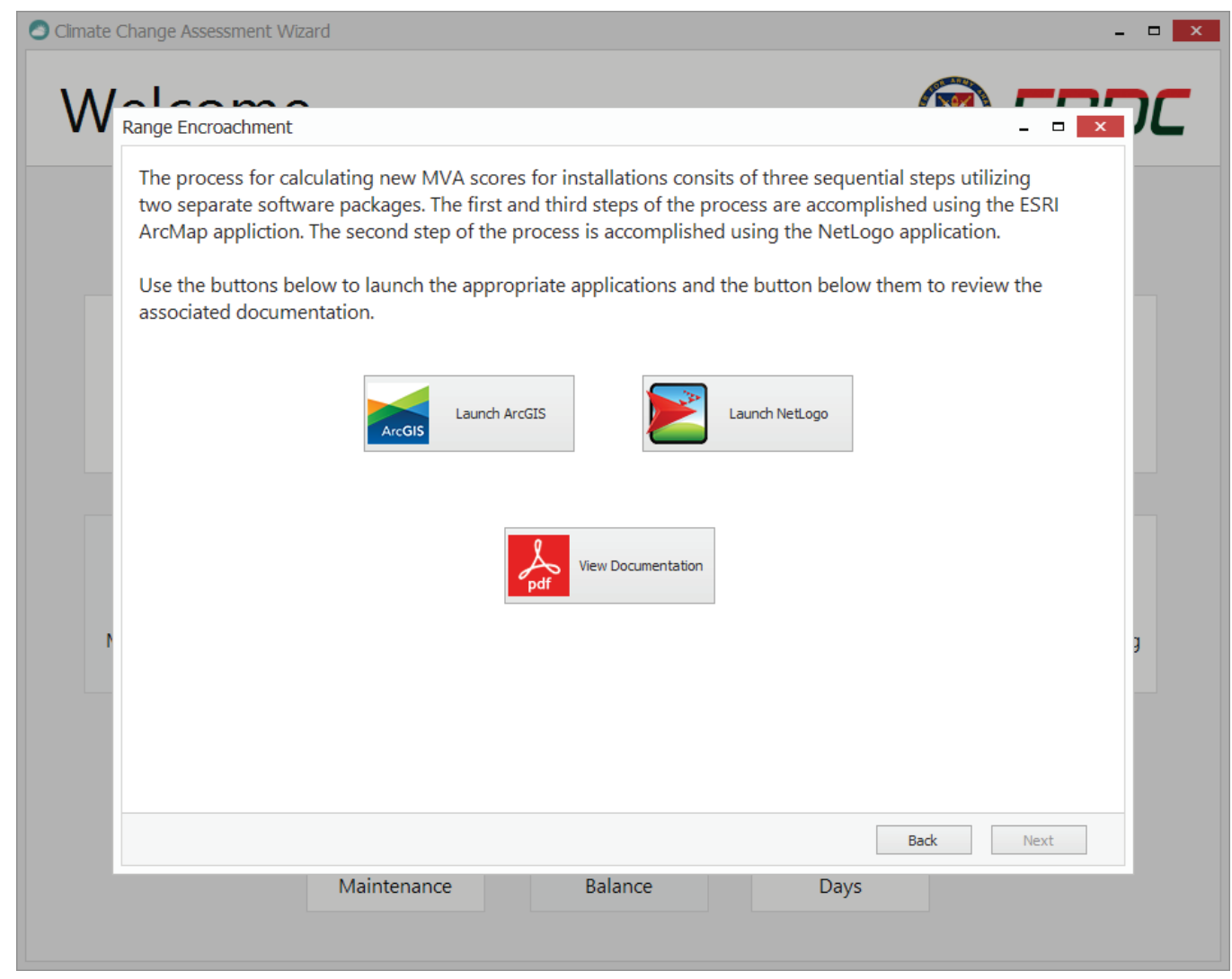

Figure 38. ESRI ArcMap start screen.

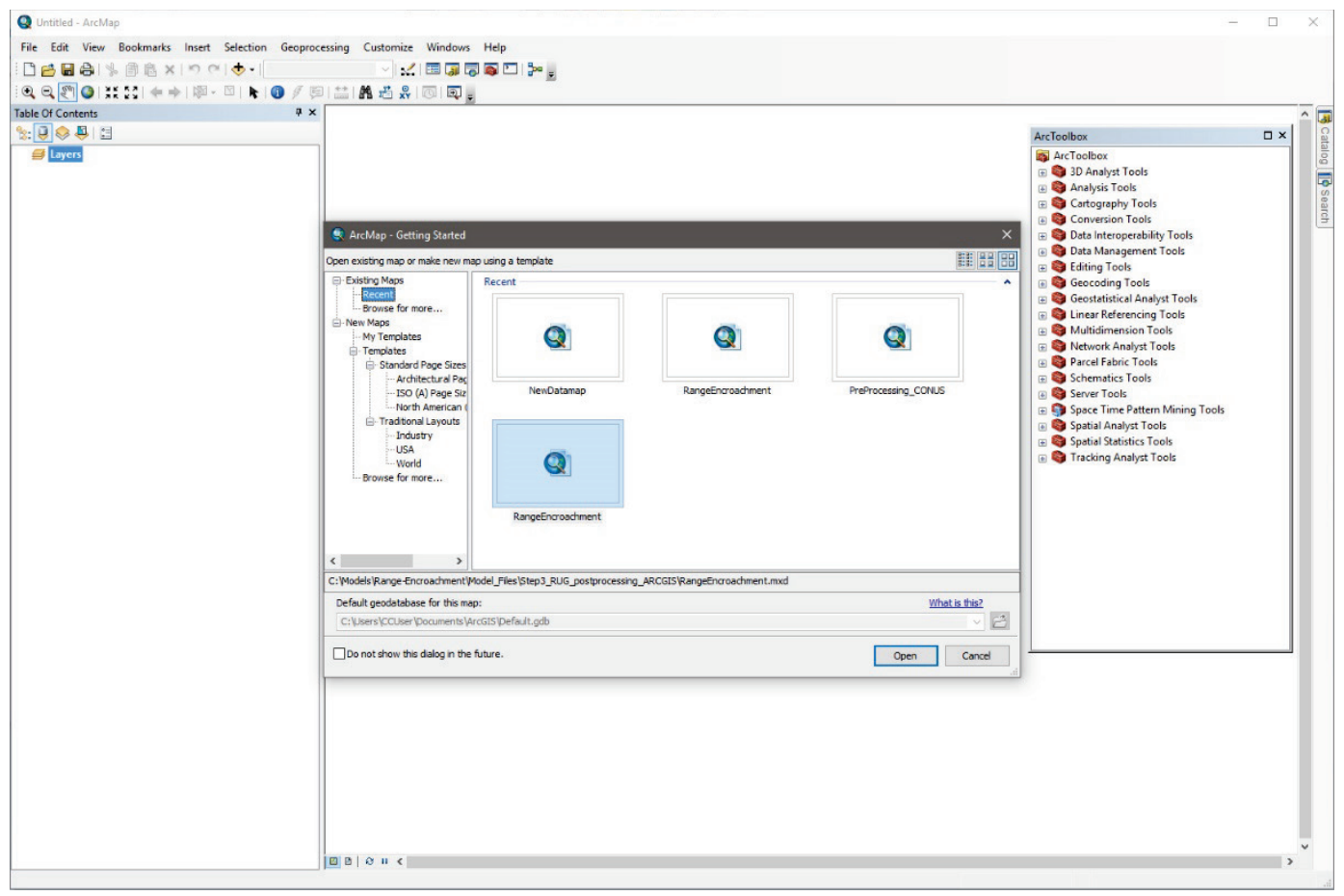


Next, it is necessary to re-project all the data to a common projection. For CONUS, this is the USA Contiguous Albers Equal Area Conic U.S. Geological Survey (USGS) version. For Alaska, this is NAD 1983 Alaska Albers. Right click the 1. Project Data CONUS (or 1. Project Data Alaska) model and choose Edit. Inside the editor, click the Run menu bar icon .

Once all the data is in the same projection, run the Population Impact Data Processing in a similar fashion by right clicking the Population Impact Data Processing CONUS (or Population Impact Data Processing ALASKA) model and choose Edit. Inside the editor, click the Run menu bar icon . The output of the Population Impact Data Processing models (AK and CONUS) will be in American Standard Code for Information Interchange (ASCII) data format, which will be used in the Regional Urban Growth (RUG) model inside of Net Logo.

The next step in the process is running the NetLogo application, which accepts the previously processed data as input. NetLogo can be launched automatically from the third model screen within the Wizard as illustrated in Figure 38. Another method of launching the application is from the Windows command prompt. Click the Windows start button, then type CMD. Note that the command prompt must be run as administrator and $100 \mathrm{~GB}$ of RAM must be available in the computer (Figures 39 and 40)

Figure 39. Run command prompt as administrator.

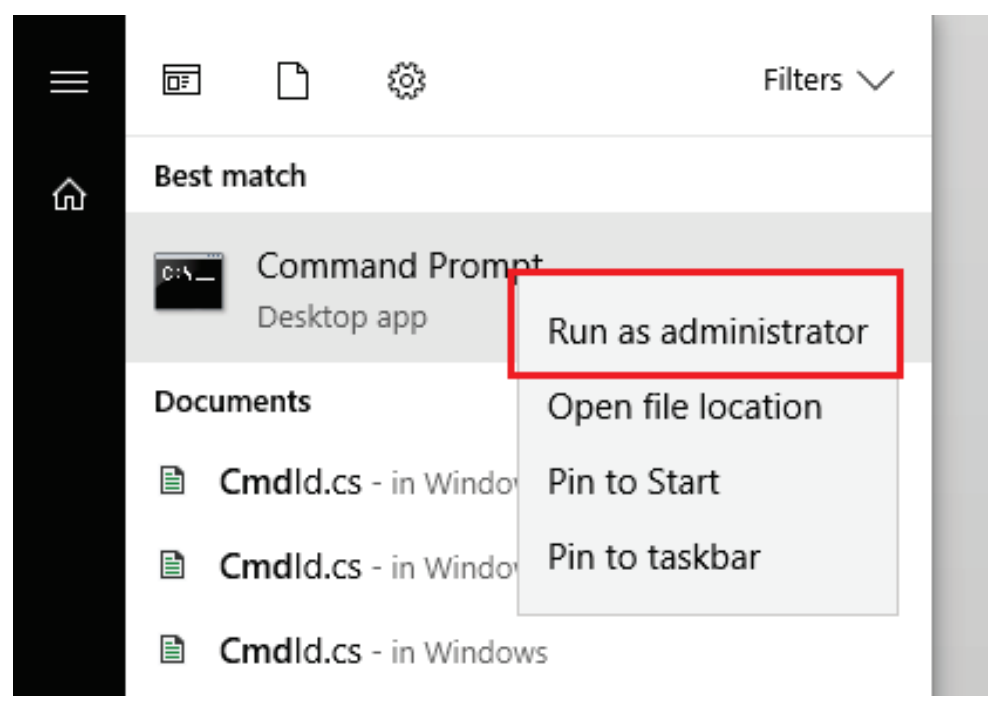


Figure 40. Command prompt window with Launch.bat command.

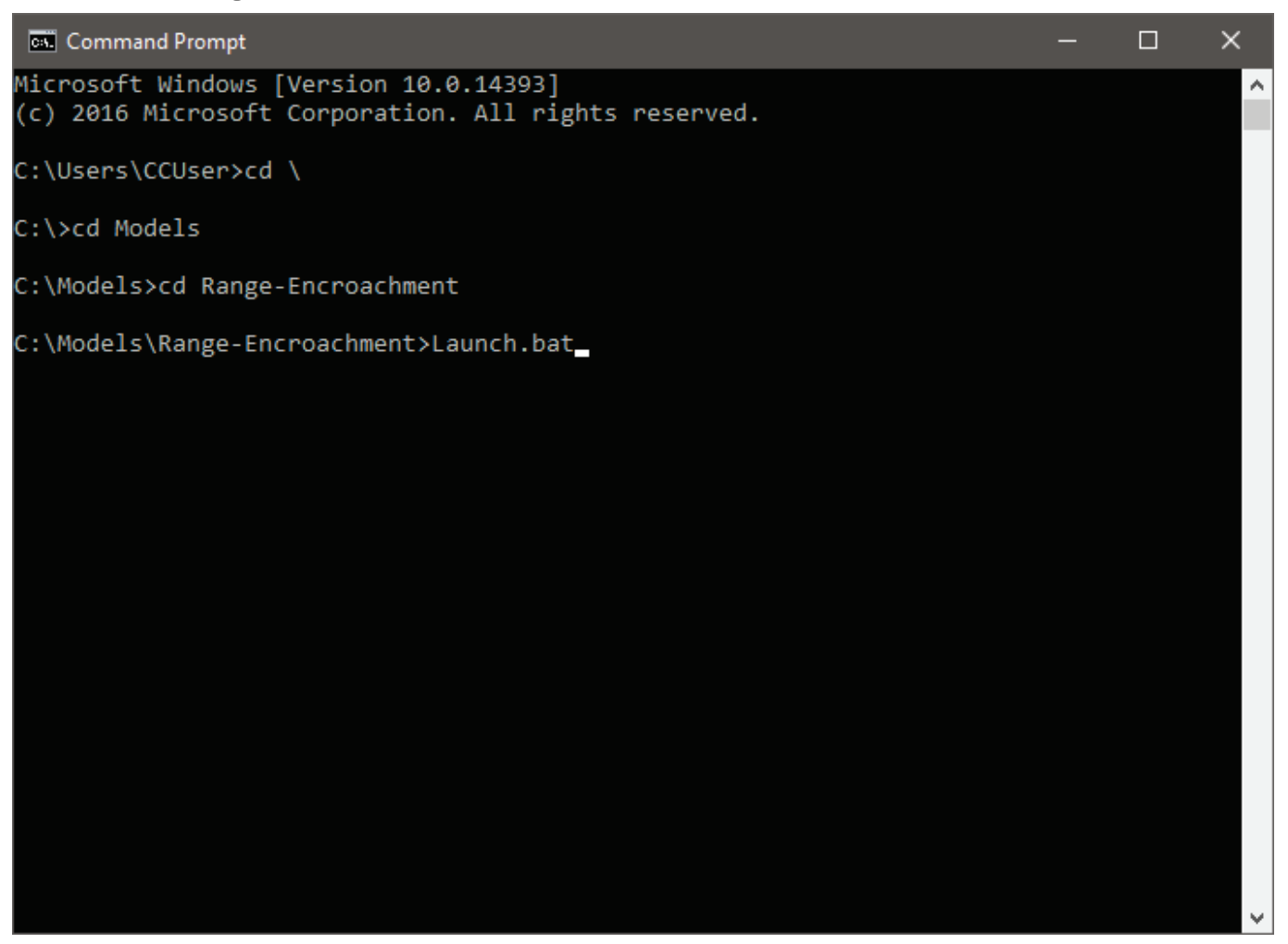

Inside NetLogo, click on File->open and navigate to the model.nlogo file located at C:/Models/RangeEncroachment/Model_Files/Step2_RUG_NetLogo/Ne tLogo/model. nlogo to launch the range encroachment model. From the area drop down list choose the desired area (fort or location) to run the model on, and click the run-all button. (See Figures 41 and 42.)

Output from NetLogo will be saved to the results folder

(C: \Models $\backslash$ Range-

Encroachment \Model_Files $\backslash$ Step2_RUG_NetLogo \results) with a separate folder for each installation. Each folder should contain four files: annual-growth.txt, equation.txt, results.png, and pct_low_density_urban_in_buffers.csv.

The final step is post-processing of the RUG results in ArcGIS using the Population Impact toolbox. Launch ArcMap again from the wizard and open the model file located at $\mathrm{C}: \backslash$ Models $\backslash$ Range-Encroachment $\backslash$ ModelFiles $\backslash$ Step3_RUG_postprocessing_ARCGIS $\backslash$ RangeEncroachment. mxd. 
Figure 41. NetLogo with Model file loaded.

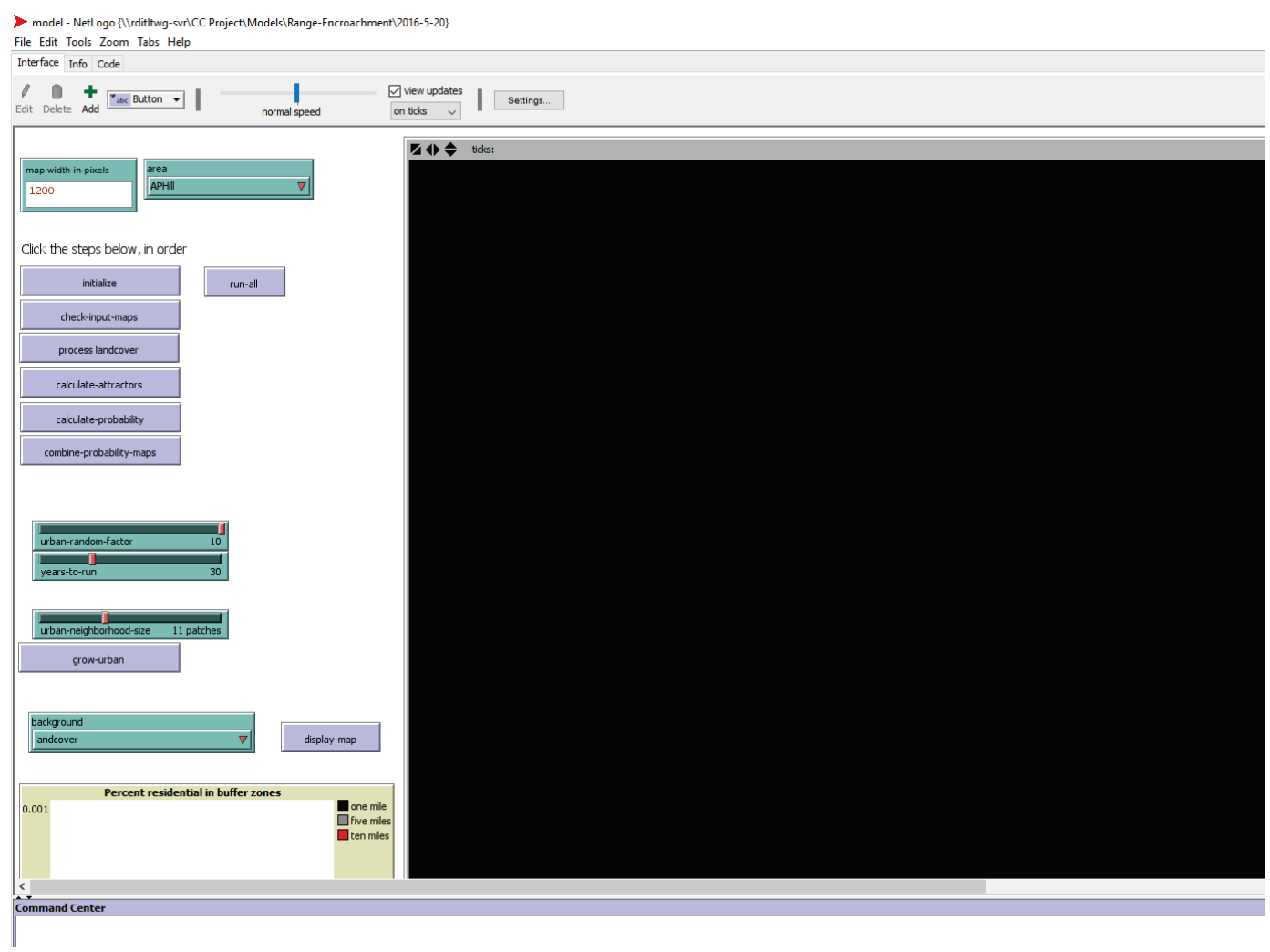

Figure 42. NetLogo with Model execution complete.

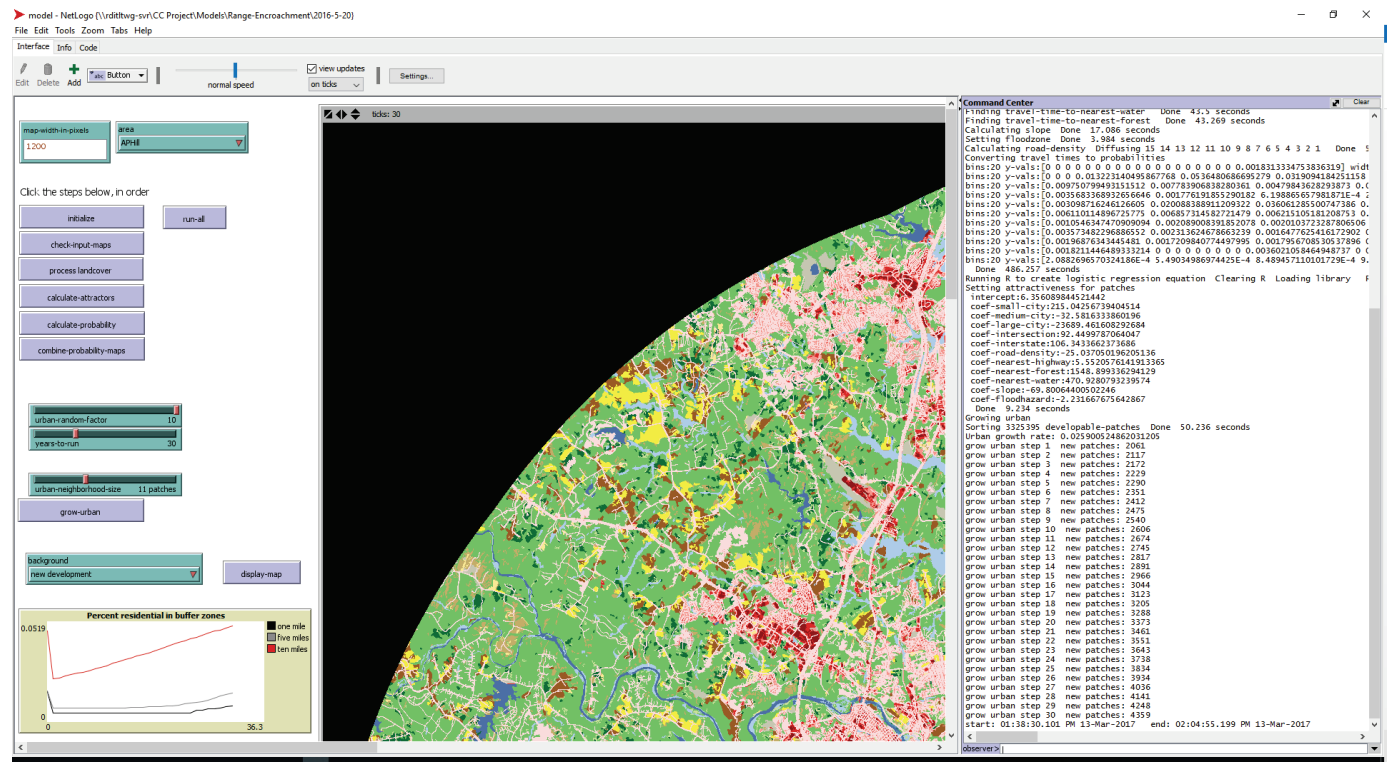

Open the toolbox viewer by clicking the Toolbox menu bar icon . Add the Population_Impact_10.2.xxx toolbox by right clicking ArcToolbox at the top of the viewer then clicking Add Toolbox. The toolbox file is located at $\mathrm{C}: \backslash$ Models $\backslash$ Range-Encroachment $\backslash$ Model- 
Files \Step3_RUG_postprocessing_ARCGIS $\backslash$ Population_Impac t. tbx. Expand the newly added toolbox by clicking the plus sign to the left to show the models inside.

The next step is to create a Workspace folder. This is a work-around because of an ESRI Model Builder error. Right click the 1. Create Workspace Folder model and choose Edit. Inside the editor, click the Run menu bar icon . Select a location for the folder to be created then choose $O K$. The model will create the empty Workspace folder.

The next step is the main model 2. Post Process data from RUG to MVA. Right click on the model and choose Edit. Validate the model by clicking the Validate menu bar icon $\checkmark$. If after validation the model processes turn white, this indicates the model has lost connection to a file that is necessary to run. This is a known issue with the model. A workaround is to change the results folder, then change back to the original results folder, and revalidate. To change the results folder, double click on the Results Folder process, and browse to results-1. Click OK. Repeat step one to change the Results Folder back to results. Validate the model again, all processes should be repaired.

After the model has run, the final output is a MS Excel ${ }^{\circledR}$ spreadsheet and the final MVA score is shown in the Final_score column. The MVA scores show the risk of encroachment to the training area of each installation, where the higher the MVA score is represents a higher risk of encroachment. The spreadsheet file should be located at C: $\backslash$ Models $\backslash$ RangeEncroachment $\backslash$ Output $\backslash$ Postprocessing_output_ArcGIS $\backslash r e s u l$ ts-RUG \Rug-Output_Clean.xls.

\subsubsection{Known issues and limitations}

As mentioned previously, building new data with this model requires a substantial amount of memory and processing power. NetLogo reserves $100 \mathrm{~GB}$ of RAM before running. Therefore, more than $100 \mathrm{~GB}$ must be present in the computer before attempting to run.

NetLogo also takes a substantial amount of execution time to complete. It is not unusual for a run-all job to take several hours or even days to finish. 


\subsection{Heat Risk on Ranges Model}

The Army places a high value on the capacity of installations to support various outdoor training exercises. Therefore, maintaining and increasing the capacity to perform training exercises on DoD lands is essential to future force readiness and effectiveness. A method was developed to predict how training throughput for ranges is likely to change over time, due to changes in precipitation and temperature. These may have a negative effect on the ability to conduct training on ranges due to the risk of heat related illness.

Temperatures above an acceptable range can negatively affect the ability to conduct training on an installation because of the potential for heat related illness resulting in a reduction of training time. TB MED 507 (HQDA and HQAF 2003) defines the weather related thresholds for determining whether training can take place.

The heat stress algorithm takes installation location, daily local minimum, maximum, and mean temperatures, and daily precipitation values as inputs. Outputs produced are values that represent the number of days with heat risk restrictions for the given location, time frame, and climate scenario categorized into low, medium, and high categories. These values can also be used to calculate a percentage of training time that is negatively affected by excessive heat conditions.

\subsubsection{Capturing the current state}

The Heat Risk on Ranges Model was received as a script written in the Python programming language. In fact, it uses the Python script previously described in Section 4.2. Each step for viewing the computed data is thoroughly documented in the following sections to limit user confusion and ensure accurate results.

Software requirements for the Range Days Lost to Heat Risk Model include the Python IDLE development environment, a basic text editor such as MS Notepad ${ }^{\circledR}$, and MS Excel ${ }^{\circledR}$ version 2013 or higher.

A working knowledge of Microsoft Office products is recommended as well as a basic understanding of editing file paths in a text file and executing Python code within the IDLE environment. 


\subsubsection{Integrating into the Wizard}

There are two parts to the Heat Risk on Ranges Model: viewing the output data and building new output data. Pre-built datasets for this model were processed using daily values from the Temperature and Precipitation Projections Model and are stored within the VM. The ability to view this output data is built in to the Wizard application.

After launching the Wizard from the VM desktop, the Heat Risk on Ranges Model is launched by clicking the icon from the Wizard dashboard screen.

The second screen within the Model allows the end user to view the datasets in graphical or tabular mode (Figure 45). Choose the desired view type from the View drop down combo box. Options within this box are Graphs and Tabular. Graphs displays the data as standard line graphs while Tabular displays the data in a table layout within an MS Excel ${ }^{\circledR}$ spreadsheet.

Figure 43. Range days lost to Heat Risk Model icon.

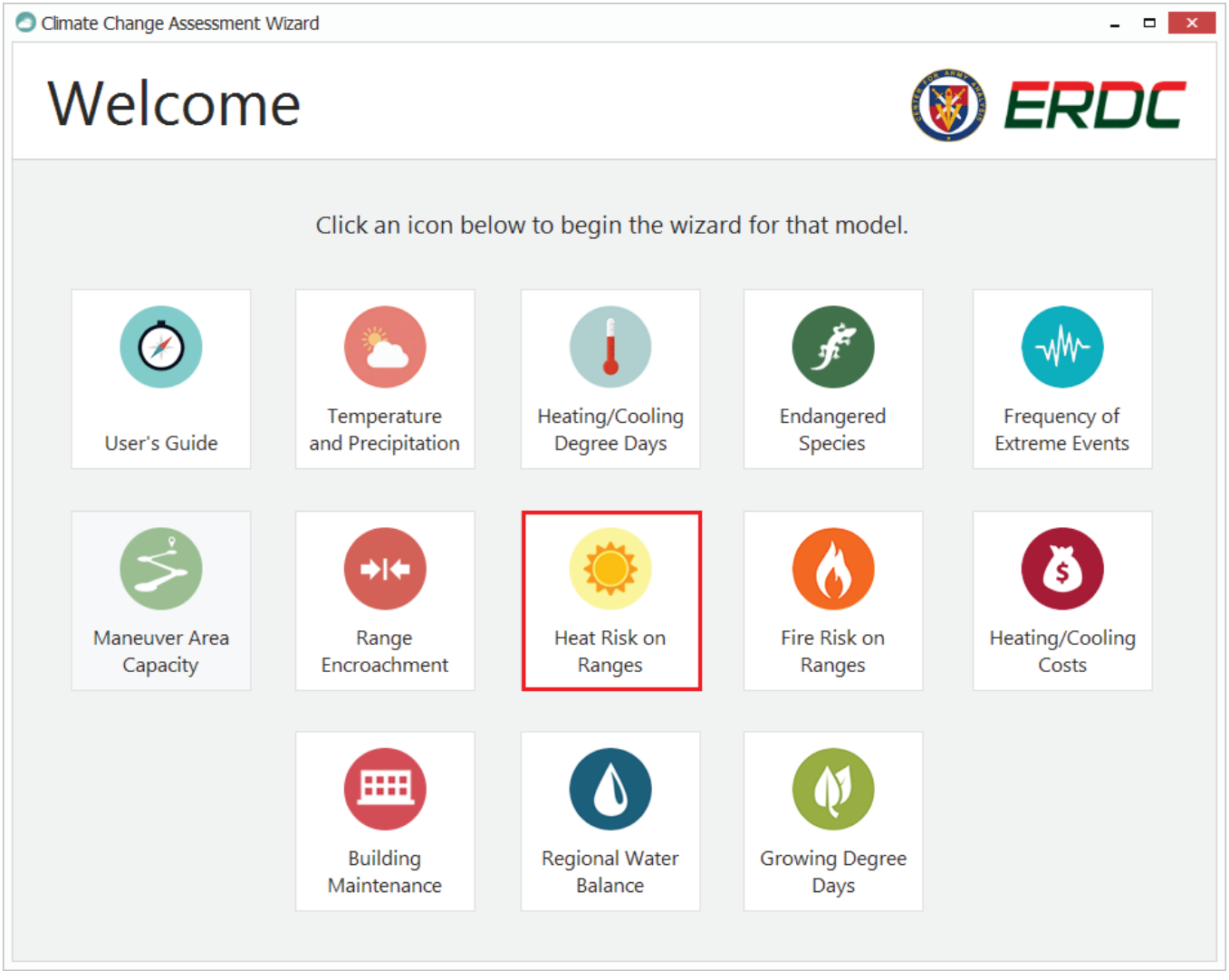


Figure 44. Range days lost to Heat Risk Model first screen.

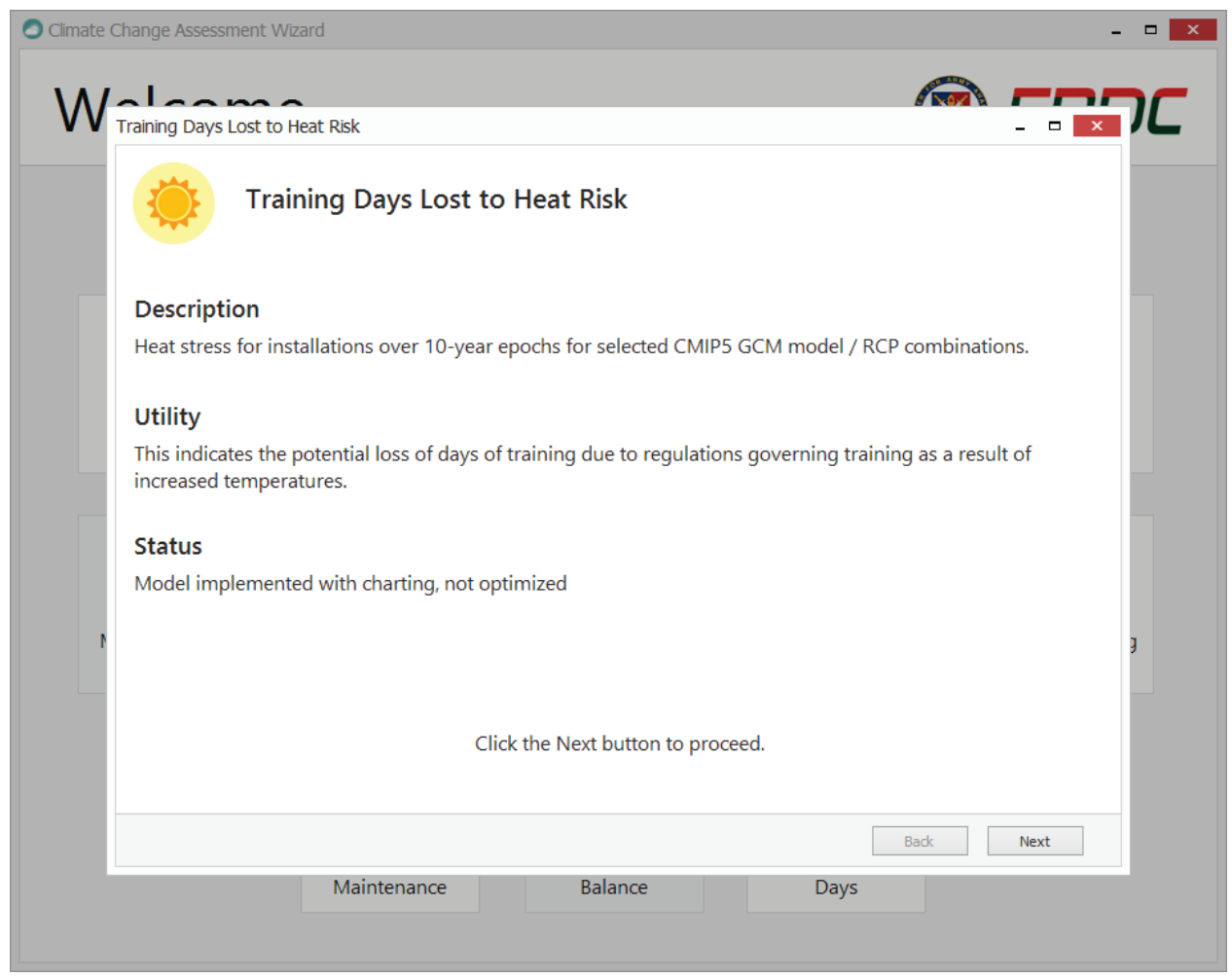

Figure 45. Range days lost to Heat Risk Model second screen.

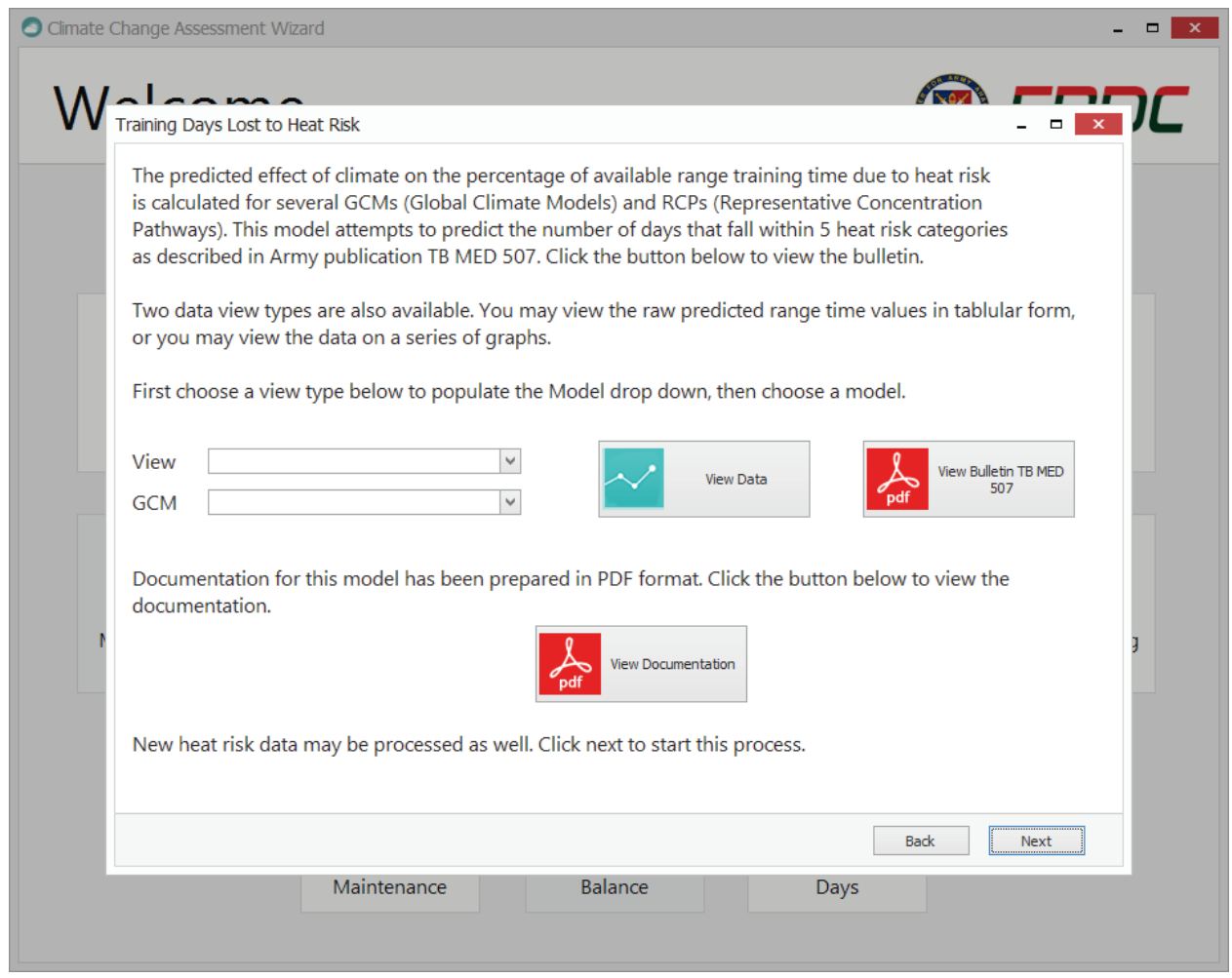


Next, choose a GCM and RCP type from the drop down combo box to filter only data related to that GCM/RCP (Figure 45). At the time of publication, there are $10 \mathrm{GCMs}$ within the dataset for this model. RCP 2.6, 4.5, and 8.5 were chosen to represent lower bound, middle, and upper bounds for each GCM. Each GCM contains these RCPs, with the exception of CNRM and GFDL.

Once both of the choices are made, click the View Data button to launch the chart viewer window (Figure 46).

Figure 46. Results in the chart viewer window.

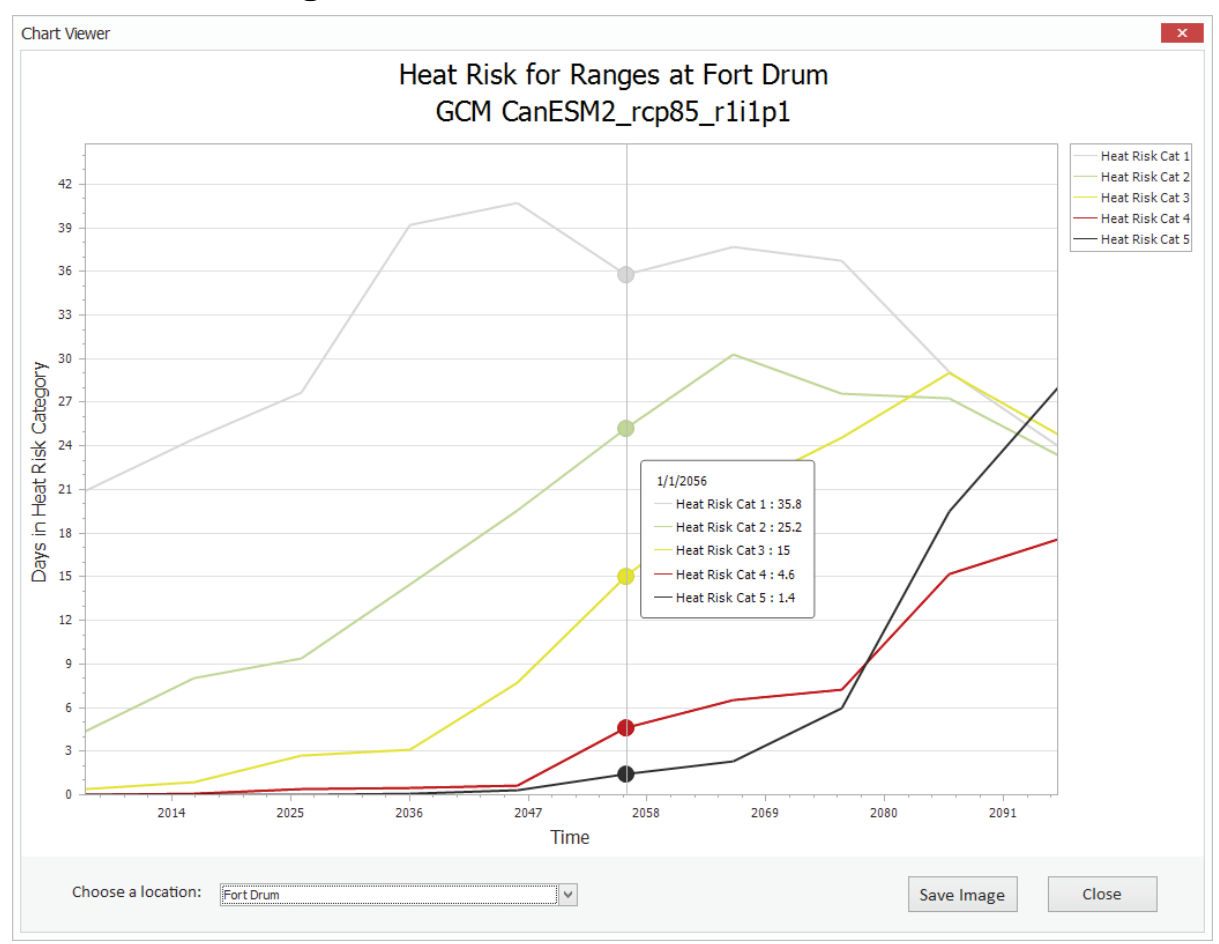

The average number of days in five different heat risk categories are plotted as line graphs with the number of days charted on the $\mathrm{Y}$-axis, and 10-year epochs are charted on the $\mathrm{X}$-axis. The user can change the charted values by choosing a different geographical location from the drop down combo box near the bottom left of the window (Figure 46). Upon selecting a location, the data will automatically filter to include only those values found within the chosen area. Table 2 lists and describes each of the five heat risk categories as defined by doctrine. 
Table 2. Doctrinal heat risk categories and guidelines.

\begin{tabular}{|c|c|c|c|c|c|c|c|c|}
\hline \multicolumn{9}{|c|}{$\begin{array}{l}\text { Work/Rest and Water Consumption Table } \\
\text { Applies to average sized, heat-acclimated soldier wearing } B D U, \text { hot weather. (See } T B \text { MED } 507 \text { for further guidance.) }\end{array}$} \\
\hline \multicolumn{3}{|c|}{ Easy Work } & \multicolumn{2}{|c|}{ Moderate Work } & \multicolumn{3}{|c|}{ Hard Work } & - The work/rest times and fluid \\
\hline \multicolumn{3}{|c|}{$\begin{array}{l}\text { - Weapon Maintenance } \\
\text { - Walking Hard Surface at } 2.5 \mathrm{mph} \text {, } \\
<30 \mathrm{lb} \text { Load } \\
\text { - Marksmanship Training } \\
\text { - Drill and Ceremony } \\
\text { - Manual of Arms }\end{array}$} & \multicolumn{2}{|c|}{$\begin{array}{l}\text { - Walking Loose Sand at } 2.5 \mathrm{mph}, \\
\text { No Load } \\
\text { - Walking Hard Surface at } 3.5 \mathrm{mph} \text {, } \\
<40 \text { Ib Load } \\
\text { - Calisthenics } \\
\text { - Patrolling } \\
\text { - Individual Movement Techniques, } \\
\text { i.e., Low Craw or High Crawl } \\
\text { - Defensive Position Construction }\end{array}$} & \multicolumn{3}{|c|}{$\begin{array}{l}\text { - Walking Hard Surface at } 3.5 \mathrm{mph} \text {, } \\
\geq 40 \mathrm{lb} \text { Load } \\
\text { - Walking Loose Sand at } 2.5 \mathrm{mph} \\
\text { with Load } \\
\text { - Field Assaults }\end{array}$} & $\begin{array}{l}\text { performance and hydration for } \\
\text { at least } 4 \mathrm{hrs} \text { of work in the } \\
\text { specified heat category. Fluid } \\
\text { needs can vary based on } \\
\text { individual differences ( } \pm 1 / \mathrm{qt} / \mathrm{hr}) \\
\text { and exposure to full sun or full } \\
\text { shade }( \pm 1 / \mathrm{q} \text { t/hr). } \\
\text { - } \mathrm{NL}=\text { no limit to work time per } \mathrm{hr} \text {. } \\
\text { - Rest = minimal physical activity }\end{array}$ \\
\hline \multirow[b]{2}{*}{$\begin{array}{c}\text { Heat } \\
\text { Category }\end{array}$} & \multirow[b]{2}{*}{$\begin{array}{c}\text { WBGT } \\
\text { Index, Fo }\end{array}$} & \multicolumn{2}{|c|}{ Easy Work } & \multicolumn{2}{|c|}{ Moderate Work } & \multicolumn{2}{|c|}{ Hard Work } & \multirow{7}{*}{$\begin{array}{l}\text { in shade if possible. } \\
\text { - CAUTION: Hourly fluid intake } \\
\text { should not exceed } 11 / 2 \text { qts. } \\
\text { Daily fluid intake should not } \\
\text { exceed } 12 \text { qts. } \\
\text { - If wearing body armor, add } 5^{\circ} \mathrm{F} \text { to } \\
\text { WBGT index in humid climates. } \\
\text { - If doing Easy Work and wearing } \\
\text { NBC (MOPP 4) clothing, add } \\
10^{\circ} \mathrm{F} \text { to WBGT index. } \\
\text { - If doing Moderate or Hard Work } \\
\text { and wearing NBC (MOPP 4) } \\
\text { clothing, add } 20^{\circ} \mathrm{F} \text { to WBGT } \\
\text { index. }\end{array}$} \\
\hline & & $\underset{(m i n)}{\text { Work/Rest }}$ & $\begin{array}{l}\text { Water } \\
\text { Intake } \\
\text { (qt/hr) }\end{array}$ & $\underset{(\mathrm{min})}{\text { Work/Rest }}$ & $\begin{array}{c}\text { Wattor } \\
\text { Intake } \\
\text { (qt/hr) }\end{array}$ & $\underset{(\mathrm{min})}{\text { Work/Rest }}$ & $\begin{array}{l}\text { Water } \\
\text { Intake } \\
\text { (qt/hr) }\end{array}$ & \\
\hline 1 & $78^{\circ}-81.9^{\circ}$ & $\mathrm{NL}$ & $1 / 2$ & NL & $3 / 4$ & $40 / 20 \mathrm{~min}$ & $3 / 4$ & \\
\hline$\frac{2}{(\text { GREN) }}$ & $82^{\circ}-84.9^{\circ}$ & NL & $1 / 2$ & $50 / 10 \mathrm{~min}$ & $3 / 4$ & $30 / 30 \mathrm{~min}$ & 1 & \\
\hline $\begin{array}{c}3 \\
\text { (reLON) }\end{array}$ & $85^{\circ}-87.9^{\circ}$ & NL & $\%$ & $40 / 20 \mathrm{~min}$ & $3 / 4$ & $30 / 30 \mathrm{~min}$ & 1 & \\
\hline $\begin{array}{c}4 \\
(R \in O)\end{array}$ & $88^{\circ}-89.9^{\circ}$ & $\mathrm{NL}$ & 3 & $30 / 30 \mathrm{~min}$ & $3 \%$ & $20 / 40 \mathrm{~min}$ & 1 & \\
\hline $\begin{array}{c}5 \\
\text { (BLACK) }\end{array}$ & $>90^{\circ}$ & $50 / 10 \mathrm{~min}$ & 1 & $20 / 40 \mathrm{~min}$ & 1 & $10 / 50 \mathrm{~min}$ & 1 & \\
\hline
\end{tabular}

Charts can be saved to the user computer by clicking the Save Image button near the bottom right of the window. The resulting file is saved to a location of the users choosing in the universal JPEG image file format.

As mentioned previously, this model uses the Python script described in the Heating and Cooling Degree Days Model. In an effort to reduce redundancy, please refer to the process for building data using the Python IDLE environment described in Section 4.2.

\subsection{Fire Risk on Ranges Model}

Maintaining and increasing the capacity to perform live fire training exercises on DoD lands is essential to future force readiness and effectiveness. The risk of fire on ranges is one factor affecting the availability of training areas. Dry conditions pose a risk on firing ranges because of the potential to start fires, thus, reducing the amount of training time available. Assessing the impact of future climate change is an essential part of ensuring future availability of live fire ranges.

The fire risk algorithm attempts to predict the likelihood of fires on ranges by calculating a Keetch-Byram drought index (KBDI) for each installation included in the study. The KBDI was devised based on mathematical 
models for predicting the likelihood of wildfire based on soil moisture and other conditions related to drought. The KBDI is a soil/duff drought index that ranges from $\mathrm{o}$ (no drought) to 800 (extreme drought) and is based on the soil capacity in $8 \mathrm{in}$. $(200 \mathrm{~mm})$ of water. The depth of soil required to hold 8 in. of water varies. A prolonged drought (high KBDI) influences fire intensity largely because fuels have a lower moisture content.

The algorithm accepts installation location and daily precipitation amounts as inputs and produces output values that represent the number of days with fire risk restrictions for the given location and climate scenario categorized into low, medium, and high categories. The values can also be used to calculate a percentage of training time that is negatively affected by fire risk conditions.

\subsubsection{Capturing the current state}

The Fire Risk on Ranges Model was received as a script written in the Python programming language. In fact, it uses the Python script previously described in Section 4.2. Each step for viewing the computed data is thoroughly documented in the following sections to limit user confusion and ensure accurate results.

Software requirements for the Range Days Lost to Heat Risk Model include the Python IDLE development environment, a basic text editor such as MS Notepad ${ }^{\circledR}$, and MS Excel ${ }^{\circledR}$ version 2013 or higher.

A working knowledge of Microsoft Office products is recommended as well as a basic understanding of editing file paths in a text file and executing Python code within the IDLE environment.

\subsubsection{Integrating into the Wizard}

There are two parts to the Fire Risk on Ranges Model: viewing the output data and building new output data. Pre-built datasets for this model were processed using daily values from the Temperature and Precipitation Projections Model and are stored within the WM. The ability to view this output data is built in to the Wizard application.

After launching the Wizard from the VM desktop, the Fire Risk on Ranges Model is launched by clicking the icon from the Wizard dashboard screen (Figures 47 and 48). 
Figure 47. Range days lost to Fire Risk on Ranges Model icon.

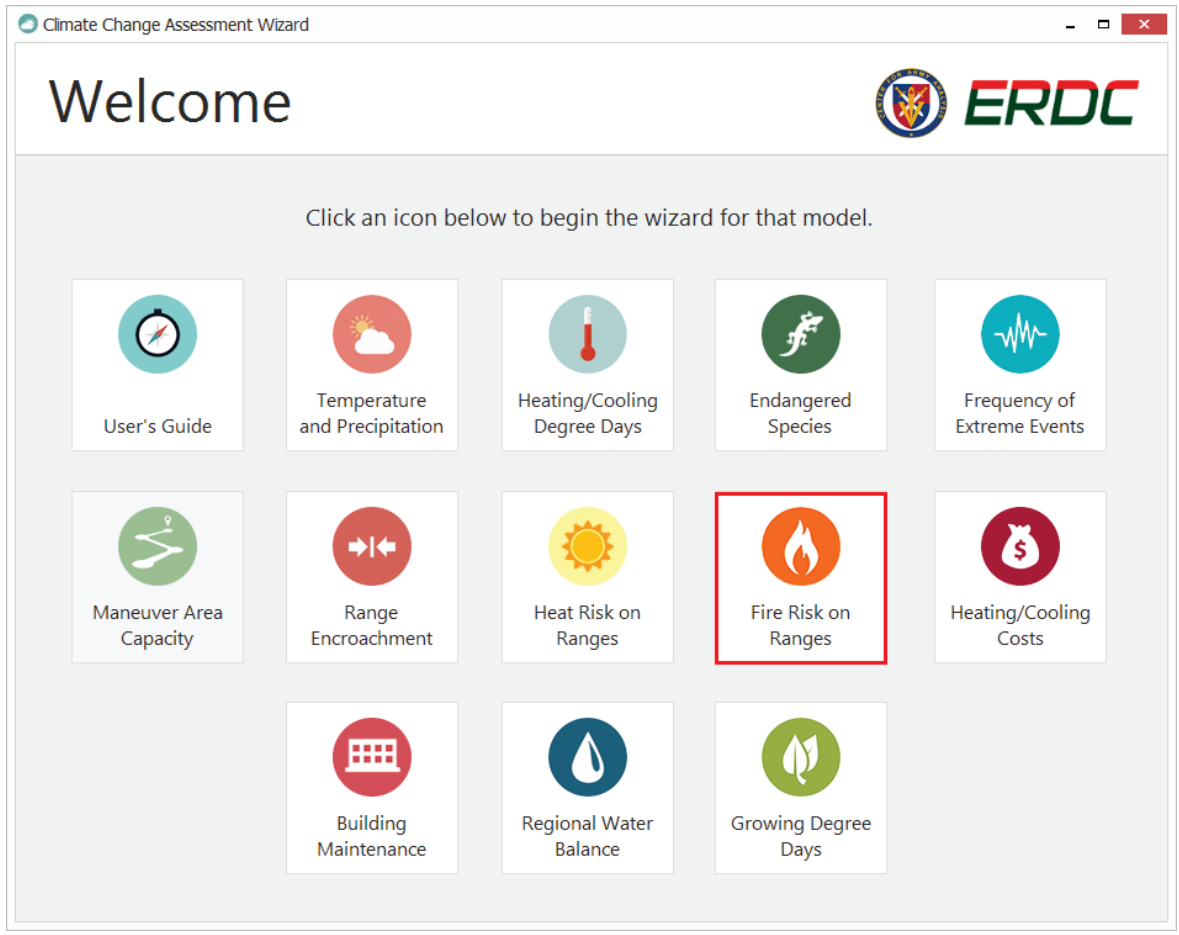

Figure 48. Range days lost to Fire Risk on Ranges Model first screen.

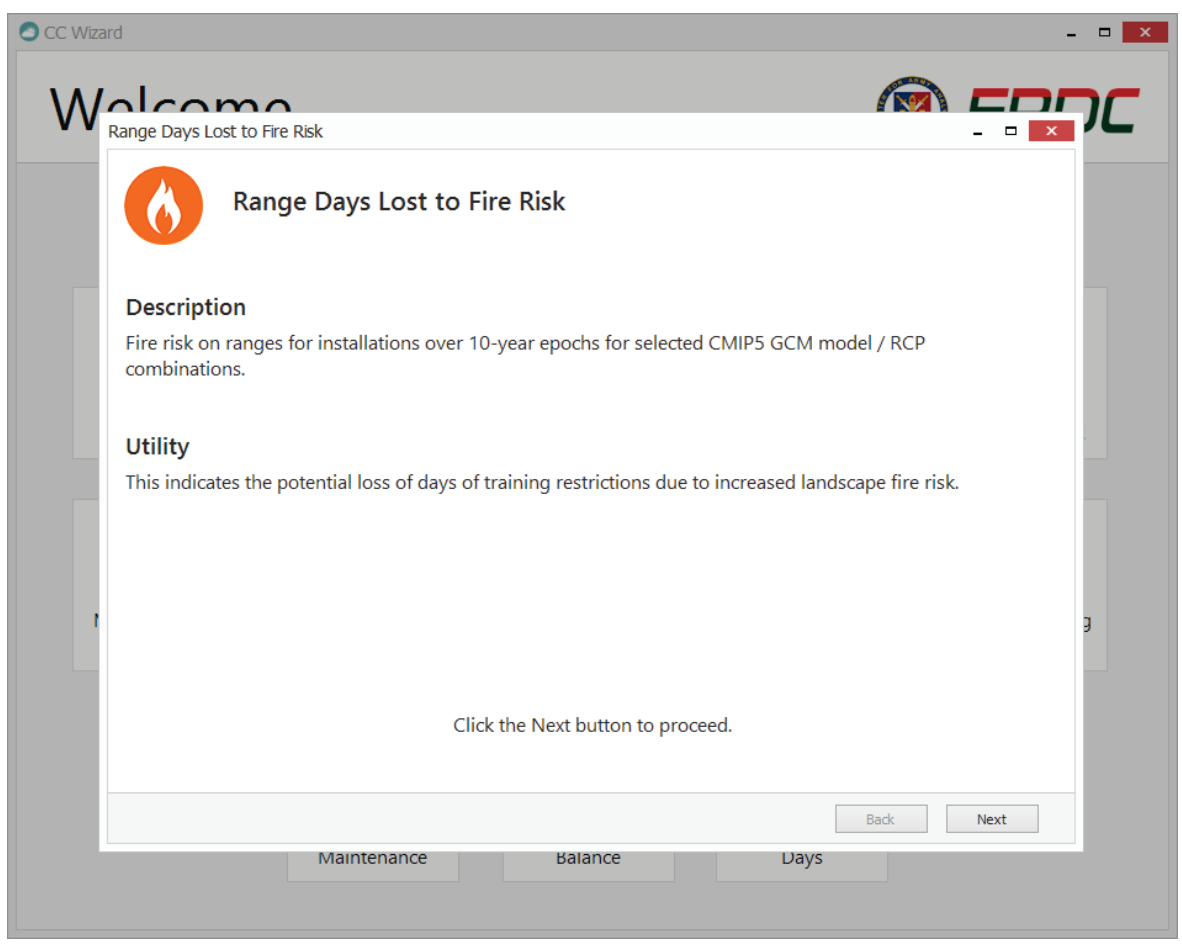

The second screen within the model allows the end user to view the datasets in graphical or tabular mode (Figure 49). Choose the desired view type from the View drop down combo box. Options within this box are 
Graphs and Tabular. Graphs displays the data as standard line graphs while Tabular displays the data in a table layout within an MS Excel ${ }^{\circledR}$ spreadsheet.

Figure 49. Range days lost to Fire Risk on Ranges Model second screen.

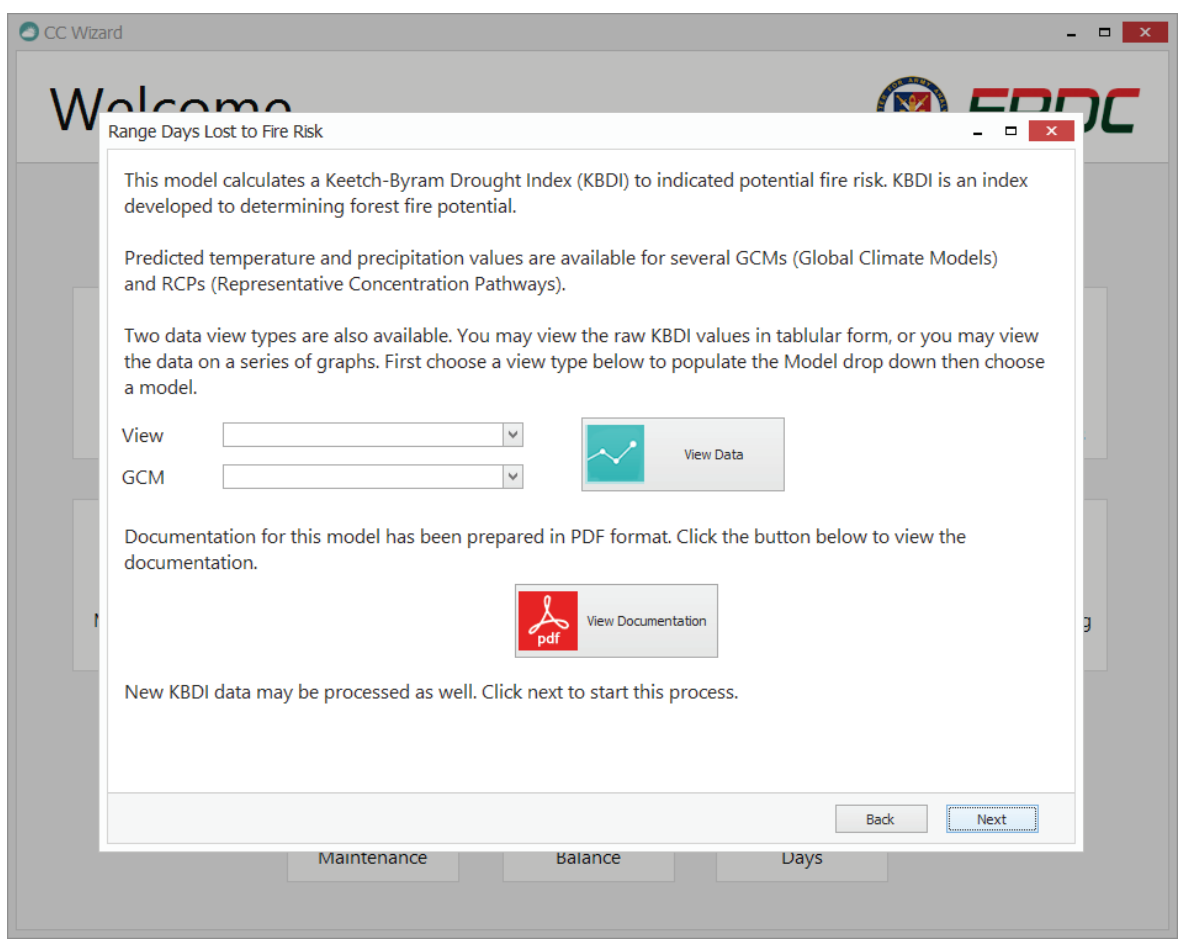

Next, choose a GCM and RCP type from the drop down combo box to filter only data related to that GCM/RCP (Figure 49). At the time of publication, there are $10 \mathrm{GCMs}$ within the dataset for this model. RCP 2.6, 4.5, and 8.5 were chosen to represent lower bound, middle, and upper bounds for each GCM. Each GCM contains these RCPs, with the exception of CNRM-CM-5 and GFDL-CM3.

Once both of the choices are made, click the View Data button to launch the chart viewer window (Figure 50). 
Figure 50. Results in the chart viewer window.

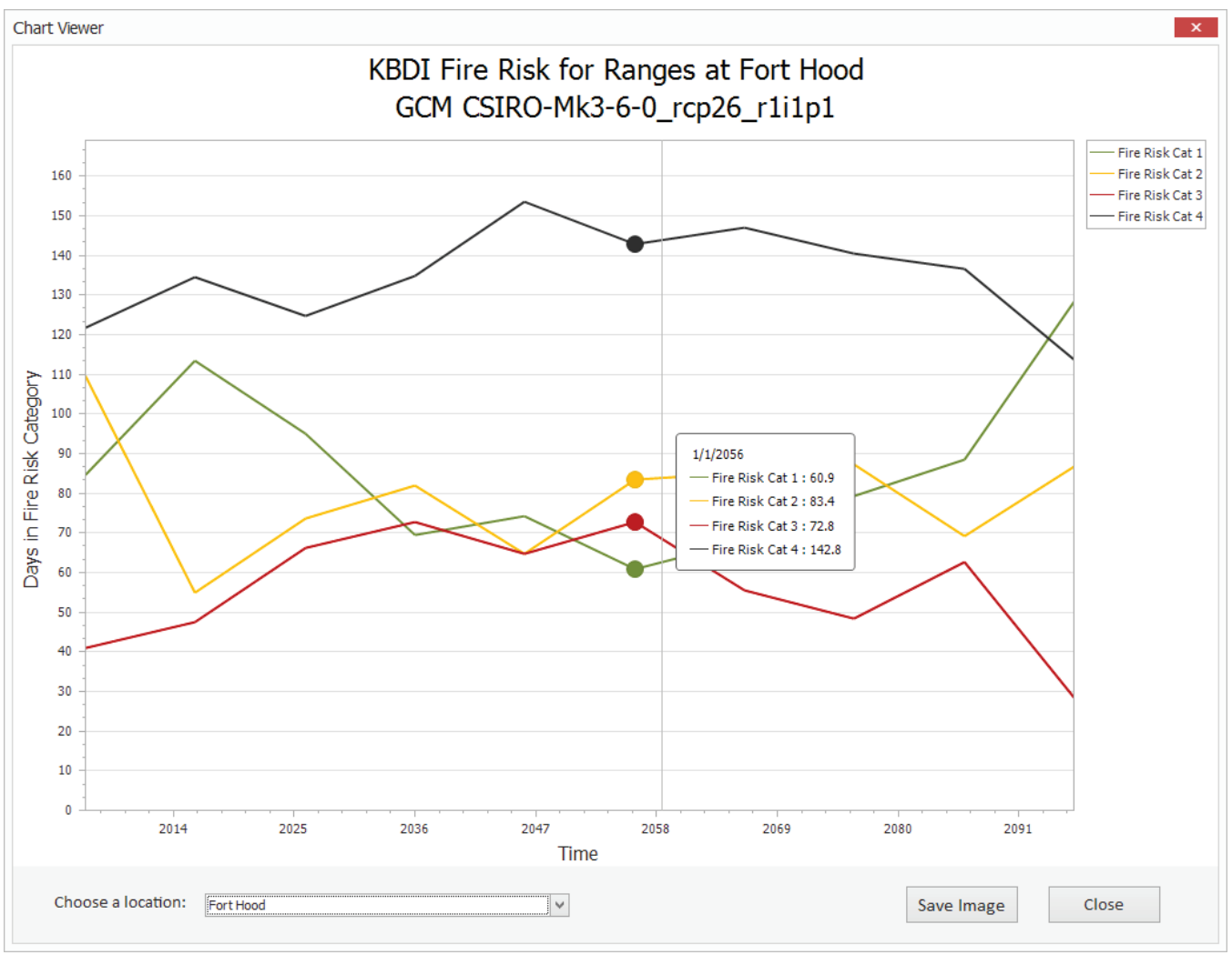

The average number of days in four different fire risk categories are plotted as line graphs with the number of days charted on the $\mathrm{Y}$-axis, and 10-year epochs are charted on the $\mathrm{X}$-axis. The user can change the charted values by choosing a different geographical location from the drop down combo box near the bottom left of the window (Figure 50). Upon selecting a location, the data will automatically filter to include only those values found within the chosen area. Table 3 lists and describes each of the four fire risk (KBDI) categories.

Charts can be saved to the user's computer by clicking the Save Image button near the bottom right of the window (Figure 50). The resulting file is saved to a location of the user's choosing in the universal JPEG image file format.

As mentioned previously, this model uses the Python script described in the Heating and Cooling Degree Days Model. In an effort to reduce redundancy, please refer to the process for building data using the Python IDLE environment described in Section 4.2. 
Table 3. KBDI fire risk categories.

\begin{tabular}{|c|c|c|c|c|c|}
\hline Category & $\begin{array}{l}\text { Fre Danger } \\
\text { Condition }\end{array}$ & $\begin{array}{l}\text { Expected Fire } \\
\text { Behavior }\end{array}$ & $\begin{array}{l}\text { Training } \\
\text { Restrictions }\end{array}$ & $\begin{array}{l}\text { Flreflinting } \\
\text { Detall } \\
\text { Requirements }\end{array}$ & $\begin{array}{l}\text { Dertved } \\
\text { KBDI* }\end{array}$ \\
\hline 1 & GREEN & $\begin{array}{l}\text { Fires are difficult to start } \\
\text { and do not burn with } \\
\text { vigor. Fires can easily be } \\
\text { controlled using direct } \\
\text { attack. }\end{array}$ & None. & None. & $0-300$ \\
\hline 2 & AMBER & $\begin{array}{l}\text { Fires start easily and may } \\
\text { burn quickly through } \\
\text { grass and shrub fuels. } \\
\text { Fires can be controlled } \\
\text { using direct attack, but in } \\
\text { some circumstances may } \\
\text { require indirect attack } \\
\text { methods. }\end{array}$ & $\begin{array}{l}\text { No aerial flares } \\
\text { outside the live-fire } \\
\text { training areas. } \\
\text { Pyrotechnics must be } \\
\text { used on roadways, } \\
\text { tank trails, or barren } \\
\text { areas. }\end{array}$ & None. & $300-600$ \\
\hline 3 & RED & $\begin{array}{l}\text { Fires start easily, move } \\
\text { quickly, burn intensely. } \\
\text { and may be difficult to } \\
\text { control. }\end{array}$ & $\begin{array}{l}\text { No pyrotechnics, } \\
\text { incendiary munitions, } \\
\text { tracers. }\end{array}$ & $\begin{array}{l}\text { 10-person fire- } \\
\text { fighting detail } \\
\text { required. } \\
\text { On-call helicopter } \\
\text { required on } 20 \text { - } \\
\text { minute standby. }\end{array}$ & $600-750$ \\
\hline 4 & BLACK & $\begin{array}{l}\text { Fires start very easily and } \\
\text { are impossible to control. }\end{array}$ & $\begin{array}{l}\text { No live-fire training. } \\
\text { No pyrotechnics. } \\
\text { Non-live-fire training } \\
\text { must be authorized } \\
\text { by the Senior Mission } \\
\text { Commander. }\end{array}$ & None. & $750-800$ \\
\hline
\end{tabular}

\subsubsection{Known issues and limitations}

The KBDI is a measure of meteorological drought and reflects water gain or loss within the soil. It does not measure fuel moisture levels in the 1-10hour fuel classes, which must be measured by other means for an accurate assessment of fuel moisture, regardless of the drought index readings.

\subsection{Heating and Cooling Cost Model}

All DoD installations depend on a secure, reliable, and abundant supply of energy in order to accomplish their missions. If climate change results in a generally warmer climate, installations in cooling-dominated locations would be expected to experience increased cooling loads and possibly reduced heating loads. This would probably result in increased electrical (cooling) requirements and possibly reduced fossil fuel (heating) requirements. Installations in heating-dominated areas might be expected to experience reduced heating requirements along with a possible increase in cooling requirements. 
The model accepts average temperature values produced by the Temperature and Precipitation Projections Model and outputs a series of Energy Use Index (EUI) values for each month within 10-year epochs. The calculated heating and cooling EUI values are intended to be used in other force stationing analysis applications as an MVA attribute.

\subsubsection{Capturing the current state}

The Heating and Cooling Cost Model was received as a MS Excel ${ }^{\circledR}$ spreadsheet with the EUI algorithms coded in VBA. The code accepts daily temperature and precipitation values that are the output of the Temperature and Precipitation Projections Model that was discussed in Section 4.1. Those outputs are required to be present in the VM for this model to execute.

Executing the model is a multiple step process that requires using MS Excel ${ }^{\circledR}$ version 2013 or higher. Data collection prior to model execution requires an internet connection and internet browser.

A working knowledge of Microsoft Office products is recommended as well as a basic understanding of accessing websites and downloading files from the internet.

Each step for viewing and building data sets is thoroughly documented in the following sections to limit user confusion and ensure accurate results.

\subsubsection{Integration into the Wizard}

There are two parts to the Heating and Cooling Cost Model: viewing the output data and building new output data. Pre-built datasets for this model were processed using daily values from the Temperature and Precipitation Projections Model and are stored within the VM. The ability to view this output data is built in to the Wizard application.

After launching the Wizard from the VM desktop, the Heating and Cooling Cost Model is launched by clicking the icon from the Wizard dashboard screen (Figures 51 and 52). 
Figure 51. Heating and Cooling Cost Model icon.

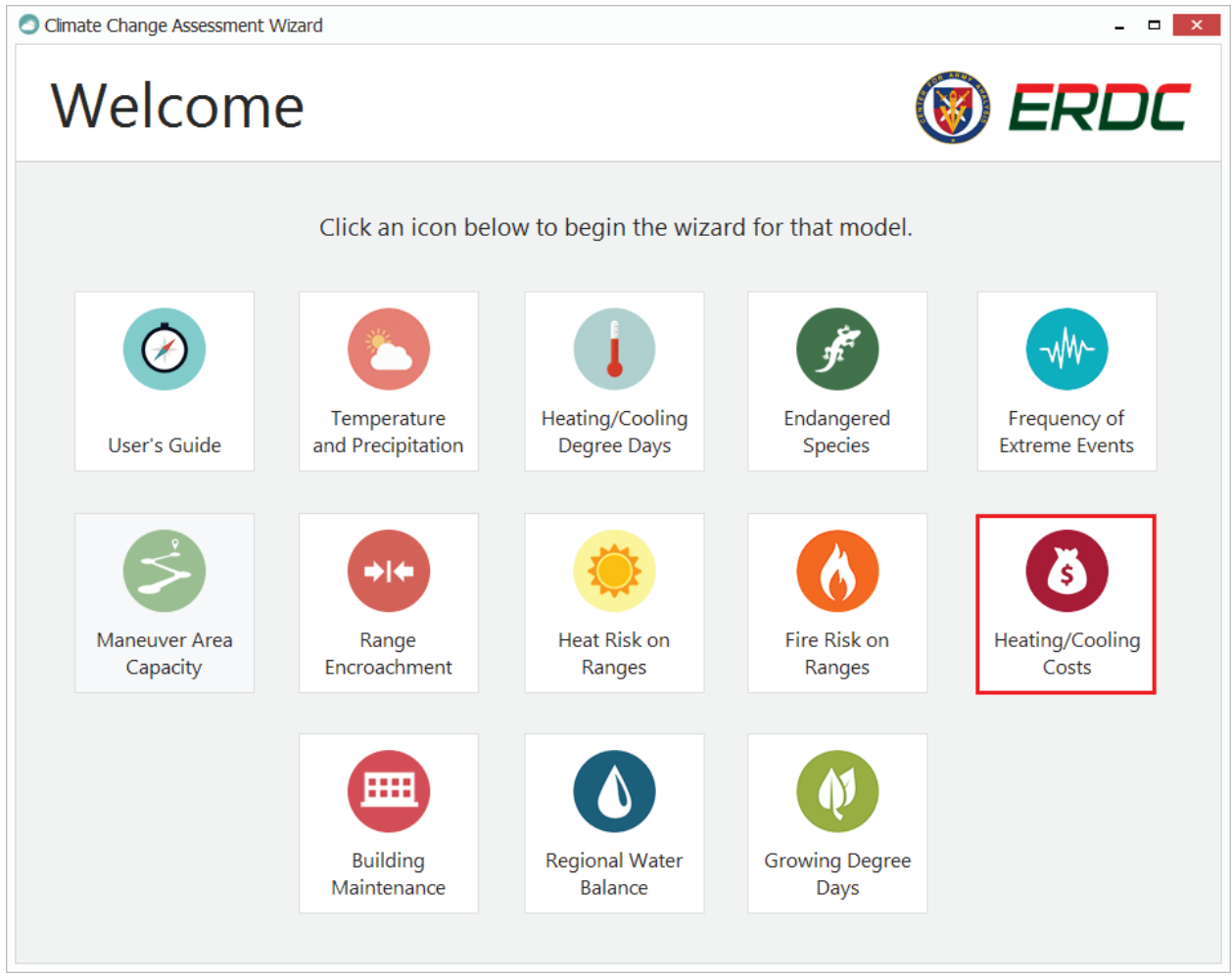

Figure 52. Heating and Cooling Cost Model first screen.

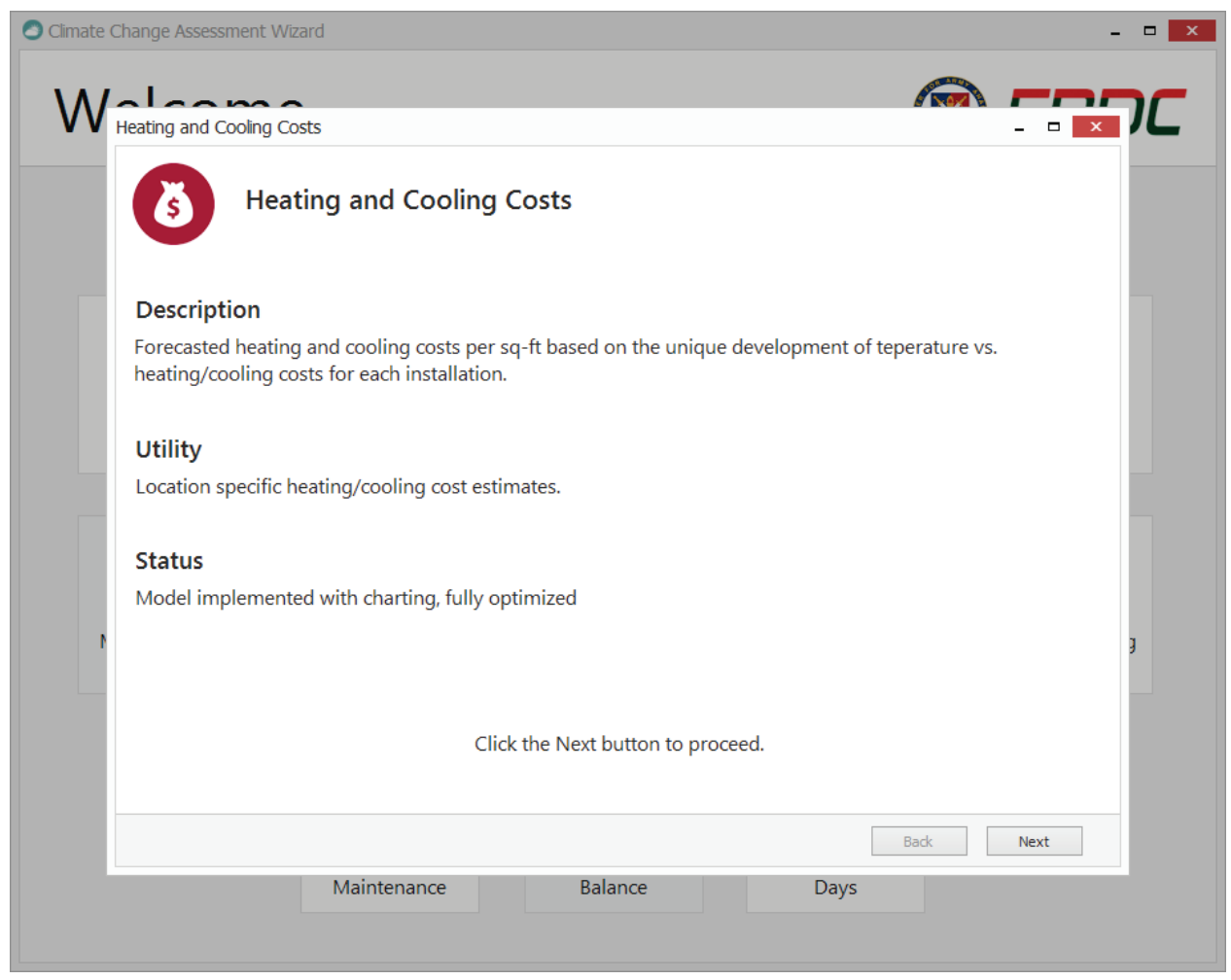


The second screen within the model allows the end user to view the datasets in graphical or tabular mode (Figure 53). Choose the desired view type from the View drop down combo box. Options within this box are Graphs and Tabular. Graphs displays the data as standard line graphs while Tabular displays the data in a table layout within an MS Excel ${ }^{\circledR}$ spreadsheet.

Figure 53. Heating and Cooling Cost Model second screen.

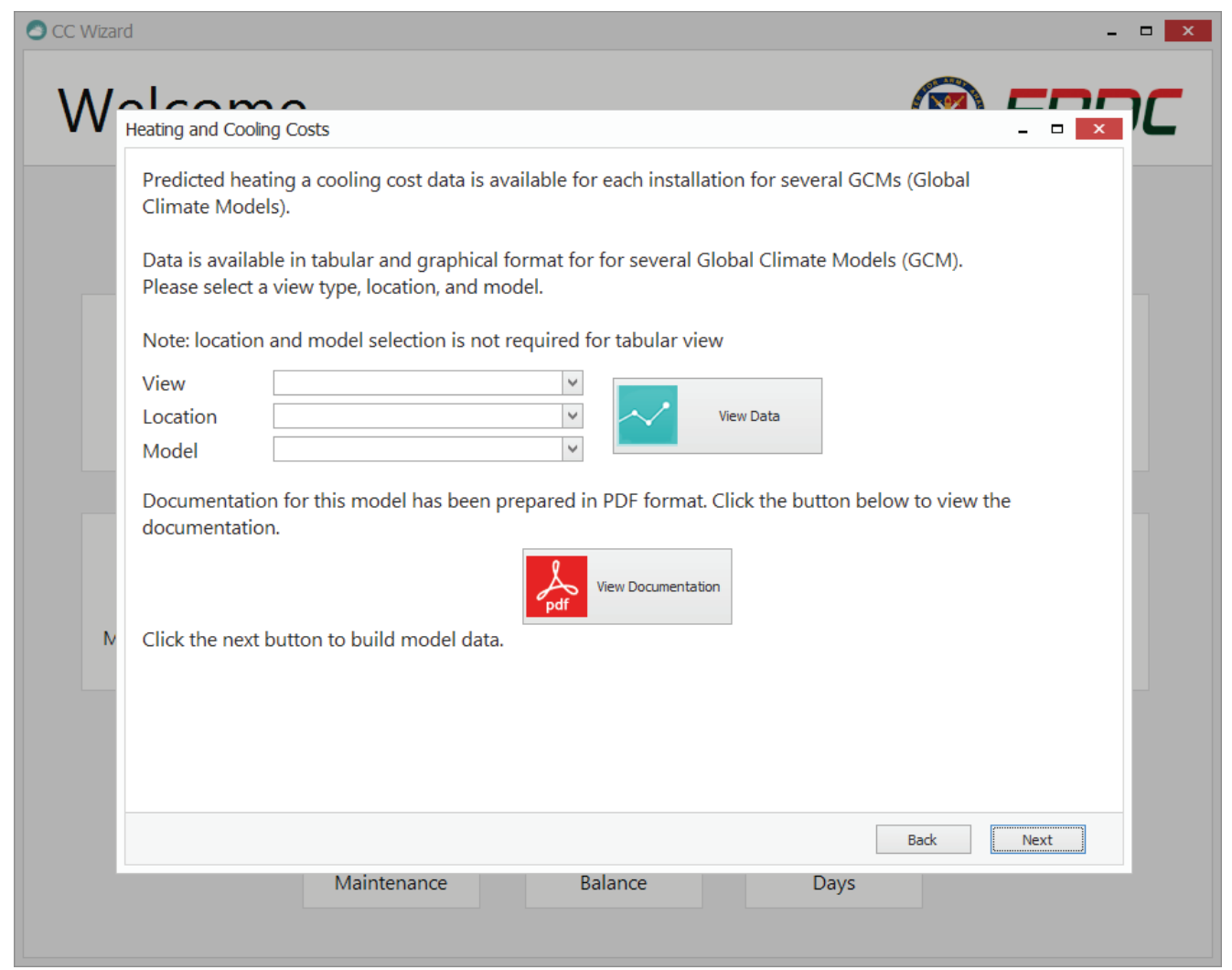

Next, choose a GCM and RCP type from the drop down combo box to filter only data related to that GCM/RCP (Figure 53). At the time of publication, there are nine GCMs within the dataset for this model. RCP 2.6, 4.5, and 8.5 were chosen to represent lower bound, middle, and upper bounds for each GCM. Each GCM contains these RCPs, with the exception of CNRM and GFDL.

Finally, choose a DoD location from the drop down box to filter only data associated with a particular location. Once all three of the choices are made, click the View Data button to launch the chart viewer window (Figure 54). 
Figure 54. Results in the chart viewer window.

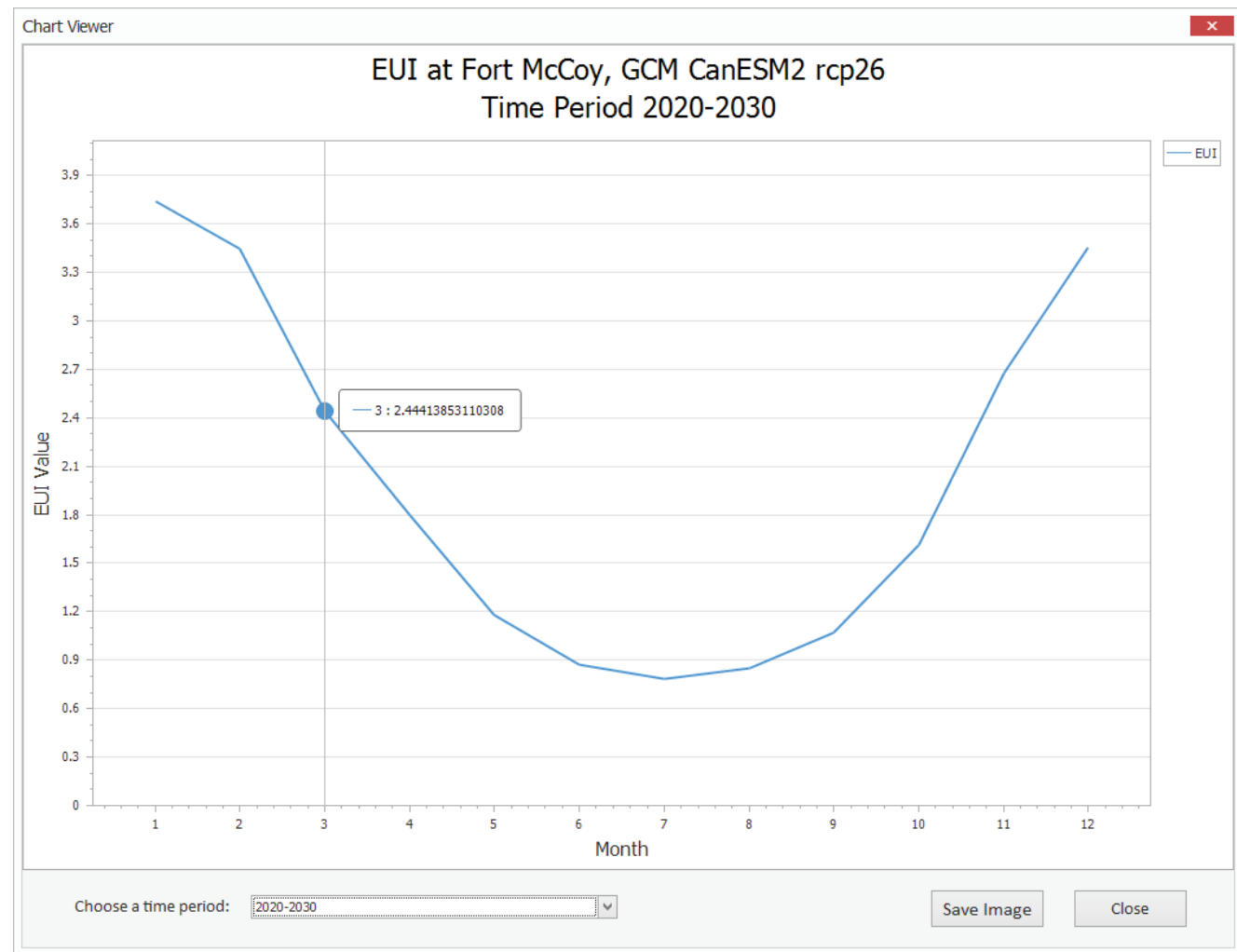

The average EUI is plotted as a line graph with the average EUI value on the $\mathrm{Y}$-axis, and 12 months plotted on the $\mathrm{X}$-axis (Figure 54). The user can change the charted values by choosing a 10-year epoch up to 2100 from the drop down box near the bottom left of the window. Upon selecting an epoch, the data will automatically filter to include 12 months of average values over the chosen 10-year period.

Charts may be saved to the user's computer by clicking the Save Image button near the bottom right of the window (Figure 54). The resulting file is saved to a location of the user's choosing in the universal JPEG image file format.

New datasets are built within the models Wizard interface on its final screen. On this screen, there are instructions and a button that starts the data building process (Figure 55). Output from the build process is displayed in the box below the button. 
Figure 55. Heating and Cooling Cost Model final screen.

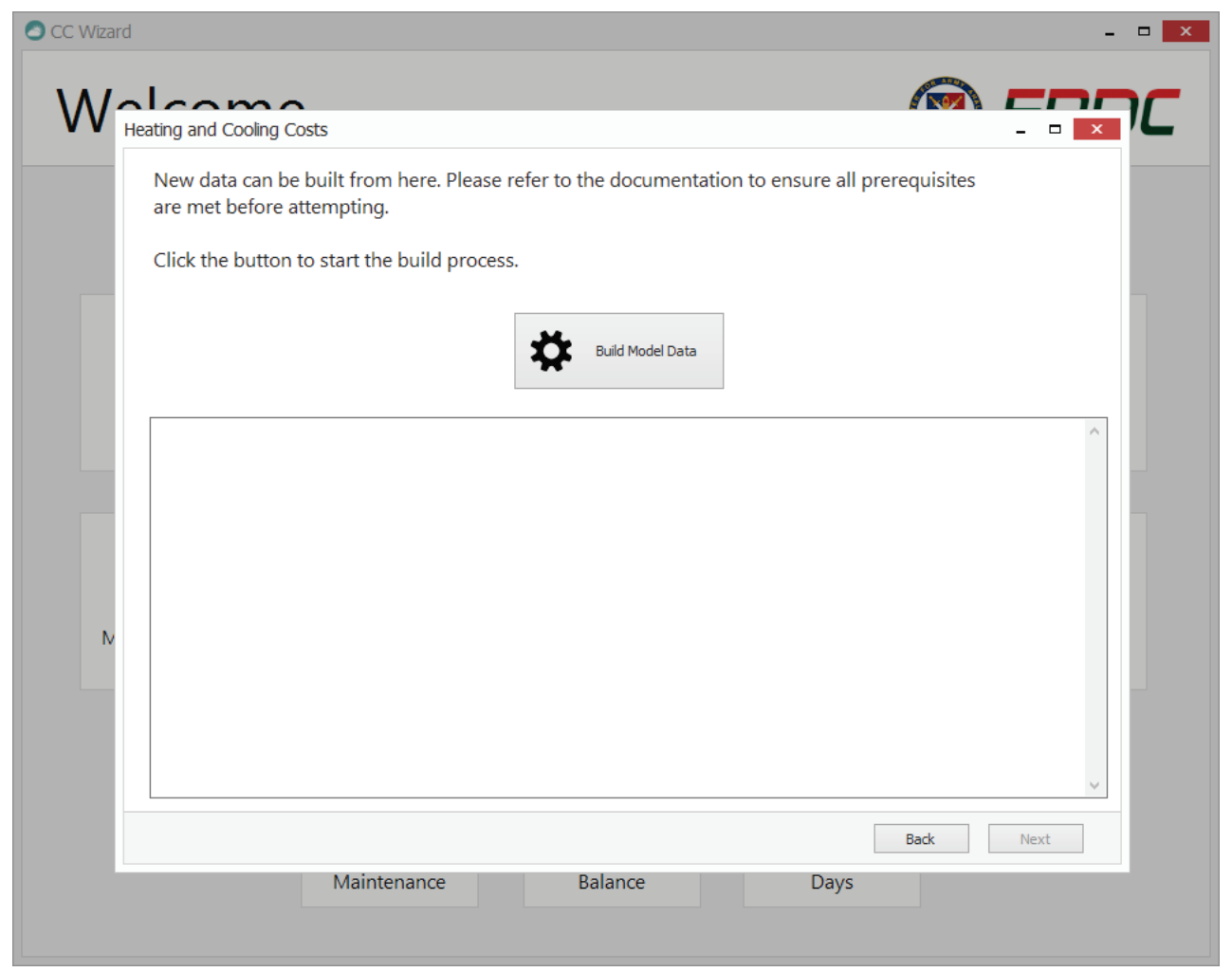

Before attempting the build process, there are a few prerequisites that must be verified.

First, the build process requires historical inputs to exist for each location. These inputs also have their own build process. The local path to these inputs on the VM is $\mathrm{C}: \backslash$ Models $\backslash$ Heating-Cooling-Cost $\backslash$ Historic Output. Inside that folder there are macro-enabled MS Excel ${ }^{\circledR}$ workbooks that are used to build the historical inputs for each location. The reason they are mentioned here is in case a user wants to view the historical data, but under no circumstances should these files be modified. Simply ensure these file exist prior to running the build process.

Second, the local folder $C: \backslash$ Model $\backslash \backslash T e m p-P r e c i p-$ Projections $\backslash$ Output $\backslash$ Monthly $\backslash$ Summary must be populated with future climate data stored in CSV files for multiple GCMs prior to attempting the build process. Check this folder and ensure those files exist. If the files do not exist, they must be built using another process. Please refer to the documentation for the Temperature and Precipitation Model for instructions on how to build execute that model to produce the required data files. 
Lastly, the future output data is placed in a folder with the following local path: C: \Models $\backslash$ Heating-Cooling-Cost $\backslash$ Future Output. This folder must be emptied prior to running the build process to ensure the integrity of the output data.

It should be noted that the build process can be quite lengthy, and patience should be observed. Also, monitor the output box during execution to recognize any repeating errors that may indicate a missing prerequisite.

As mentioned previously, historical data has already been processed and should not need to be reprocessed for the current locations that are being analyzed. This process will be required for new locations. The paragraph below describes the steps for processing historical data for new locations.

Historical data for each desired installation must be obtained from the Army Energy and Water Reporting System (AEWRS) by logging into the system at http://army-energy.hqda.pentagon.mil/ and from the National Climatic Data Center (NCDC) CLIMATE DATA ONLINE website available at http://www7.ncdc.noaa.gov/CDO/cdoselect.cmd?datasetabbv=GSOD\&resolution=40. Data for installation square footage, energy usage, and Global Surface Summary of the Day (GSOD) weather data must be downloaded and saved to these folders on the VM in the CSV file format:

- C: $\backslash$ Models $\backslash$ Heating-Cooling-Cost\Data \SqFt Files

- C: Models $\backslash$ Heating-Cooling-Cost\Data\Utilities Files

- C: $\backslash$ Models $\backslash$ Heating-Cooling-Cost\Data \GSOD Weather Data

A template file located at $\mathrm{C}: \backslash$ Models $\backslash$ Heating-CoolingCost $\backslash$ Historic Output $\backslash$ Template.xlsm must be used to import and process the data for new installations. This file contains MS Excel ${ }^{\circledR}$ data connections on each tab that must be refreshed and pointed to the new downloaded data files (Figure 56). 
Figure 56. Data connections function in MS Excel ${ }^{\circledR}$.

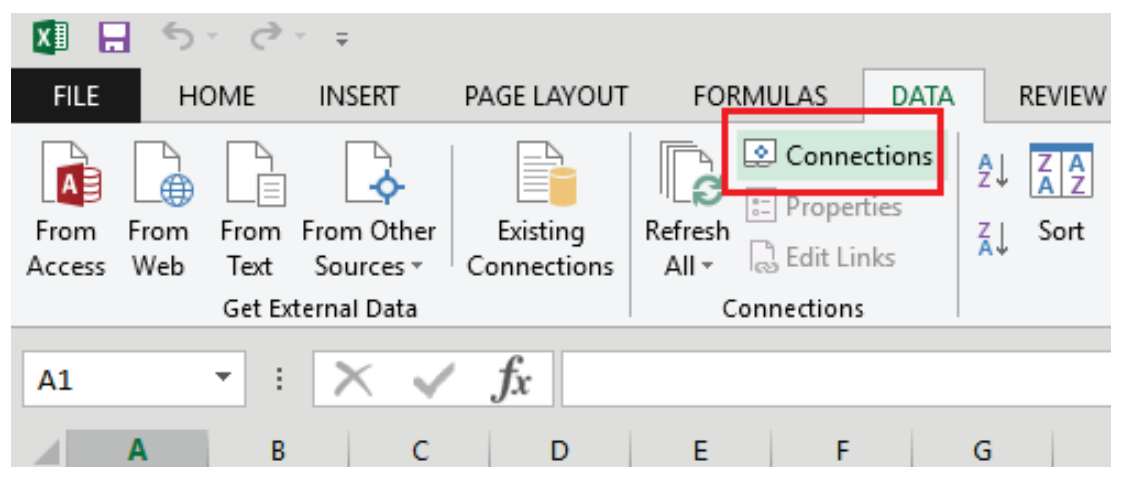

Also, on each tab inside this file there are buttons that need to be clicked to run VBA code that parses, averages, and formats the newly refreshed data. There are buttons for calculating Million British Thermal Units (MMBTU), Kilo Square Feet (KSF), Weather, and EUI. Only installations that have future weather data available from the Temperature and Precipitation model can be evaluated by the Heating and Cooling Cost model. If additional locations are required that do not have future weather data already processed, then those locations must be processed through the Temperature and Precipitation Model prior to attempting to process them through this model. Please refer to the documentation for the Temperature and Precipitation Model in Section 4.1 for instructions on how to process those locations.

\subsubsection{Known issues and limitations}

For purposes of the study, a number of significant simplifying assumptions were employed in the analysis.

\subsection{Regional Water Balance Model}

The combination of shortsighted planning and global climate change has resulted in an imbalance in U.S. freshwater resources, (e.g., too much water in some regions and not enough in others). Better information on how climate change will affect different regions in the United States is needed to guide the U.S. Army in making effective decisions on how to properly adapt to climate change.

The Water Balance Model attempts to predict how the balance of freshwater resources is likely to shift as a result of climate change by calculating those shifts based on several climate scenarios for various DoD installations. It accepts data values associated with watershed, runoff, 
water usage, and water replenishment. The calculated water balance forecast is intended to be used in other force stationing analysis applications as an MVA attribute.

This model also makes use of the predicted precipitation values that are the output of the Temperature and Precipitation Projections Model discussed previously. Those outputs are required to be present in the VM prior to executing this model.

\subsubsection{Capturing the current state}

The Regional Water Balance Model was received as an ESRI ArcMap project, a MS Access ${ }^{\circledR}$ Database, and a Stella Model project. The ArcMap projects perform data preprocessing. The actual calculation of water balance for various DoD installations is performed by the Stella modeling application. Data associated with watershed, runoff, water usage, and water replenishment is stored in an Access database that uses queries to combine and sort the input values.

Software requirements for the Regional Water Balance Model include ESRI ArcMap 10.3.1, Stella 10.0.6, MS Access ${ }^{\circledR}$ version 2013 or higher, and an internet connection and internet browser. A working knowledge of ArcMap, Stella, and Microsoft Office products is recommended as well as a basic understanding of accessing websites and downloading files from the internet.

Executing the model is a multi-step process that requires using ESRI ArcMap and MS Access ${ }^{\circledR}$ applications. Each step for viewing and building data sets is thoroughly documented in the following sections to limit user confusion and ensure accurate results.

\subsubsection{Integrating into the Wizard}

There are two parts to the Regional Water Balance Model: viewing the output data and building new output data. Pre-built datasets for this model were not completed prior to the end of this effort. Normally, the outputs are accessible within the VM in a MS Excel ${ }^{\circledR}$ spreadsheet. Future data builds will result in output in this format. The Wizard application does not have the ability to automatically locate and launch the output file, so this has to be done manually. 
The procedure for building new data consists of three steps, each of which can be launched automatically from the final Water Balance Model screen (Figure 57).

Figure 57. Regional Water Balance Model final screen launch buttons.

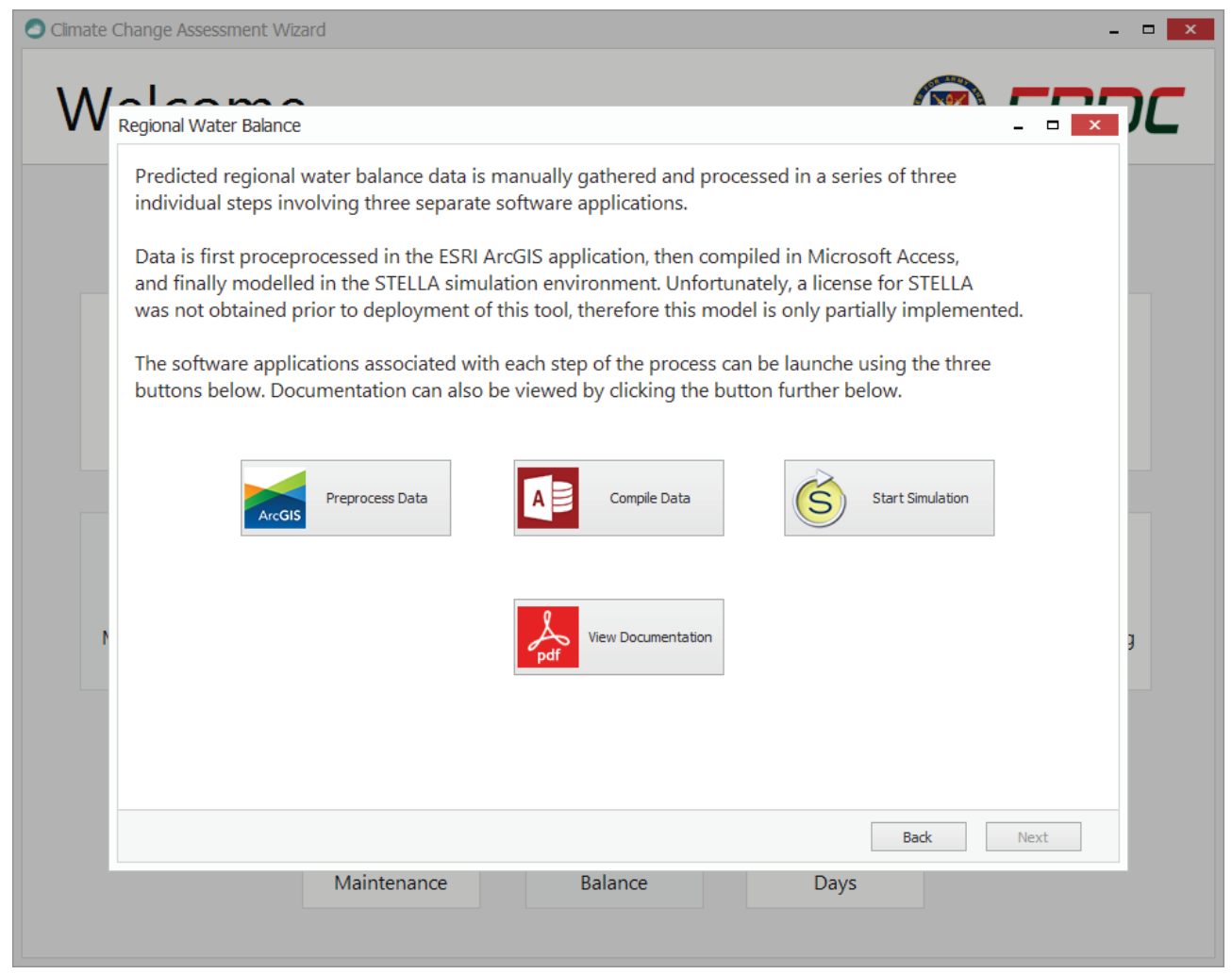

First, raw input data must be preprocessed in ESRI ArcMap (Figure 58). These inputs as described previously were collected from various online resources that were not disclosed during the capturing of this model. Refer to the Additional Assistance information in Chapter 5 for more information on where and how to acquire these input data files.

Start the data preprocessing by launching ArcMap from the wizard by clicking the Preprocess Data button in the Wizard, or access it manually from the Windows start menu within the VM. 
Figure 58. ESRI ArcMap start screen.

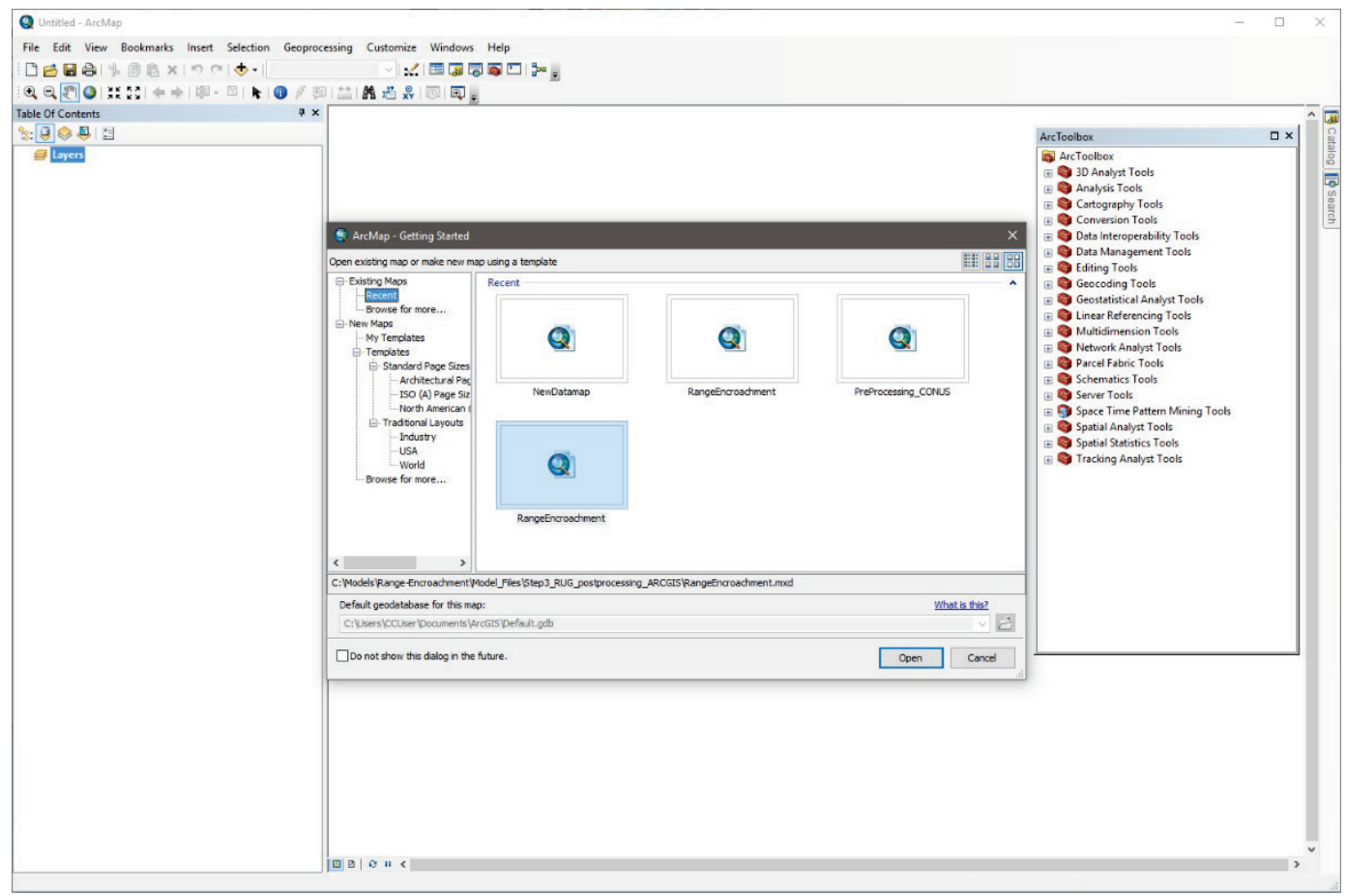

Open the NewDatamap model file located at C: \Models $\backslash$ WaterBalance $\backslash$ Model

Files \Step1_ArcGIS_Data_Prep \NewDatamap.mxd. This model can also likely be opened from the list of recent models in ArcMap as shown in Figure 58. Once the file loads, open the toolbox viewer by clicking the Toolbox menu bar icon . Add the WASP_Preparation toolbox by right clicking ArcToolbox at the top of the viewer then clicking Add Toolbox. The toolbox file is located at $\mathrm{C}: \backslash$ Models $\backslash$ WaterBalance $\backslash$ Model Files \Step1_ArcGIS_Data_Prep \WASP_Preparation.tbx. Expand the newly added toolbox by clicking the plus sign to the left to show the models inside. Open the 1 . Create Output .gdb model by right clicking it, then choosing Edit. Inside the editor, click the Run menu bar icon . The model will prompt for a location to save the output geodatabase. Provide the output location $\mathrm{C}: \backslash$ Model $\backslash \mathrm{S} \backslash$ WaterBalance $\backslash$ Model Files $\backslash$ Step1_ArcGIS_Data_Prep folder \Output, then click OK to create the geodatabase.

Next, exit the editor then edit the 2. WASP Data Preparation USE model. Choose the location of the Data Folder ( $\mathrm{C}: \backslash$ Models $\backslash$ WaterBalance $\backslash$ Model Files $\backslash$ Step1_ArcGIS_Data_Prep \Data). Click the 
Run icon within the editor to run the model. If the model fails to run, file links have most likely been broken and further assistance will be required to continue. Refer to the Additional Assistance information in Chapter 5 .

Step two of the process is to compile the data in MS Access ${ }^{\circledR}$. MS Access ${ }^{\circledR}$ can be launched automatically from last model screen by clicking the Compile Data button as illustrated previously, or access it manually from the Windows start menu within the VM. Open the database file $\mathrm{C}: \backslash$ Models $\backslash$ Water-Balance $\backslash$ Model Files $\backslash$ Step2_Access_Database $\backslash 112116$ Access.accdb. Once the database is opened, confirm the following output files from ArcGIS are properly linked in the MS Access ${ }^{\circledR}$ database by refreshing them in the Linked Table Manager (Figure 59). If links are not correct, a prompt will request the path to the linked files (Figure 60). All linked files are located at $\mathrm{C}: \backslash$ Models $\backslash$ Water-Balance $\backslash$ Model Files $\backslash$ Step2_Access_Database $\backslash$ Access_Linked_Data.

Figure 59. Linked table manager menu button.

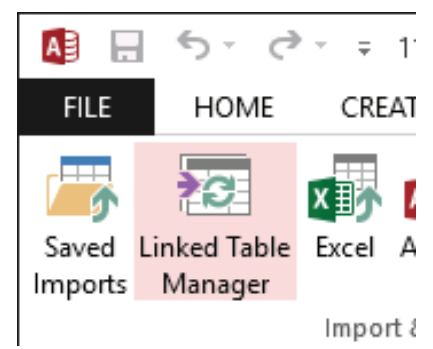

Figure 60. Linked table manager window.

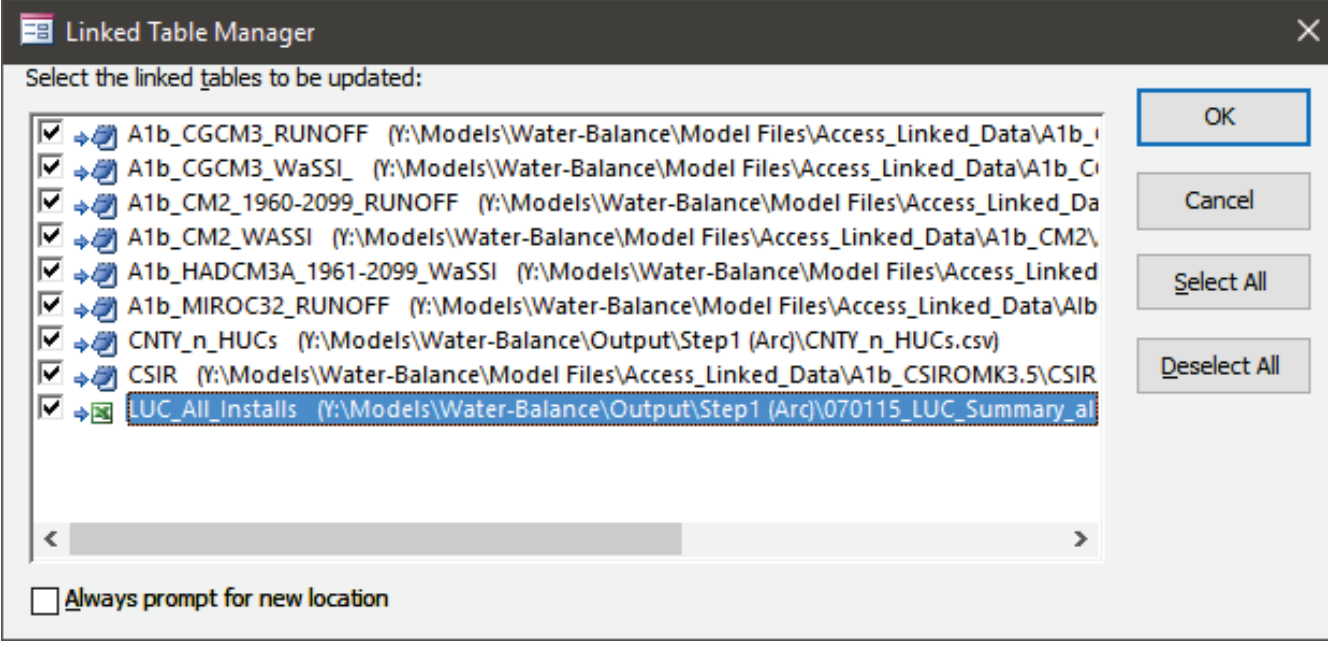


Locate the Queries section of the All Access Objects panel on the left hand side of MS Access ${ }^{\circledR}$ (Figure 61). The 0826_CNTY_Water_Use query contains a field used to identify a particular DoD location and must be modified for each installation by entering Design View. The Fort field criteria must be changed to match one of the Fort names stored within the various tables (Figure 62). Available fort locations at the time of publication are Bliss, Bragg, Drum, Lewis, and Riley.

Figure 61. Query design view menu button.

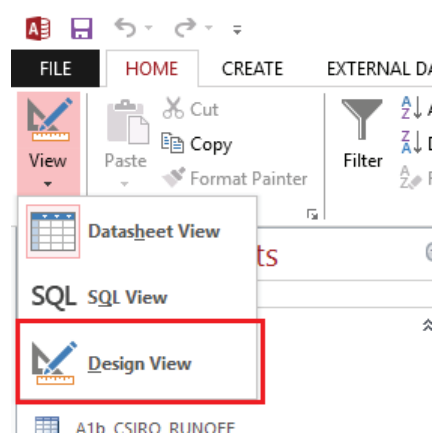

Figure 62. Modify the Fort field criteria.

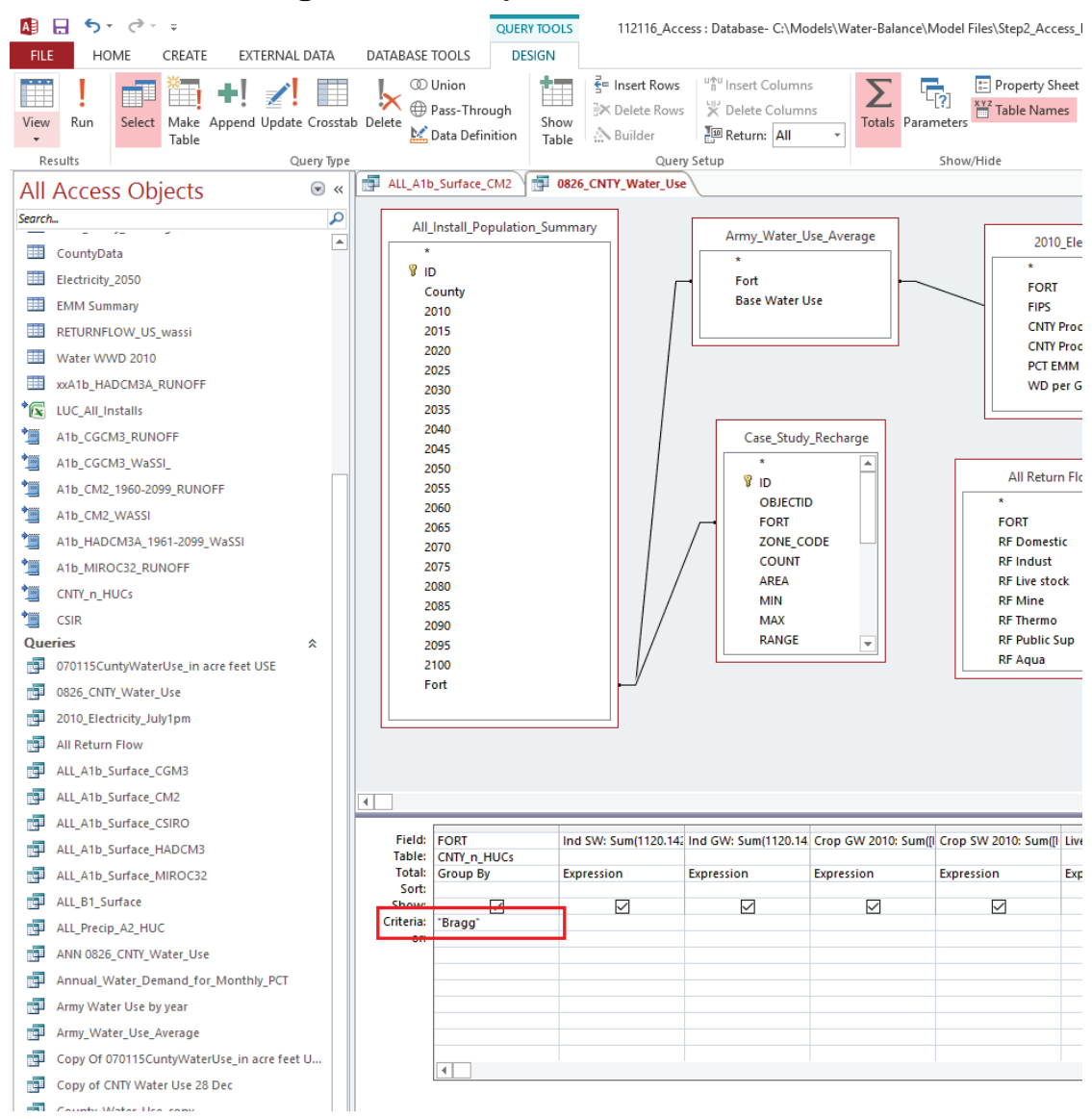


Run the following list of queries one at a time for each of the installations by double clicking each of them in the Queries section, or by clicking the Run button in the top menu (the Run button contains a large red exclamation mark icon). Export the results from each query as a MS Excel ${ }^{\circledR}$ (.xlsx) file by using the MS Excel ${ }^{\circledR}$ Export menu button (Figure 63). Save the results in $\mathrm{C}: \backslash$ Models $\backslash$ Water-Balance $\backslash$ Model

\section{Files $\backslash$ Output $\backslash$ Step2 (Access).}

- 0826_CNTY_Water_Use

- ALL_A1b_Surface_CGM3

- ALL_A1b_Surface_CM2

- ALL_A1b_Surface_CSIRO

- ALL_A1b_Surface_HADCM3

- ALL_A1b_Surface_MIROC32

Figure 63. Export query results to Excel.

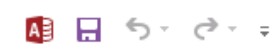

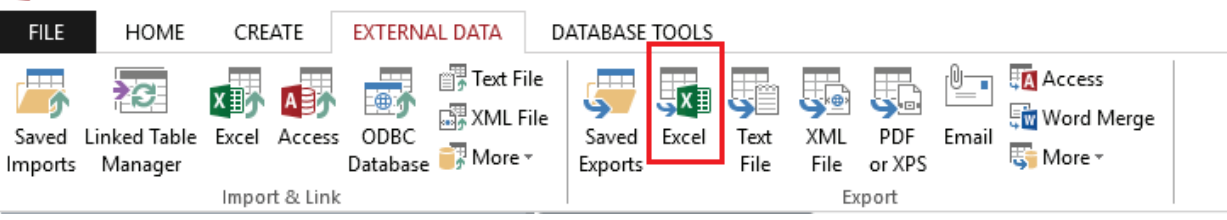

The exported MS Excel ${ }^{\circledR}$ files must be manually combined into a single MS Excel ${ }^{\circledR}$ file for each Fort. Name the combined files with the name of the Fort (e.g., Bliss.xlsx).The following tabs must be included in the combined MS Excel ${ }^{\circledR}$ file:

- Precip_CGMC3

- Precip_CM2

- Precip_CSIROMK35

- Precip_HADCM2

- Precip_MIROC32

- RO_CGM3

- RO_CM2

- RO_CSIROMK35

- RO_HADCM3

- RO_MIROC32

- Month Demand

- Pop

- CNTY Water USE 
The final step in the process is to run the data from MS Access ${ }^{\circledR}$ that is now stored in MS Excel ${ }^{\circledR}$ files through a Stella model (Figure 64). Stella can be launched automatically from last model screen by clicking the Start Simulation button as illustrated previously, or access it manually from the Windows start menu within the VM. Open the model file

$\mathrm{C}: \backslash$ Models $\backslash$ Water-Balance $\backslash$ Model

Files \Step3_Stella $\backslash 0826$ _bragg_working_monthly.stmx. Once the file is opened, link (or refresh existing links) to the combined MS Excel ${ }^{\circledR}$ data in Stella. Each file has to be linked individually per Stella instance. In the Stella menu, go to Edit > Manage Persistent Links For each of the listed tables select EDIT. From there, use the Edit Import Link dialog box where to browse to select the file for the desired installation (Figures 64 and 65). Once the links have been updated, run the model for each of the five Special Report on Emissions Scenarios (SRES) scenarios. This is done by unchecking the ENABLED box next to the SRES scenarios that are not being run. Go to Run > Run and the model will run.

After the model is done running, copy the water sustainment score from the table to a new MS Excel ${ }^{\circledR}$ file. The water sustainment score is a withdrawal-to-availability ratio, which is the monthly water demand (D) divided by monthly water supply (S), hence D/S. D/S values greater than 1 indicate that the demand is outstripping the sustainable supply.

Figure 64. Stella manage persistent links menu item.

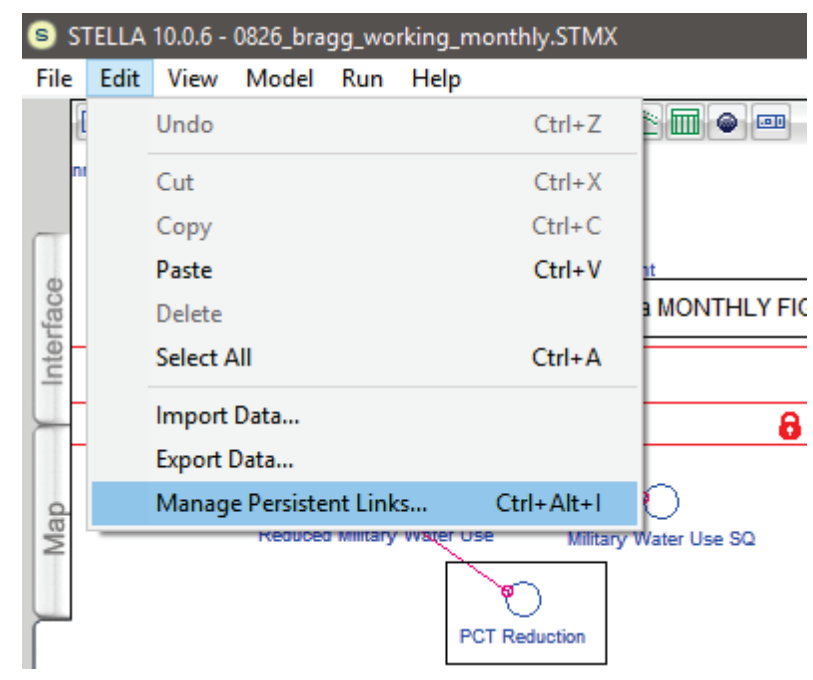


Figure 65. Stella manage persistent links window.

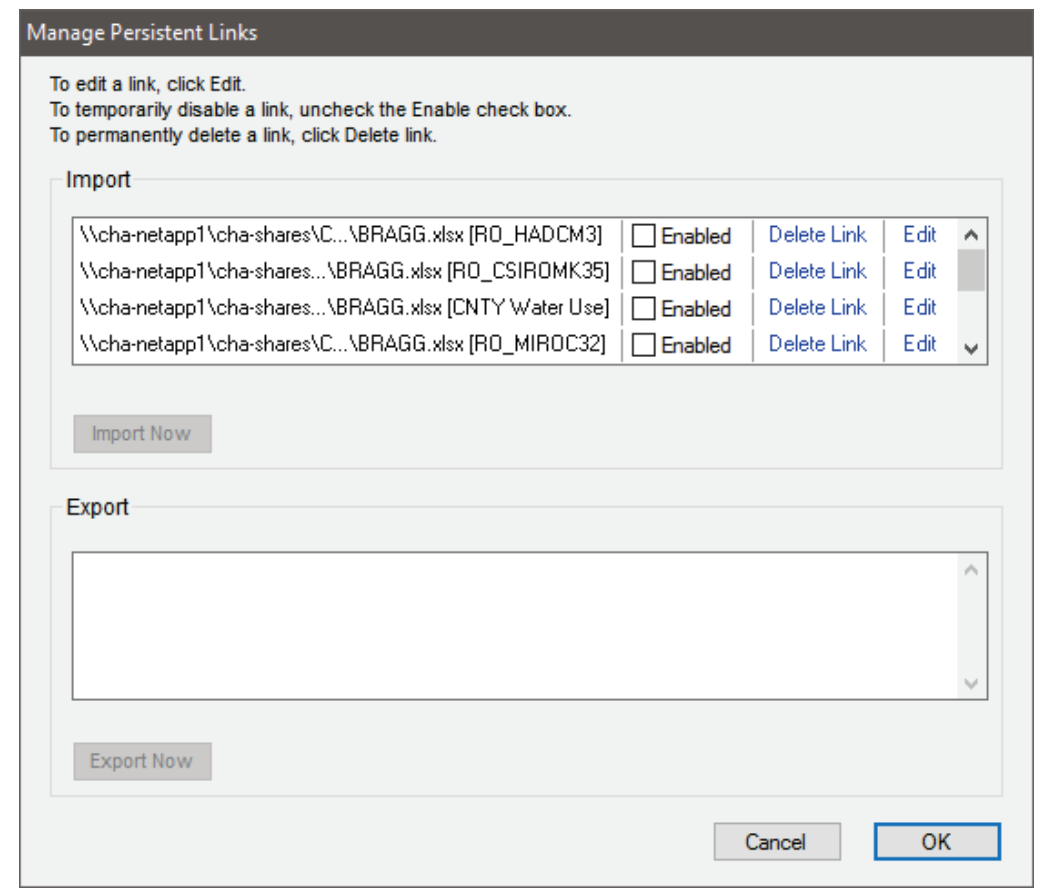

The MVA attribute is calculated within the new MS Excel ${ }^{\circledR}$ file. Using formulas embedded within an MS Excel ${ }^{\circledR}$ spread sheet, the indexed results were grouped into 5-year blocks from 2015-2100 to assess the minimum stress and the maximum stress. A range of the minimum-maximum and the absolute maximum numbers is obtained to better show the worst case scenarios that the five climate models project. For this reason, the analysis focuses on the maximum values. To simplify the analysis, it was assumed that the peaks can occur at any moment within the 5 years, although the value is graphed at the end of the period. To develop the MVA score, the data were weighted on two factors: stress and time levels.

1. Stress Level: The categorical rankings of no stress, low stress, moderate stress, and high stress were applied based on the ratio of D/S. Higher stress was given a higher value. Categorical rankings were selected rather than using the $\mathrm{D} / \mathrm{S}$ ratio because these rankings account for some of the uncertainty present in model outputs, and because more complicated statistics would be required to parse out outliers in stress.

2. Time: Water stress values for the years 2015-2035 were given twice the weight of those from 2040-2100. This was done because the CAA was primarily concerned with a 20-year Net Present Value (NPV). However, projections of the future should be included outside of that range because that will affect future installation capacity. The values for 2015-2035 range 
from zero (o) to 3 and are given according to the water stress category (a value of zero [o] when there is no stress to 3 when there is high stress). While the scores from 2040-2100 range from zero (o) to 1.5.

To obtain the final score for an installation, all of the values are summed and divided by the total possible score. The resulting ratio was then standardized on a scale of zero (o) to 10.

\subsubsection{Known issues and limitations}

Stella Professional has a known bug in version 10.0.6 where the application crashes when exiting, but this does not affect the processing or output data. The crash can be safely ignored.

\subsection{Building Maintenance Model}

The potential cost of increased maintenance on metal buildings due to corrosion caused by climate change is a particularly important factor to consider for force stationing analysts. The Building Maintenance Model attempts to predict corrosion to Army facilities where metal is the primary building material.

The model predicts a corrosion index for various types of metals given a relative humidity value as an input variable that is adjusted for predicted climate change effects for several Army installations. Those corrosion indices are then applied to the identified buildings on each installation using a cost estimation formula to determine the total cost of corrosion for each building. The calculated corrosion cost is intended to be used in other force stationing analysis applications as an MVA attribute.

\subsubsection{Capturing the current state}

The Building Maintenance Model was received as a pair of MS Access ${ }^{\circledR}$ databases. The corrosion database contains VBA code that calculates predicted corrosion values for a given location, precipitation value, relative humidity values, and chloride value. The second database, Headquarters Installation Information System (HQIIS), contains assets known to exist on various DoD installations, and uses queries to identify and sort buildings and other structures whose primary material is corrosive metal. 
Software requirements for the Building Maintenance Model include MS Access ${ }^{\circledR}$ and MS Excel ${ }^{\circledR}$ version 2013 or higher. Data collection prior to model execution requires an internet connection and internet browser.

A working knowledge of Microsoft Office products is recommended as well as a basic understanding of accessing websites and downloading files from the internet.

\subsubsection{Integrating into the Wizard}

There are two parts to the Building Maintenance Model: viewing the output data, and building new output data. Pre-built datasets for this model were not completed prior to the end of this effort. Normally, the outputs are accessible within the VM in an MS Excel ${ }^{\circledR}$ spreadsheet. Future data builds will result in output in this format. The Wizard application does not have the ability to automatically locate and launch the output file, so this has to be done manually.

The procedure for building new data consists of four steps. First, facility data must be collected from the internet. The HQIIS provides access to a database of all assets known to exist on various Army installations. This database includes buildings and facilities that are of interest to this model. Download current and historic databases from the Office of the Assistant Chief of Staff for Installation Managements website at http://www.acsim.army.mil/. Existing copies of the database for FY 15, 16, and 17 are located on the VM at $\mathrm{C}: \backslash$ Models $\backslash$ BuildingMaintenance $\backslash$ Model.

The second step in this model is to build a scenario inside the Corrosion Model Database. The database is located within the VM at $\mathrm{C}: \backslash$ Models $\backslash$ BuildingMaintenance \Model \CorrosionModel_v101107_nl_2024. The database may be launched from the Wizard by clicking the Building Maintenance icon from the start screen, then clicking the Open Corrosion Database button on the second model screen (Figures 66 and 67). 
Figure 66. Building Maintenance icon on the home screen.

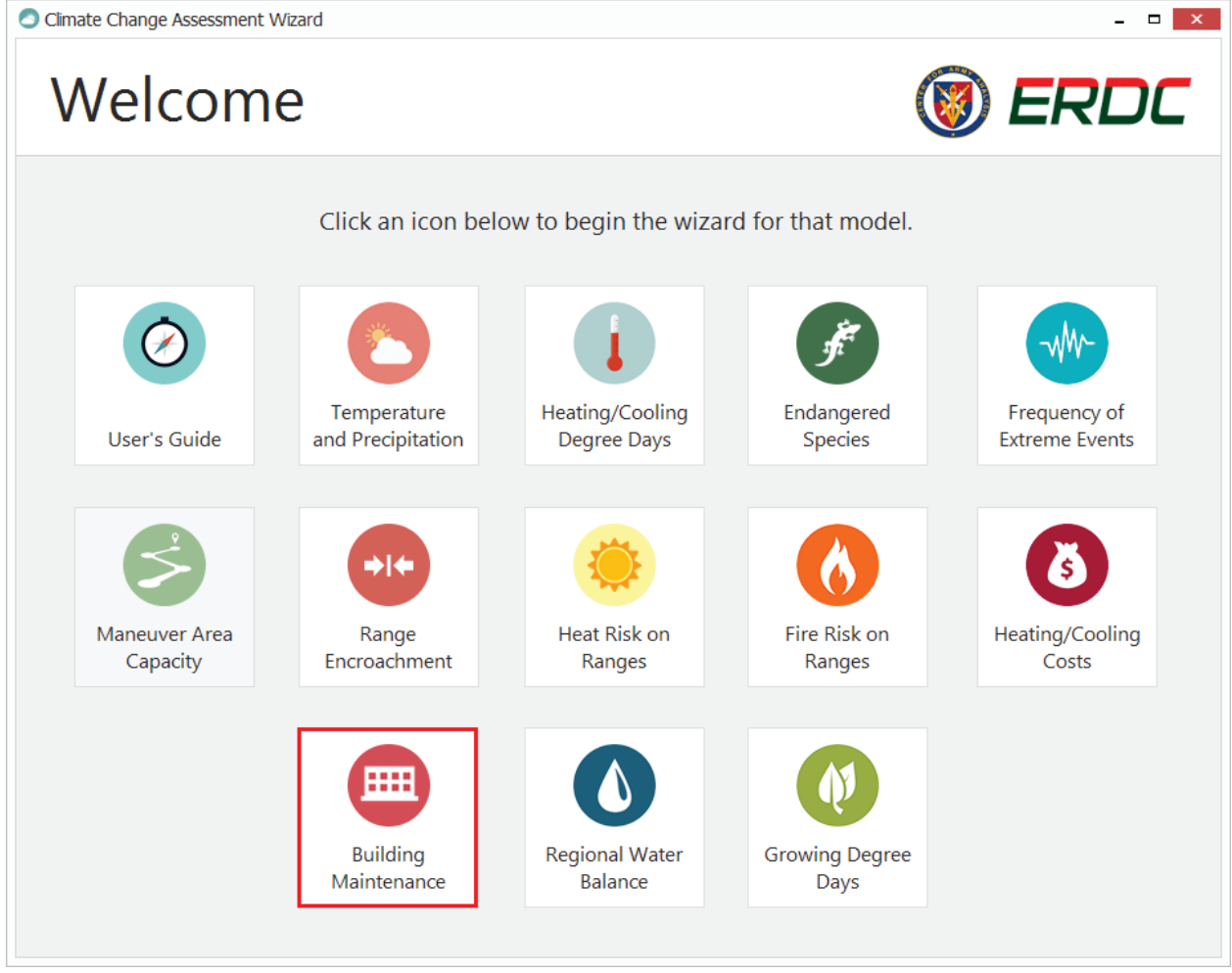

Figure 67. Open the corrosion database.

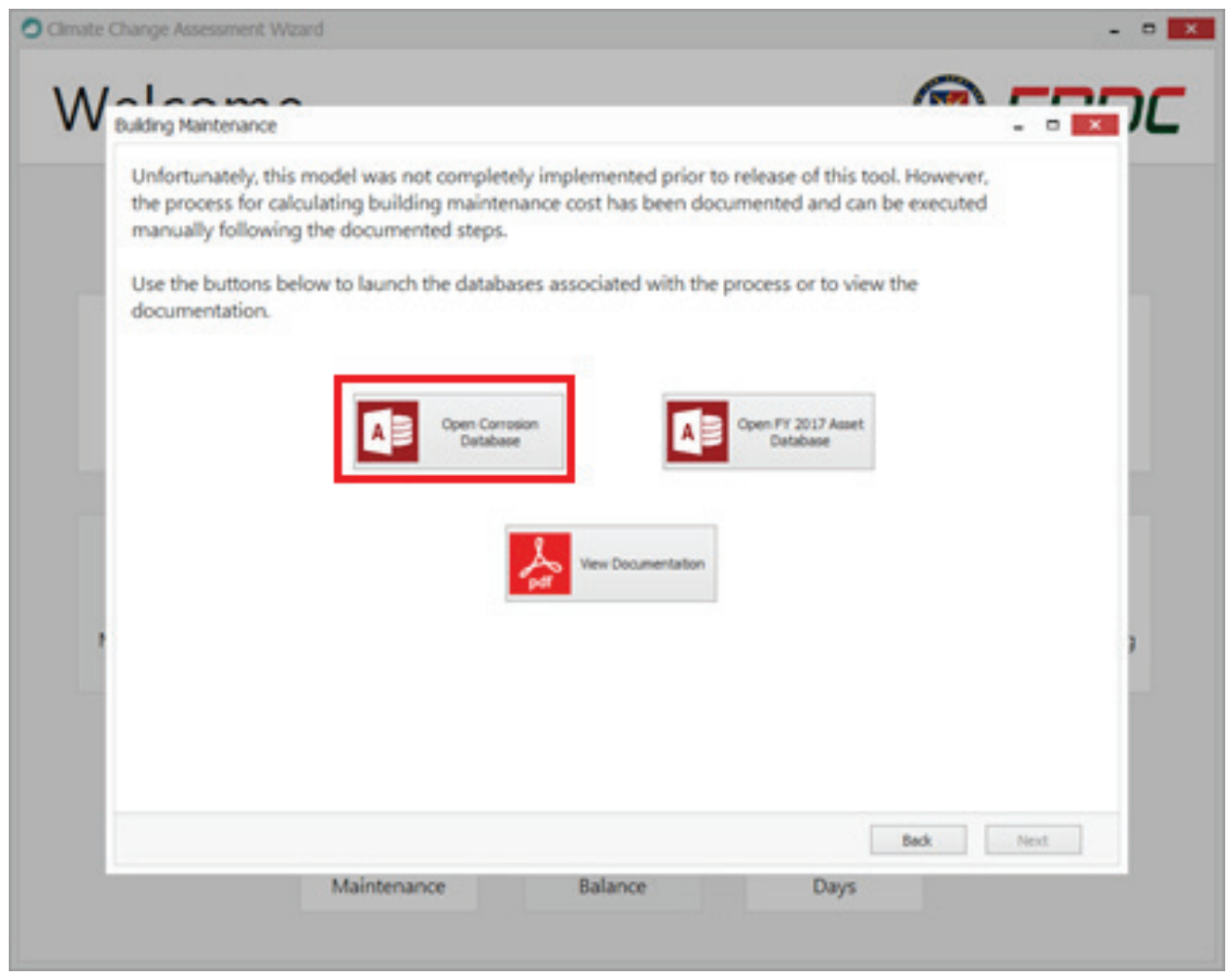


Once the Corrosion Model database has been launched, click the Build Scenario button within the start screen (Figure 68).

Figure 68. Corrosion Model database start screen.

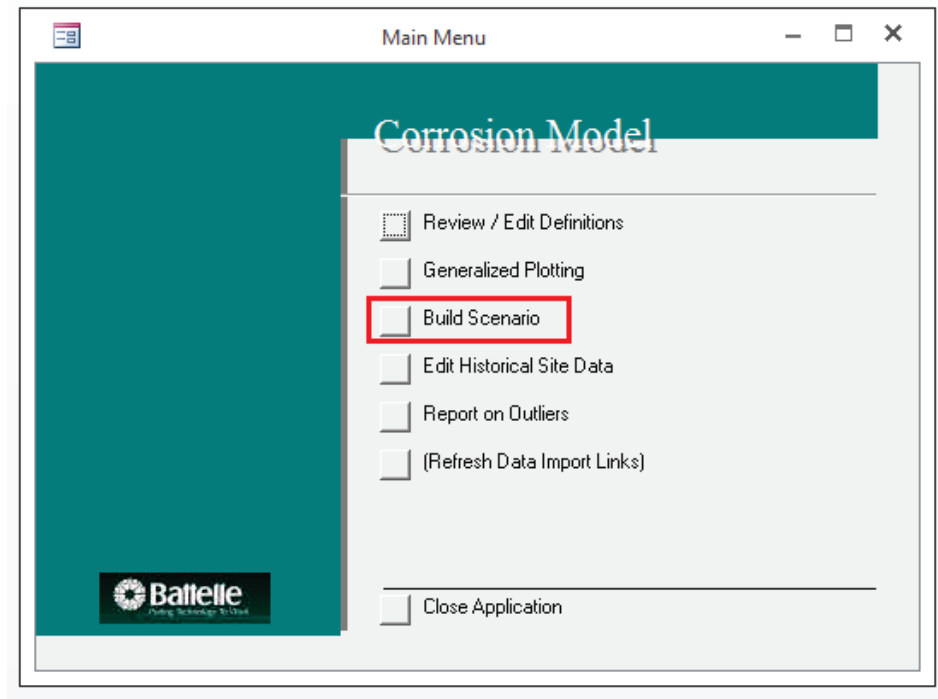

For each location analyzed, required inputs for the scenario are 12-month weather data variables for precipitation, $\mathrm{RH} 70, \mathrm{RH} 80, \mathrm{RH} 90$, and chloride, where RH stands for Relative Humidity. This data should be calculated in a separate effort, preferably in a spreadsheet, then copied manually into the model. The following equations should be used to calculate relative humidity, where $t=$ wet bulb temperature and $t d=$ dry bulb temperature (DBT).

\subsubsection{Relative humidity formulas}

$$
\begin{gathered}
R H \approx 100-\beta_{2}\left(t-t_{d}\right) \\
\beta_{2}=\frac{L(R H-100)}{R_{w} T T_{d} \ln \left(\frac{R H}{100}\right)}=\beta_{1}\left(\frac{\left(\frac{R H}{100}-1\right)}{\ln \left(\frac{R H}{100}\right)}\right)
\end{gathered}
$$

Equation 1 is further defined by Lawrence (2005). The document is located within the VM at $\mathrm{C}: \backslash$ Models $\backslash$ BuildingMaintenance $\backslash$ Documentation $\backslash$ BAMS-86-2-225.pdf.

Precipitation values should be acquired from the Temperature and Precipitation model, which is accessed within the Wizard by clicking the 
Temperature and Precipitation icon from the Wizard start screen. Refer to the user guide for that model for more information on how to obtain precipitation values. The guide is located on the $\mathrm{VM}$ at $C: \backslash$ Models $\backslash$ Help-Documents $\backslash P D F \backslash T e m p$ Precip User Guide.pdf.

Use the calculated RH values and acquired precipitation values for the location to be analyzed to build the scenario. Once the scenario is properly built, click the Run Prediction Model button to calculate a corrosion index value. This value will be used in the final step of the process (Figure 69).

Figure 69. Corrosion scenario built and run.

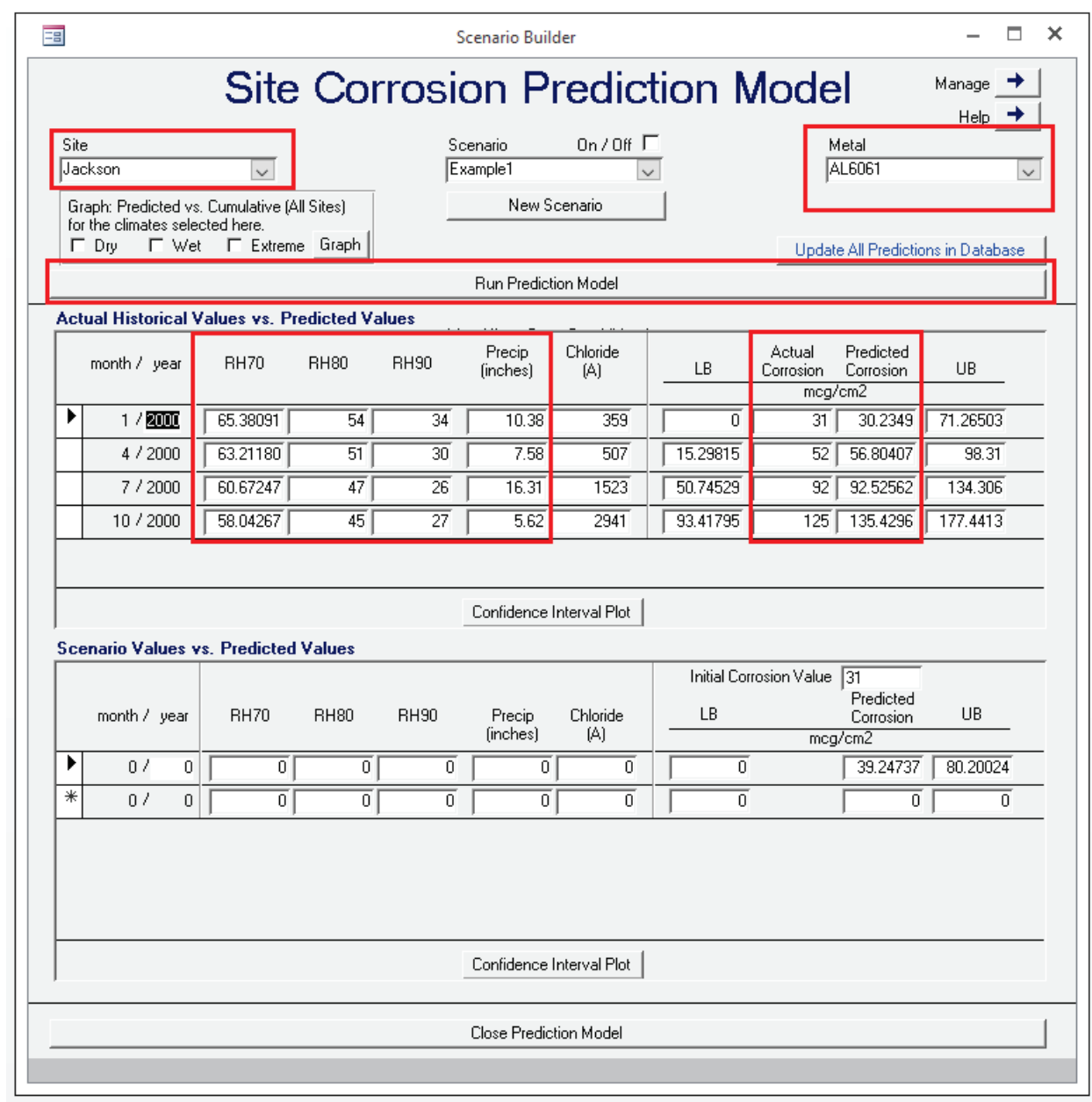

A predefined query is stored within the HQIIS databases. The third step in this model consist of executing that query to isolate asset data that is relevant to the installations that are being analyzed. The database for FY 17 can be launched from the Wizard by clicking the Open FY 2017 Asset Database button on the second model screen (Figure 70). 
Figure 70. Open FY 2017 HQIIS database.

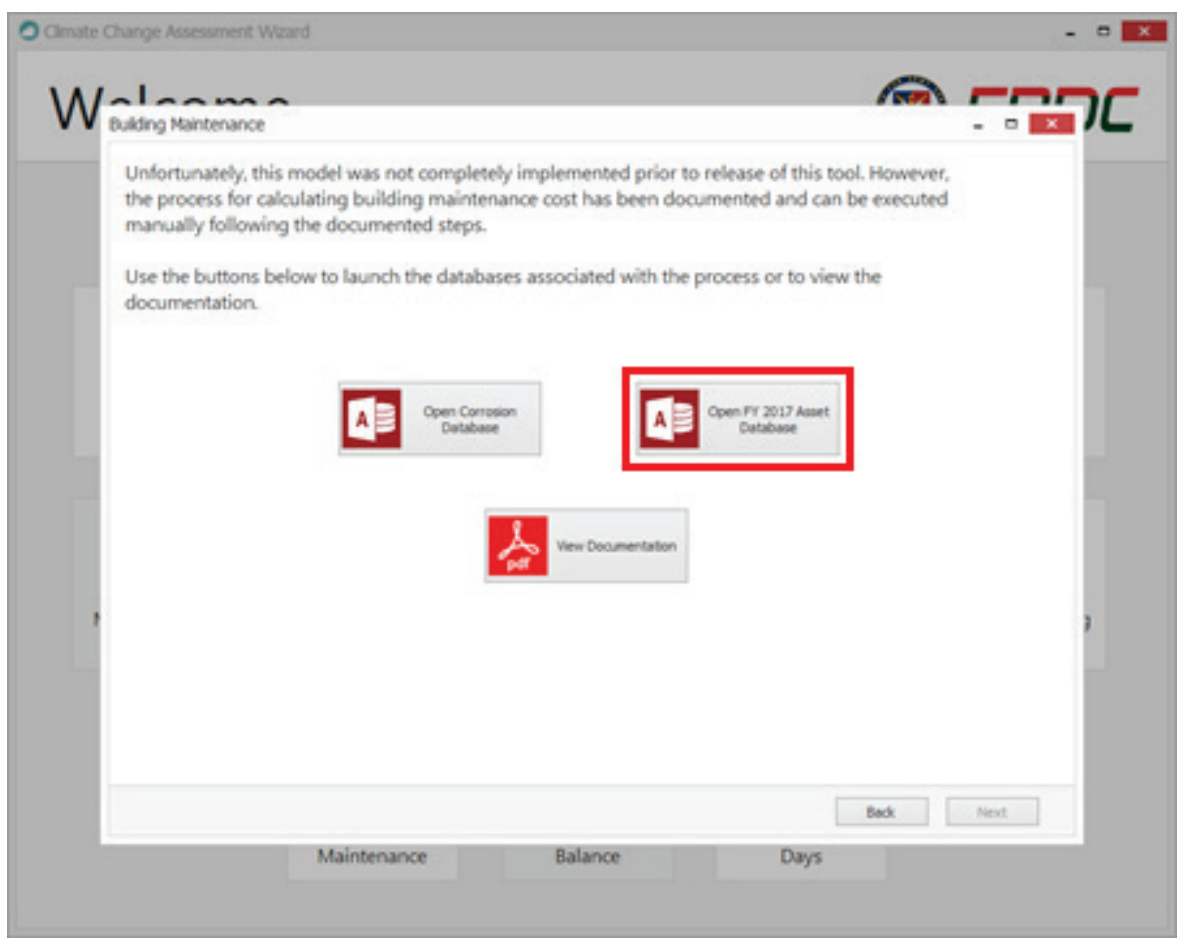

A predefined query named qryCC_nonzero is stored within the database. Run the query by double clicking it in the left side panel (Figure 71).

Figure 71. Execute the query by double clicking it.

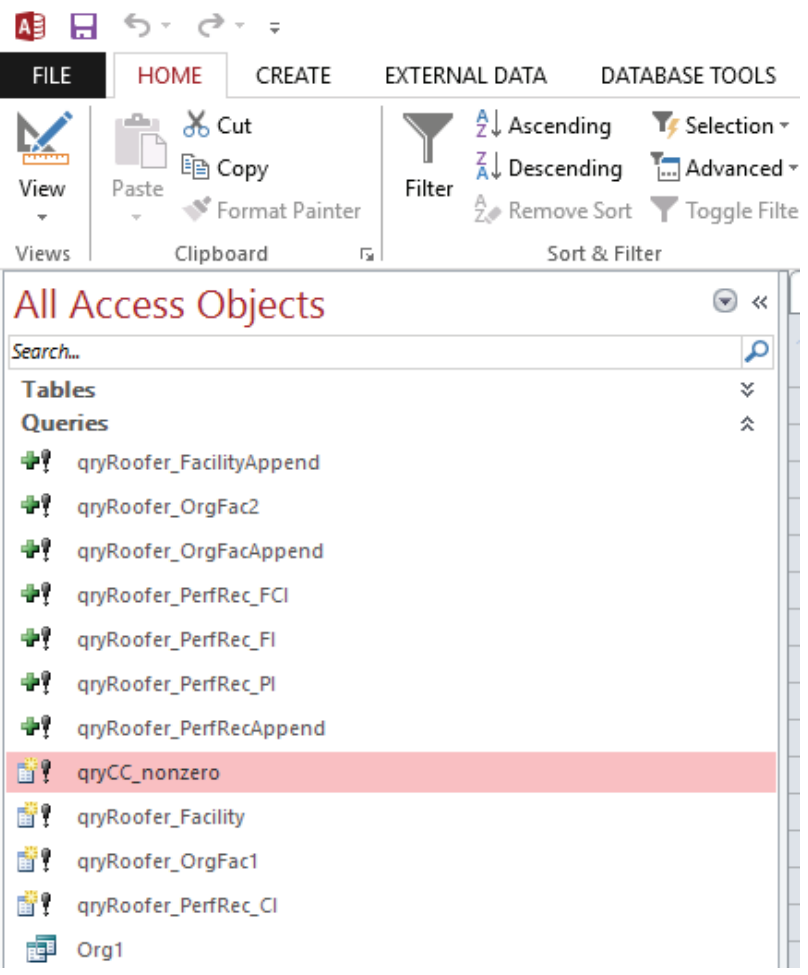


A new table named CC_CCFACCC_nonzero will be created with the query results. Within that table are all the assets of interest to the model for every installation in the database. To filter the results to just the site of current interest, identify the site ID by opening the SITES table. Look through the SITE_NAME field to locate the site of current interest and identify the SITE_UID associated with that site. Use that SITE_UID to filter the results in the CC_CCFACCC_nonzero table by using the filter down arrow as illustrated in Figure 72.

Figure 72. Use the filter to limit results to the site of current interest.

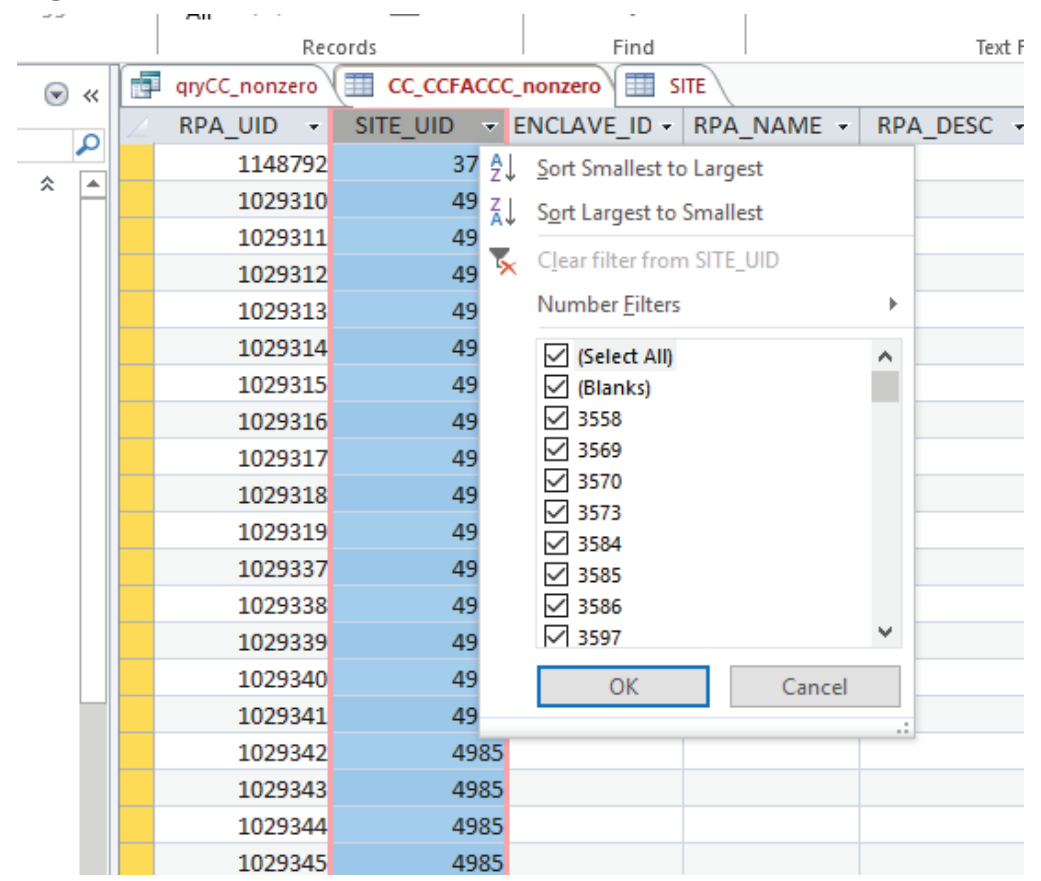

Use the External Data tab in MS Access ${ }^{\circledR}$ to export the filtered results from table CC_CCFACCC_nonzero to an MS Excel ${ }^{\circledR}$ spreadsheet in preparation for the next step (Figure 73).

Figure 73. Export filtered table to Excel spreadsheet.

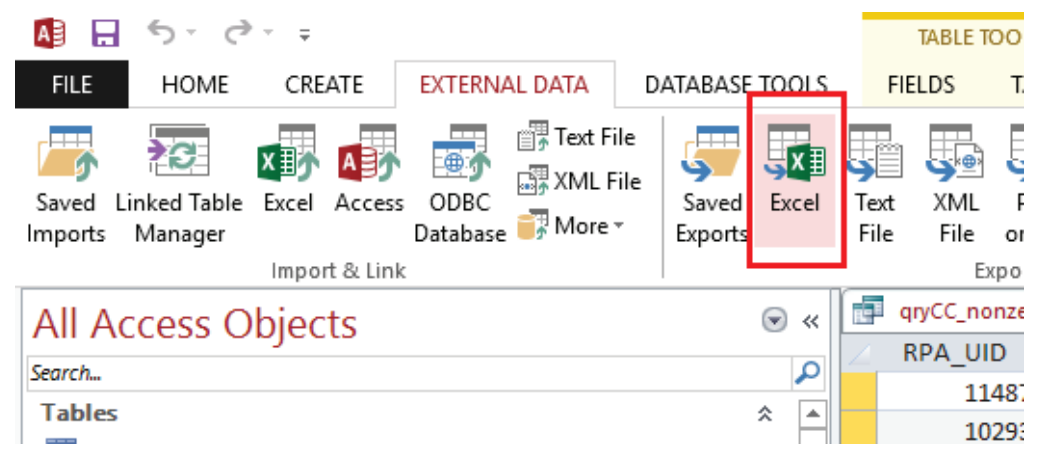


The final step in the process is to perform a simple mathematical calculation to determine the total sustainment cost of corrosion. In two empty cells outside of the main data columns in the spreadsheet created previously, enter the actual and predicted corrosion costs from step one for the appropriate installation. Next, add an additional column to the spreadsheet data and enter a formula to multiply the ratio of the actual vs. predicted corrosion values times the SUS_CC column. For example, if the actual corrosion value is in cell F2, predicted corrosion value is in cell G2, and SUS_CC is column D, the formula may look like this: $=($ F2 / G2 $){ }^{*}$ D2. Copy that formula down to the last row of data using the cell fill handle. The value generated from this calculation is the predicted sustainment cost MVA attribute.

Repeat this entire process for each DoD installation to be analyzed.

\subsection{Growing Degree Days Model}

Growing degree days (GDD) is a weather-based indicator related to heat accumulation from air temperature for assessing the suitability for growing plan life in a specific region. The growing of vegetation on training ranges is important to the potential increase or decrease of usefulness of those ranges. For example, an installation that experiences a greater number of days suitable for growing of plant life may have an advantage over one that does not due to the fact that training ranges have the potential to remain operational more often when vegetation is able to recover from various training exercises. Assessing the impact of future climate change is an essential part of ensuring future availability of maneuver ranges.

The model attempts to predict the number of GDD that will occur in the future based on future climate projections for various DoD installations and provide some insight into the installations potential to grow and regenerate plant life on its training ranges. The predicted effect of climate change on GDD is intended to be used in other force stationing analysis applications as a MVA attribute.

\subsubsection{Capture the current state}

The GDD Model was received as a script written in the Python programming language. In fact, it uses the Python script previously described in Section 4.2. Each step for viewing the computed data is 
thoroughly documented in the following sections to limit user confusion and ensure accurate results.

Software requirements for the GDD Model include the Python IDLE development environment, a basic text editor such as MS Notepad ${ }^{\circledR}$, and Microsoft MS Excel ${ }^{\circledR}$ version 2013 or higher.

A working knowledge of Microsoft Office products is recommended as well as a basic understanding of editing file paths in a text file and executing Python code within the IDLE environment.

\subsubsection{Integrate into the Wizard}

There are two parts to the GDD Model: viewing the output data and building new output data. Pre-built datasets for this model were processed using daily values from the Temperature and Precipitation Projections Model and are stored within the VM. The ability to view this output data is built in to the Wizard application.

After launching the Wizard from the VM desktop, the GDD Model is launched by clicking the icon from the Wizard dashboard screen (Figures 74 and 75).

Figure 74. Growing Degree Days (GDD) Model icon.

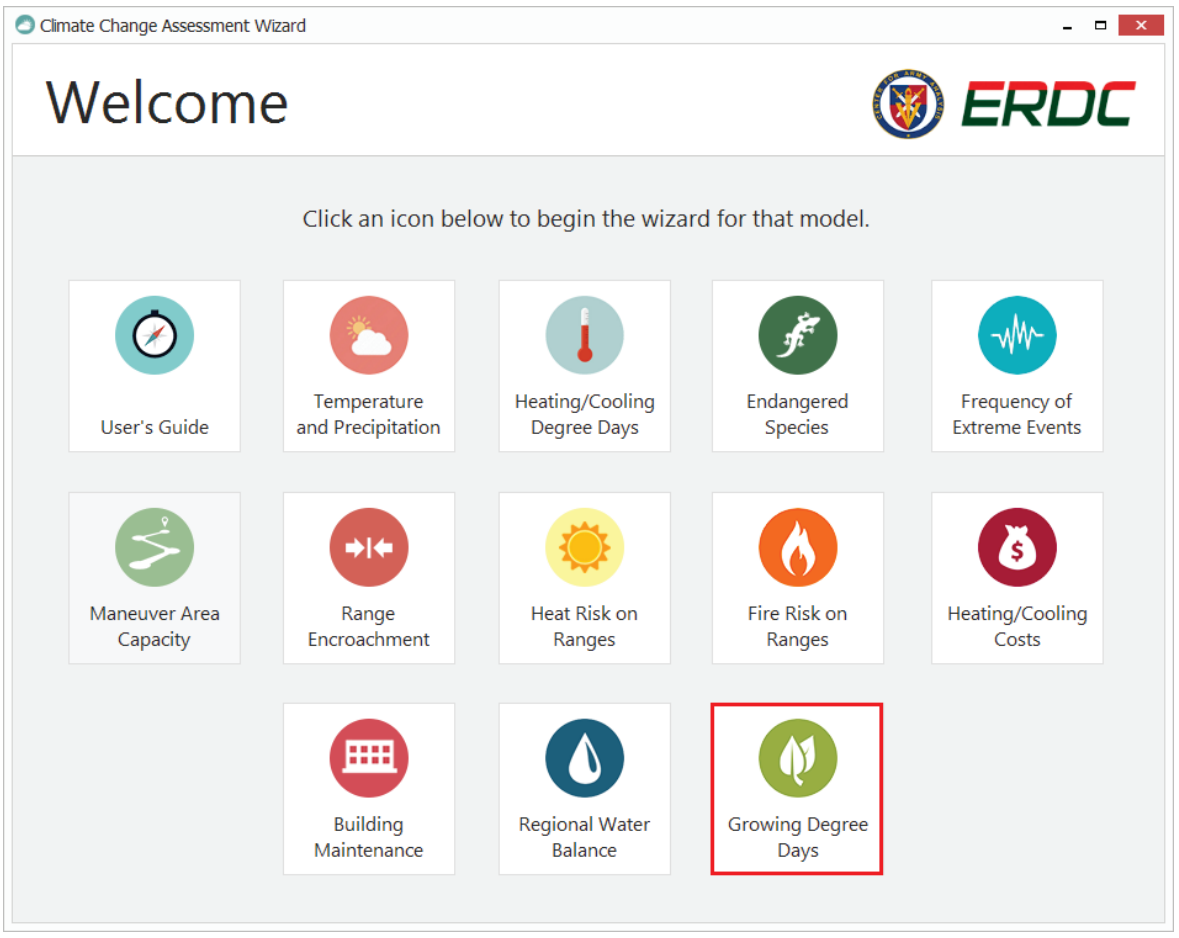


Figure 75. GDD Model first screen.

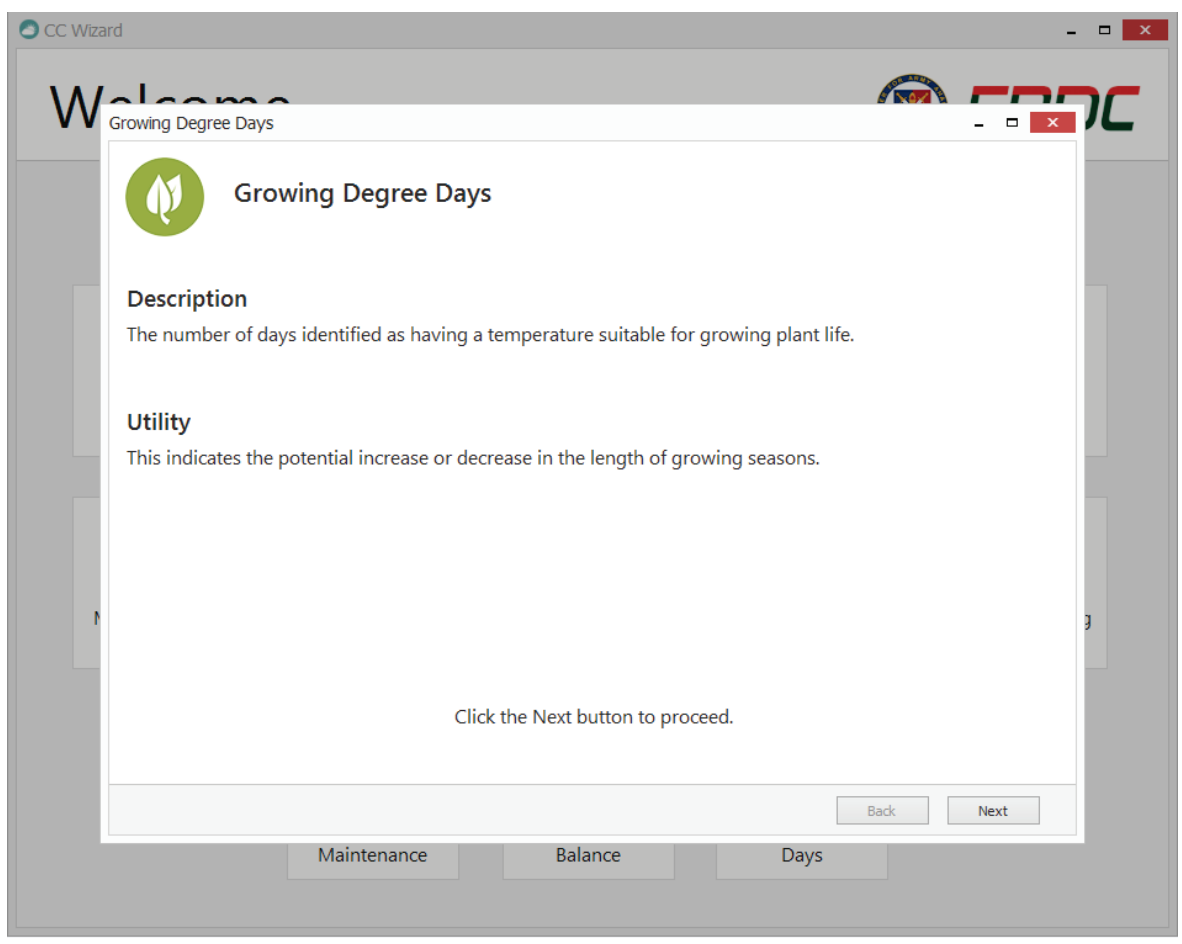

The second screen within the model allows the end user to view the datasets in graphical or tabular mode. Choose the desired view type from the View drop down combo box. Options within this box are Graphs and Tabular. Graphs displays the data as standard line graphs while Tabular displays the data in a table layout within an MS Excel ${ }^{\circledR}$ spreadsheet (Figure 76).

Next, choose a GCM and RCP type from the drop down combo box to filter only data related to that GCM/RCP. At the time of this publication, there are nine GCMs within the dataset for this model. RCP 2.6, 4.5, and 8.5 were chosen to represent lower bound, middle, and upper bounds for each GCM. Each GCM contains these RCPs, with the exception of CNRM and GFDL.

Once both of the choices are made, click the View Data button to launch the chart viewer window (Figure 77). 
Figure 76. GDD Model second screen.

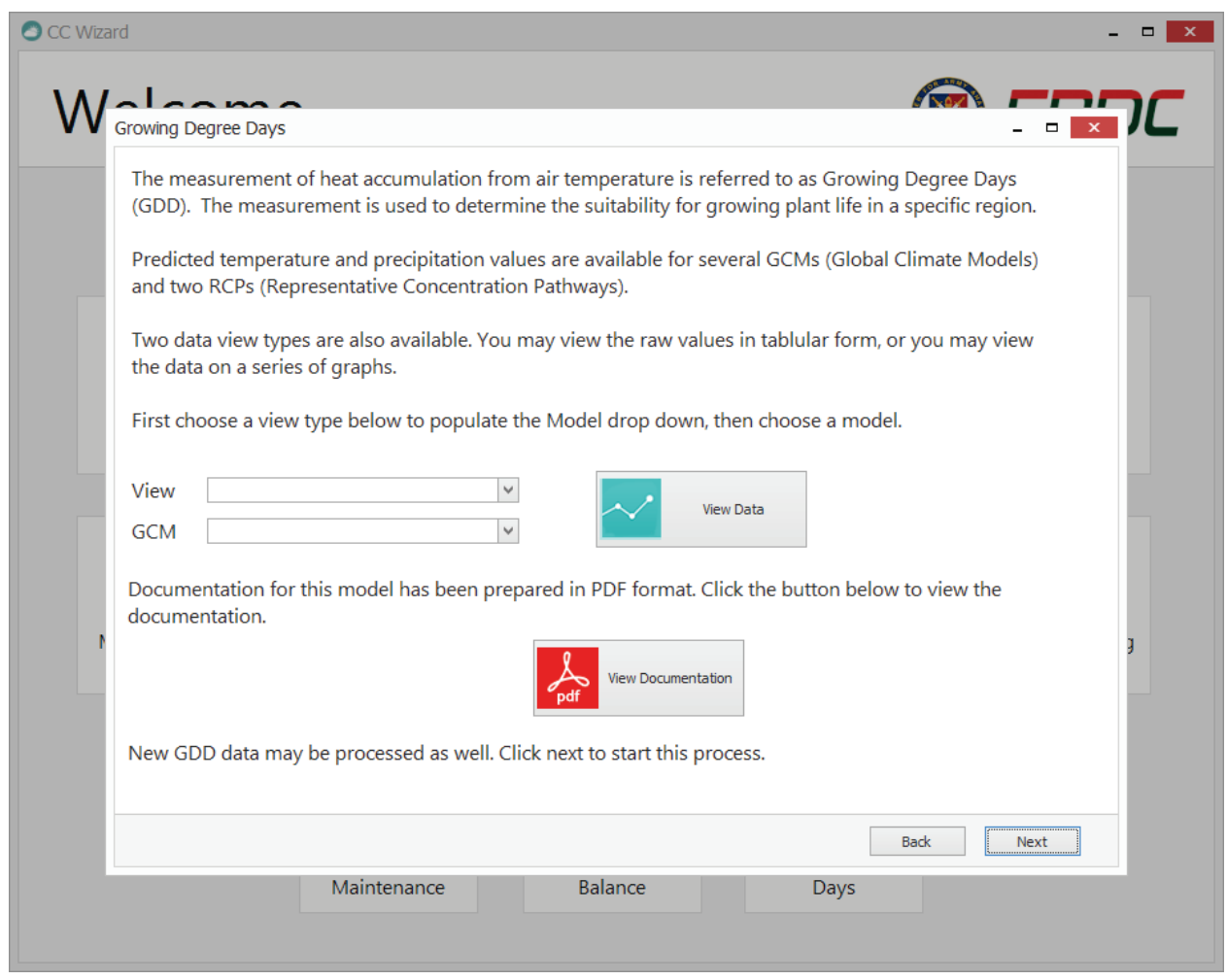

Figure 77. Results in the chart viewer window.

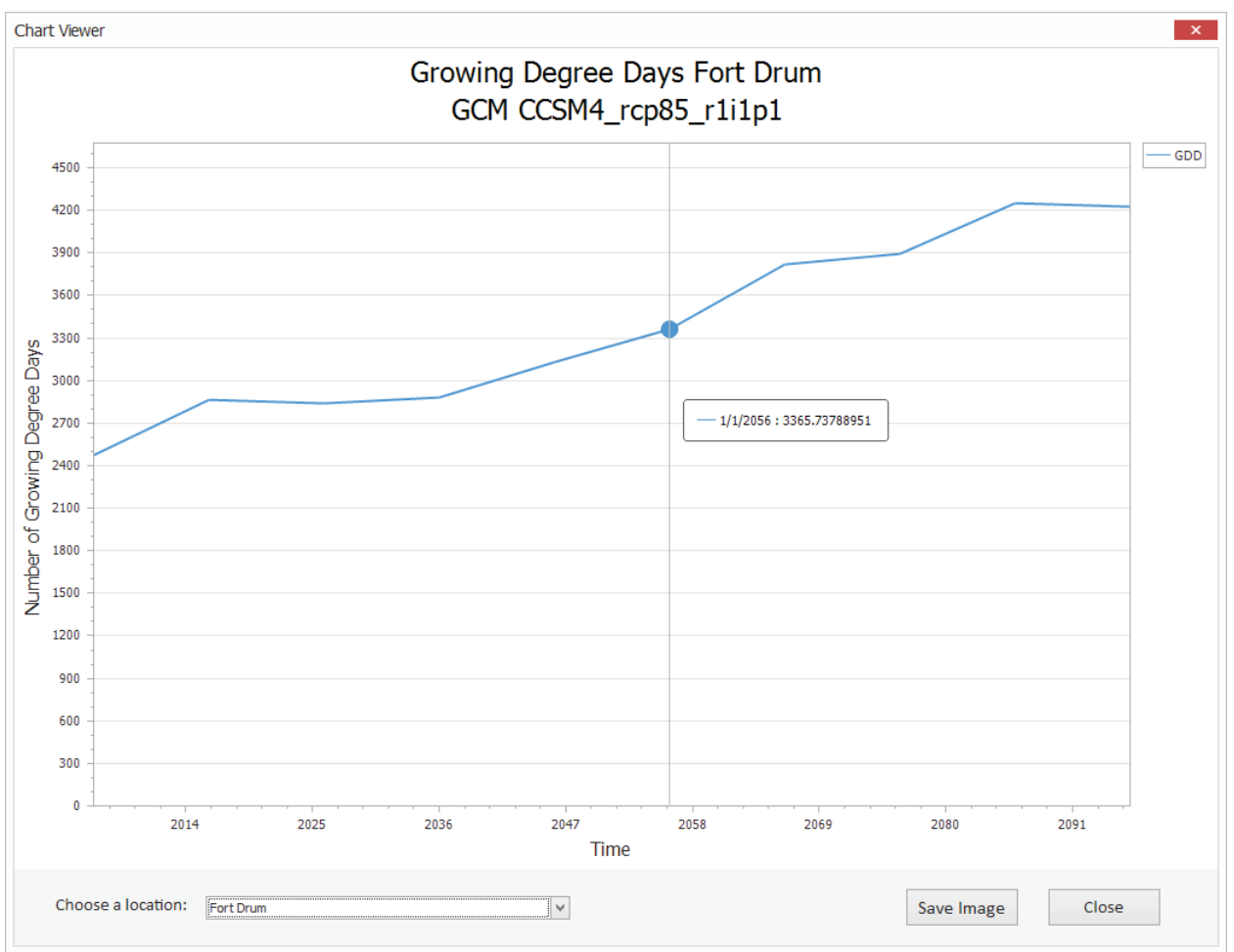


The average number of GDD for epochs ending in 2100 is plotted as a line graph with the number of days charted on the $\mathrm{Y}$-axis, and 10-year epochs are charted on the $\mathrm{X}$-axis. The user can change the charted values by choosing a different geographical location from the drop down combo box near the bottom left of the window. Upon selecting a location, the data will automatically filter to include only those values found within the chosen area.

Charts can be saved to the user's computer by clicking the Save Image button near the bottom right of the window. The resulting file is saved to a location of the user's choosing in the universal JPEG image file format.

As mentioned previously, this model uses the Python script described in the Heating and Cooling Degree Days Model. In an effort to reduce redundancy, please refer to the process for building data using the Python IDLE environment described in Section 4.2. 


\section{Summary and Conclusions}

The software integration effort ended in March of FY 2017 when remaining funding was expended. Nine of the 12 models that were proposed were captured and fully implemented during the main software integration effort. Only one of those models, Maneuver Area Capacity, was not captured or implemented due to lack of code availability. While work was performed in this area, a computational code was not created to match the research that was conducted. All efforts were made to capture and integrate all of the proposed models prior to the end of funding. While most models were successfully captured and integrated into the common computational environment and the Wizard application, only a select few were completely optimized to simplify the process and reduce computational effort. There is a great deal more that could be accomplished in this area with additional time, cooperation, and funding.

Some models lend themselves well to a high performance computing (HPC) environment and could be adapted to the ERDCs HPC systems. Resources are available to make the appropriate adaptations to the code and execute the currently very lengthy and processing intensive codes on HPC systems. Again, with the proper time, cooperation, and funding, this could certainly be accomplished and would greatly benefit force stationing analysis efforts by reducing the time and effort required to compute the more computationally intensive models.

Deliverables from this effort were completed and transferred to the PM as requested. The VM, which captured the final state of the common computational environment, Wizard assistance application, and other required software applications and settings was delivered as a set of VMWare files on a universal serial bus (USB) external hard drive. A backup copy of those files was also kept at ITL for archival purposes. Also included in the deliverables was a non-networked standalone Dell personal computer (PC) that served as the source for the VMWare, VM image. Programs and settings on that PC quite possibly could be changed, but it could be restored from the VM files since it was the source for those files.

Finally, a set of help documents was delivered in draft form. Included in this set of documents were individual user guides for each of the implemented models, and a main technical report that also serves as an overall user guide for the entire effort. As mentioned, these documents were in draft form at the end of the effort awaiting funding for editing and publishing as technical and special reports. 


\section{References}

Headquarters, Department of the Army (HQDA). 2001. Management Stationing. Army Regulation (AR) 5-10. Washington, DC: HQDA, http://www.apd.army.mil/epubs/DR_pubs/DR_a/pdf/web/r5_10.pdf

Headquarters, Department of the Army and Air Force (HQDA and HQAF). 2003. Heat Stress Control and Heat Casualty Management. Technical Bulleting Medical 507/Air Force Pamphlet 48-152 (I) (TB MED 507/AFPAM 48-152 [I]). Washington, DC: Headquarters, Department of the Army and Air Force, https://www.dir.ca.gov/oshsb/documents/Heat_illness_prevention_tbmed507.pdf

Lawrence, M. 2005. The Relationship Between Relative Humidity and the Dewpoint Temperature in Moist Air. Junior Research Group, Department of Atmospheric Chemistry. Mainz, Germany: Max Planck Institute for Chemistry, https://doi.org/10.1175/BAMS-86-2-225

Miller, J. P., J. M. Wilhoit, K. Tranel, and L. E. Curvey. 2015 Climate Change Impacts on Water and Energy for Army Installations. Integrated Climate Assessment for Army Enterprise Planning. ERDC/CERL TR 15-24. Champaign, IL: U.S. Engineer Research and Development Center.

U.S. Forestry Service (USFS). 2017. Keetch-Bryam Draught Index.” USFS -WFAS Wildland Fire Assessment System. Website, Accessed 1 December 2017, https://www.wfas.net/index.php/keetch-byram-index-moisture--drought-49 


\section{Acronyms and Abbreviations}

Term

AEWRS

AFPAM

ANSI

AOGCM

ASCII

BCCA

BCSD

BRAC

CAA

CCCMA

CCSM

CDD

CEERD

CERL

CMIP

CNRM

\section{Definition}

Army Energy and Water Reporting System

Air Force Pamphlet

American National Standards Institute

Atmosphere-Ocean General Circulation Models

American Standard Code for Information

Interchange

Bias Corrected Constructed Analogs

Bias Corrected Spatially Downscaled

Base Realignment and Closure

Center of Army Analysis

Canadian Centre for Climate Modelling and Analysis

Community Climate System Model

Cooling Degree Days

US Army Corps of Engineers, Engineer

Research and Development Center

Construction Engineering Laboratory

Coupled Model Intercomparison Project

Centre National de Recherches

Meteorologiques, Meteo France, France 
COBRA

CONUS

COTS

CPU

CSED

CSIRO

CSV

DBT

DoD

ERDC

ERDC-CERL

ERDC-ITL

ESA

ESRI

EUI

FTP

FY

GB
Comprehensive Omnibus Budget

Reconciliation Act

Continental United States

Commercial Off The Shelf

Central Processing Cores

Computational Science and Engineering

Division

Commonwealth Scientific and Industrial

Research Organisation

Comma Separated Values

Dry Bulb Temperature

Department of Defense

Engineering Research and Development Center

Engineer Research and Development Center, Construction Engineering Research Laboratory

Engineer Research and Development Center, Information Technology Laboratory

Endangered Species Act

Environmental Systems Research Institute

Energy Usage Index

File Transfer Protocol

Fiscal Year

Gigabytes 


\begin{tabular}{|c|c|}
\hline GCM & General Circulation Model \\
\hline GDD & Growing Degree Days \\
\hline GFDL & Geophysical Fluid Dynamics Laboratory \\
\hline GIS & Geographical Information System \\
\hline GOTS & Government Off The Shelf \\
\hline GSOD & Global Surface Summary of the Day \\
\hline HDD & Heating Degree Days \\
\hline $\mathrm{HPC}$ & High Performance Computing \\
\hline HQAF & Headquarters, Air Force \\
\hline HQDA & Headquarters, Department of the Army \\
\hline HQIIS & $\begin{array}{l}\text { (Army) Headquarters Installation Information } \\
\text { System }\end{array}$ \\
\hline ID & Identification \\
\hline IPSL & Institut Pierre Simon Laplace \\
\hline ITAM & Integrated Training Area Management \\
\hline ITL & Information Technology Laboratory \\
\hline JPEG & Joint Photographic Experts Group \\
\hline KBDI & Keetch-Byram Drought Index \\
\hline KSF & Kilo Square Feet \\
\hline MMBTU & Million British Thermal Units \\
\hline
\end{tabular}




\begin{tabular}{|c|c|}
\hline MPI-ESM-LR & $\begin{array}{l}\text { Max Planck Institute for Meteorology, } \\
\text { Germany }\end{array}$ \\
\hline MVA & Military Value Analysis \\
\hline NCDC & National Climatic Data Center \\
\hline NetCDF & Network Common Data Form \\
\hline NOAA & $\begin{array}{l}\text { National Oceanic and Atmospheric } \\
\text { Administration }\end{array}$ \\
\hline NorESM & Norwegian Earth System Model \\
\hline NPV & Net Present Value \\
\hline NSN & National Supply Number \\
\hline OMB & Office of Management and Budget \\
\hline OSAF & Optimal Stationing of Army Forces \\
\hline $\mathrm{PC}$ & Personal Computer \\
\hline PI & Principle Investigator \\
\hline PM & Program Manager \\
\hline RAM & Random Access Memory \\
\hline $\mathrm{RCP}$ & Representative Concentration Pathway \\
\hline RH & Relative Humidity \\
\hline RUG & Regional Urban Growth \\
\hline SAR & Same As Report \\
\hline SF & Standard Form \\
\hline
\end{tabular}




$\begin{array}{ll}\text { SRES } & \text { Special Report on Emissions Scenarios } \\ \text { SSB } & \text { Scientific Software Branch } \\ \text { TB } & \text { Terabytes } \\ \text { TR } & \text { Technical Report } \\ \text { URL } & \text { Universal Resource Locator } \\ \text { USB } & \text { Universal Serial Bus } \\ \text { USFS } & \text { U.S. Forest Service } \\ \text { USGS } & \text { U.S. Geological Survey } \\ \text { VBA } & \text { Visual Basic for Applications } \\ \text { VM } & \text { Virtual Machine } \\ \text { WCRP } & \text { World Climate Research Program } \\ \text { WFAS } & \text { Wildland Fire Assessment System } \\ & \end{array}$




\section{Appendix A: Additional Assistance}

Additional questions or concerns should be directed to the PMs of the Integrated Climate Assessment for Army Enterprise Planning program and software integration effort.

Paul M. Loechl

ERDC-CERL

Paul.M.Loech|@usace.army.mil

217-373-5892

Marty Garton

ERDC-ITL

Byron.m.garton@usace.army.mil

601-634-2888 


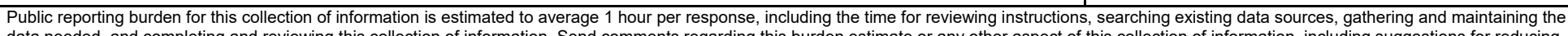

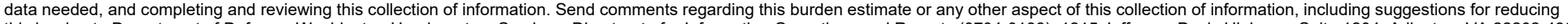

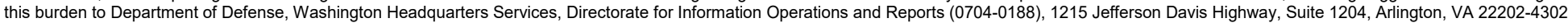

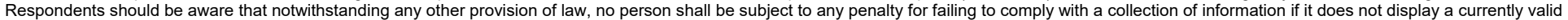
OMB control number. PLEASE DO NOT RETURN YOUR FORM TO THE ABOVE ADDRESS.

\begin{tabular}{l|l} 
1. REPORT DATE (DD-MM-YYYY) & 2. REPORT TYPE
\end{tabular} July 2019 Final

\section{TITLE AND SUBTITLE}

Analytical Model Software Integration Methods

\section{DATES COVERED (From - To)}

5a. CONTRACT NUMBER

5b. GRANT NUMBER

5c. PROGRAM ELEMENT

5d. PROJECT NUMBER

402188

5e. TASK NUMBER

5f. WORK UNIT NUMBER

8. PERFORMING ORGANIZATION REPORT NUMBER

ERDC/ITL SR-19-4

U.S. Army Engineer Research and Development Center (ERDC)

Information Technology Laboratory (ITL)

Waterways Experiment Station, 3909 Halls Ferry Road,

Vicksburg, MS 39180-6199

\section{SPONSORING / MONITORING AGENCY NAME(S) AND ADDRESS(ES)}

10. SPONSOR/MONITOR'S ACRONYM(S)

U.S. Army Corps of Engineers

Washington, DC 20314-1000

11. SPONSOR/MONITOR'S REPORT NUMBER(S)

\section{DISTRIBUTION / AVAILABILITY STATEMENT}

Approved for public release; distribution is unlimited.

\section{SUPPLEMENTARY NOTES}

\section{ABSTRACT}

This document explores and describes the methods and technologies developed and employed at the Engineer Research and Development Center-Information Technology Library (ERDC-ITL) to integrate various software models created by principle investigators as part of the Integrated Climate Assessment for Army Enterprise Planning work package into a single software package. These software models identify and calculate various metrics related to the effects of climate change and its potential impact on force stationing and are intended to be used in future analyses for the purpose of determining optimal force stationing. This software integration effort sought to understand these independently conceived and developed software models, capture and preserve them in their current state, and integrate them into a common computational environment while simultaneously documenting and optimizing their functionality. This work ensures that future analysis of climate change metrics will be easily accessible and executable by those seeking the data.

\section{SUBJECT TERMS}

Computer software

Computer systems

16. SECURITY CLASSIFICATION OF:

\begin{tabular}{|l|c|c|}
\hline $\begin{array}{c}\text { a. REPORT } \\
\text { Unclassified }\end{array}$ & $\begin{array}{c}\text { b. ABSTRACT } \\
\text { Unclassified }\end{array}$ & $\begin{array}{c}\text { c. THIS PAGE } \\
\text { Unclassified }\end{array}$ \\
\hline
\end{tabular}

Systems integration

Software engineering

\section{LIMITATION} OF ABSTRACT

SAR
Software architecture

18. NUMBER 1 19a. NAME OF RESPONSIBLE PERSON OF PAGES

103 19b. TELEPHONE NUMBER (include area code) 